\title{
Replacing Fossil Carbon in the Production of Ferroalloys with a Focus on Bio-Based Carbon: A Review
}

\author{
Marcus Sommerfeld *(D) and Bernd Friedrich $\mathbb{D}$
}

check for

updates

Citation: Sommerfeld, M.;

Friedrich, B. Replacing Fossil Carbon

in the Production of Ferroalloys with

a Focus on Bio-Based Carbon:

A Review. Minerals 2021, 11, 1286.

https://doi.org/10.3390/

$\min 11111286$

Academic Editors:

Sunil Kumar Tripathy

and Chenna Rao Borra

Received: 11 October 2021

Accepted: 15 November 2021

Published: 18 November 2021

Publisher's Note: MDPI stays neutral with regard to jurisdictional claims in published maps and institutional affiliations.

Copyright: (c) 2021 by the authors. Licensee MDPI, Basel, Switzerland. This article is an open access article distributed under the terms and conditions of the Creative Commons Attribution (CC BY) license (https:/ / creativecommons.org/licenses/by/ $4.0 /)$.
IME Process Metallurgy and Metal Recycling, Institute of RWTH Aachen University, 52056 Aachen, Germany; bfriedrich@ime-aachen.de

* Correspondence: msommerfeld@ime-aachen.de; Tel.: +49-24-18095200

Abstract: The production of ferroalloys and alloys like ferronickel, ferrochromium, ferromanganese, silicomanganese, ferrosilicon and silicon is commonly carried out in submerged arc furnaces. Submerged arc furnaces are also used to upgrade ilmenite by producing pig iron and a titania-rich slag. Metal containing resources are smelted in this furnace type using fossil carbon as a reducing agent, which is responsible for a large amount of direct $\mathrm{CO}_{2}$ emissions in those processes. Instead, renewable bio-based carbon could be a viable direct replacement of fossil carbon currently investigated by research institutions and companies to lower the $\mathrm{CO}_{2}$ footprint of produced alloys. A second option could be the usage of hydrogen. However, hydrogen has the disadvantages that current production facilities relying on solid reducing agents need to be adjusted. Furthermore, hydrogen reduction of ignoble metals like chromium, manganese and silicon is only possible at very low $\mathrm{H}_{2} \mathrm{O} / \mathrm{H}_{2}$ partial pressure ratios. The present article is a comprehensive review of the research carried out regarding the utilization of bio-based carbon for the processing of the mentioned products. Starting with the potential impact of the ferroalloy industry on greenhouse gas emissions, followed by a general description of bio-based reducing agents and unit operations covered by this review, each following chapter presents current research carried out to produce each metal. Most studies focused on pre-reduction or solid-state reduction except the silicon industry, which instead had a strong focus on smelting up to an industrial-scale and the design of bio-based carbon for submerged arc furnace processes. Those results might be transferable to other submerged arc furnace processes as well and could help to accelerate research to produce other metals. Deviations between the amount of research and scale of tests for the same unit operation but different metal resources were identified and closer cooperation could be helpful to transfer knowledge from one area to another. Life cycle assessment to produce ferronickel and silicon already revealed the potential of bio-based reducing agents in terms of greenhouse gas emissions, but was not carried out for other metals until now.

Keywords: biomass; nickel; manganese; silicon; chromium; ilmenite; submerged arc furnace; greenhouse gas; ferroalloys; bio-based carbon

\section{Introduction}

Compared to the pre-industrial era, the anthropogenic emissions of greenhouse gases are on a historically high level, which is a dominant reason for climate change. In the last century, not only an increase in average land and ocean temperatures, greenhouse gas concentrations in the atmosphere and sea levels were observed, but also acidification of the oceans due to accelerated $\mathrm{CO}_{2}$ uptake. Since the 1950s an intensification in extreme climate and weather events can also be seen, which is most likely at least partially due to human influence. It is expected, that a continuous emission of anthropogenic greenhouse gases could lead to even more severe changes in the climate conditions [1]. One industry responsible for such gas emissions is the metallurgical industry. To decrease those emissions, two possibilities are evident: implementation of breakthrough technologies or the usage of $\mathrm{CO}_{2}$ lean fuels. Possibilities could be the usage of biomass, bio-based carbon or 
hydrogen. Bio-based carbon can be considered $\mathrm{CO}_{2}$ neutral if the same amount of biomass consumed is recultivated [2] and therefore, the replacement of fossil carbon carriers by for example charcoal could lead to a decrease in specific $\mathrm{CO}_{2}$ emissions [3]. Hydrogen is also $\mathrm{CO}_{2}$ neutral, if the electricity used to produce hydrogen is $\mathrm{CO}_{2}$ neutral. However, hydrogen has the disadvantage, that major changes in the current production processes and facilities for the investigated metals have to be employed. In addition, hydrogen has a lower affinity to oxygen than carbon, which makes it unsuitable for the reduction of ignoble metals. Figure 1 shows the Gibbs free energy of relevant reactions for pre-reduction or reduction for metal oxides of nickel, iron, chromium, manganese and silicon covered by this review at $1 \mathrm{~atm}$ per mole of carbon or hydrogen. The reaction module of FactSage $\mathrm{e}^{\mathrm{TM}}$ 8.0 [4] and the databases FactPS and FToxid were used as a source.

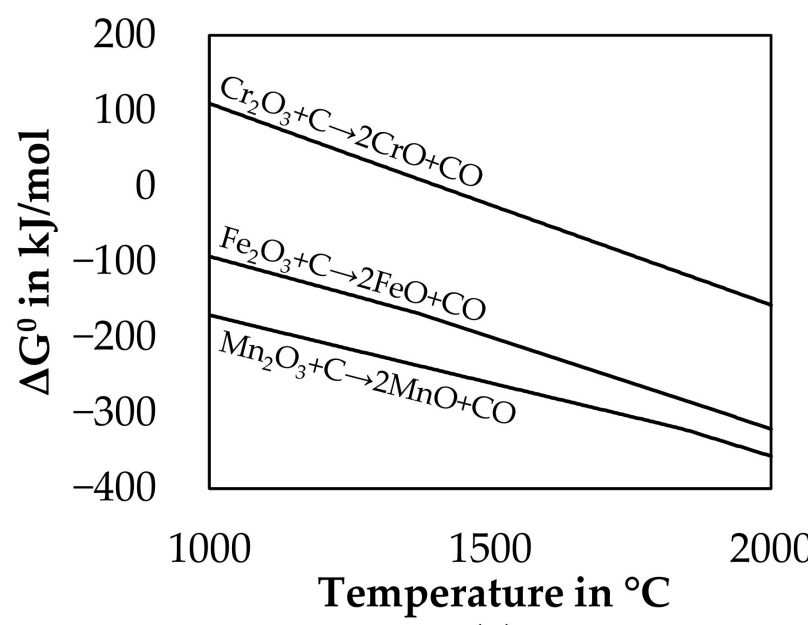

(a)

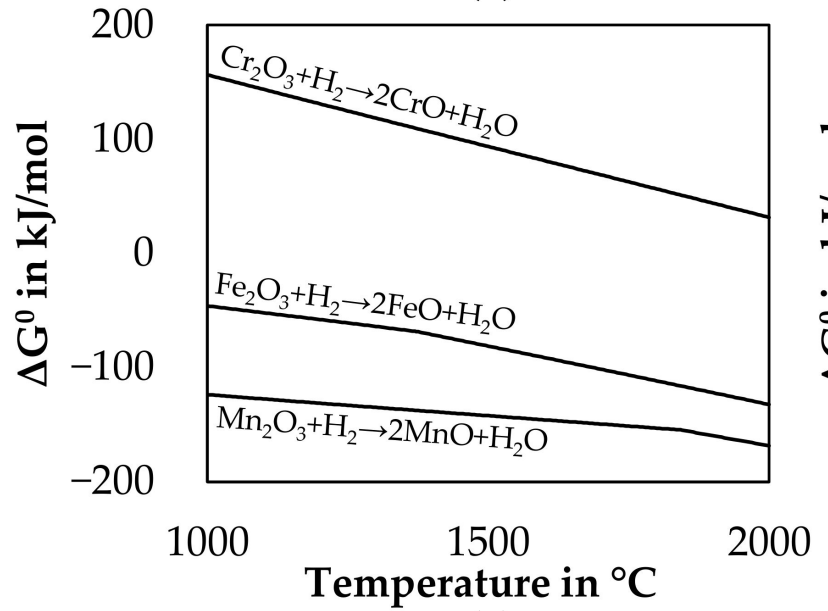

(c)

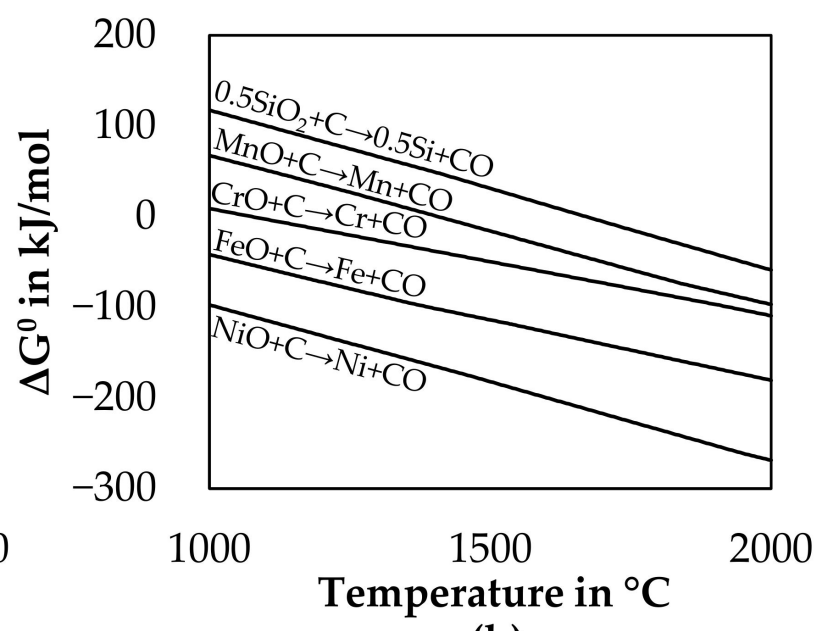

(b)

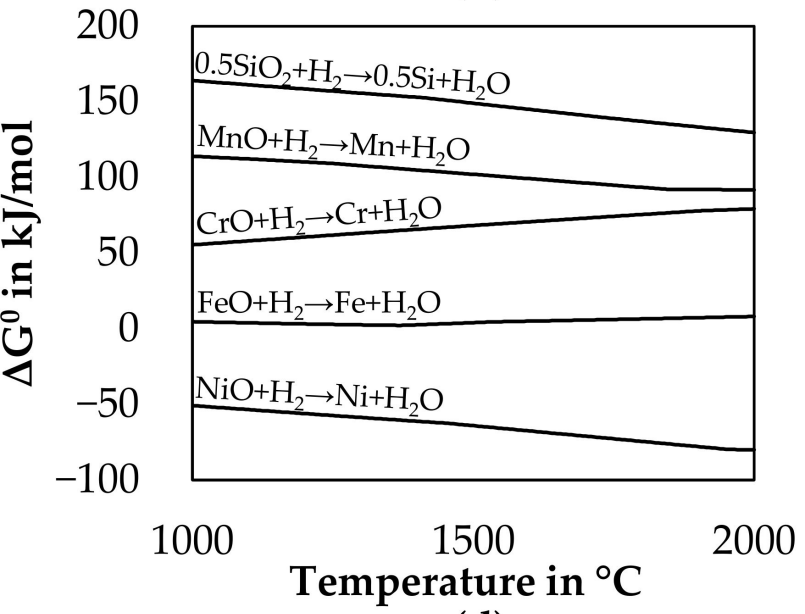

(d)

Figure 1. Gibbs free energy of reduction reactions per mole reducing agent. (a) pre-reduction with carbon; (b) reduction with carbon; (c) pre-reduction with hydrogen; (d) reduction with hydrogen.

As shown by Figure 1, the pre-reduction and reduction of the oxides by carbon is thermodynamically feasible, if the temperature is high enough. Hydrogen can only be used for the pre-reduction of $\mathrm{Fe}_{2} \mathrm{O}_{3}$ and $\mathrm{Mn}_{2} \mathrm{O}_{3}$ and the reduction of NiO. However, since Figure 1 is calculated for an activity of 1 for condensed substances and a partial pressure of $1 \mathrm{~atm}$ for gaseous compounds, the reactions with hydrogen are possible, if the partial pressure ratio of $\mathrm{H}_{2} \mathrm{O}$ to $\mathrm{H}_{2}$ is low enough. Though, the reduction of $\mathrm{CrO}, \mathrm{MnO}$ and $\mathrm{SiO}_{2}$ with hydrogen will require a low ratio, which is shown in the Supplementary Materials (Figure S1). The usage of hydrogen is suitable for ferronickel production, ilmenite treatment and pre-reduction of iron oxides and manganese oxides, but if hydrogen is used for the 
production of chromium, manganese or silicon, it will only be possible to accept an off-gas with a high hydrogen content.

The use of bio-based carbon in metallurgical applications does not only have a positive impact on the environment due to the non-polluting nature and the renewability, but it can also lead to several social and economic benefits, like rural industrialization, transfer of capital from industrial to rural areas, savings of foreign exchanges and job creation $[5,6]$. On the other hand, non-sustainable forest management is contributing to deforestation, loss of biodiversity, forest degradation and increases the chance of droughts and floods [7-9]. Therefore, it is necessary to meet the demand for bio-based carbon by harvesting sustainable sources of biomass or currently unused vegetative waste.

The usage of bio-based carbon has already been extensively investigated for the iron and steel industry $[2,10-18]$. Compared to the iron and steel industry, less research was carried out to substitute fossil carbon with bio-based carbon for the production of alloys reviewed by this article. This is likely because the production figures for the metals investigated by this paper are significantly lower compared to the production of raw steel, as can be seen in Table 1 .

Table 1. Production figures of some alloys for 2016 in million tons, excluding the USA.

\begin{tabular}{cccccccc}
\hline Alloy & FeCr [19] & FeMn [19] & SiMn [19] & FeNi [19] & FeSi [19] & Si [20] & Raw Steel [21] \\
\hline $\begin{array}{c}\text { Production in } \\
\text { million tons }\end{array}$ & 11.900 & 4.655 & 12.500 & 3.740 & 6.870 & 2.850 & 1551.5 \\
\hline
\end{tabular}

Although the production figures for ferroalloys are even in sum significantly lower than for steel, the substitution of fossil carbon by renewably sourced bio-based carbon can reduce the emission of greenhouse gases. Based on the yearly production figures presented in Table 1 and the generic $\mathrm{CO}_{2}$ emission per ton of produced liquid alloy reported by Lindstadt et al. [22] for FeCr, $\mathrm{HC}$ FeMn, SiMn, FeSi65 and Si, the $\mathrm{CO}_{2}$ emissions for the production of those metals in the year 2016 can be estimated. The specific generic $\mathrm{CO}_{2}$ emissions and the total generic $\mathrm{CO}_{2}$ emissions are presented in Table 2. The total emissions are calculated by multiplying the emission factors and the production figures. As there are deviations in the applied processes, alloy grades and reducing agents utilized in the industry, those values are only rough estimates. Nevertheless, it is a fair assumption that million of tons of $\mathrm{CO}_{2}$ emissions could be avoided each year by replacing fossil carbon with renewable carbon sources to produce these metals.

Table 2. Exemplary generic $\mathrm{CO}_{2}$ emissions for the production of ferroalloys per metric ton of liquid alloy and the total emissions for 2016, excluding the USA.

\begin{tabular}{cccccc}
\hline Alloy & FeCr & HC FeMn & SiMn & FeSi65 & Si \\
\hline Ton $\mathrm{CO}_{2} /$ ton liquid metal [22] & 1.3 & 1.3 & 1.4 & 3.6 & 5.0 \\
Million tons $\mathrm{CO}_{2} /$ per year & 15.5 & 6.1 & 17.5 & 24.7 & 14.3 \\
\hline
\end{tabular}

Using the calculated total generic emissions for the alloys presented in Table 2 and the available data for greenhouse gas emissions, $[23,24]$ the share of the generic emissions for the production of those alloys can be calculated. In 2016 the global greenhouse gas emissions were 49.4 billion tons of $\mathrm{CO}_{2 \mathrm{eq}}$ while the energy consumption in industries contributed to $24.2 \%$ of the total emissions $[23,24]$. Figure 2 shows the share of different industries contributing to those emissions. As the emissions for the production of ferroalloys are included in the category for iron and steel [25], the generic emissions from Table 2 resulting in 78.1 million tons of $\mathrm{CO}_{2}$ are deducted from the iron and steel share and are listed as their own category. Furthermore, Figure 2 shows the stake of FeCr, FeMn, SiMn, $\mathrm{FeSi}$ and $\mathrm{Si}$ contributing to the total generic $\mathrm{CO}_{2}$ emissions of the mentioned ferroalloys. In comparison to the worldwide $\mathrm{CO}_{2}$ emissions, the generic $\mathrm{CO}_{2}$ emissions from those alloys are equal to the mean $\mathrm{CO}_{2}$ emission of 11.8 million people, taking the $\mathrm{CO}_{2}$ emissions per capita of 2016 as a reference [23]. 


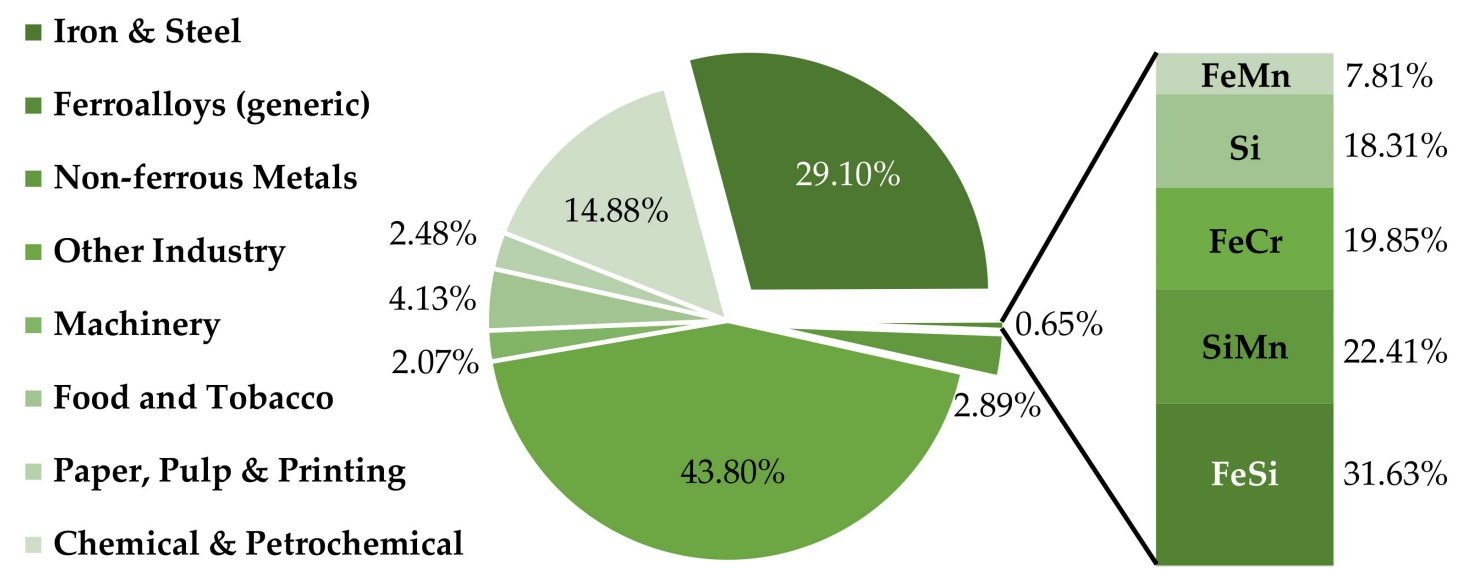

Figure 2. Global greenhouse gas Emissions by industries in 2016, based on data from [23,24] and share of the generic $\mathrm{CO}_{2}$ emissions of ferroalloys.

Even though the positive influence of charcoal on the environment, process and product quality were already expressed nearly 20 years ago for the ferroalloy industry [26], fossil carbon carriers are still highly relevant and for example, at least until 1998, no biological carbon was used for the production of manganese ferroalloys and chromium ferroalloys in Norway, instead, coke was the main reducing agent [27]. Probably, because the specific price related to the fixed carbon content of charcoal or wood compared to fossil reducing agents is normally higher [26]. However, in some countries like Brazil with large forests and scarce coal deposits the use of charcoal can also be accompanied by reduced costs [6]. Furthermore, there are technical and practical issues to solve, if a replacement of fossil carbon like coke by bio-based carbon is planned. Biomass fuels can show undesirable characteristics like low energy density, low bulk density and limited carbon content, leading to high transportation and storage costs [28]. Therefore, upgraded biomass is considered for metallurgical applications, but even pyrolyzed biomass is still associated with those disadvantages [29,30]. Furthermore, biomass sources are quite diffuse and it might be difficult to obtain quantities sufficient [28] to have an impact on the greenhouse gas emissions of the ferroalloy industry. Another challenge, especially for large shaft furnaces, is the inferior mechanical properties like the crushing strength, density and friability [31].

Approaches to utilize bio-based carbon in the ferroalloy industry accepting those undesirable characteristics or to overcome those obstacles are shown in this article. First, an overview of the ultimate and proximate analysis of reducing agents used in the industry and research are presented, followed by an introduction about common unit operations to produce alloys containing nickel, chromium, silicon, manganese and for the upgrading of ilmenite ore. The subsequent chapters present research carried out in the last decades investigating the usage of bio-based carbon to produce the investigated metals. Subchapter 6.2. investigating the production of agglomerates containing biomass is especially mentioned, because the agglomerates considered for the usage in silicon submerged arc furnaces may also be usable in other smelting processes described by this article.

\section{Characterization of Reducing Agents}

As quite different biomass-based reducing agents are either currently considered in metallurgical research as a replacement for fossil carbon or partially already used for industrial operations, biomass-based reducing agents are categorized into five categories in this study and compared to coal and coke as a fossil reference. Table 3 shows examples of used biomass-based and fossil reducing agents and in which category they were assigned. 
Table 3. Examples of reducing agents or feedstocks used by authors cited in this study and own data.

\begin{tabular}{ccc}
\hline Category & Examples & Reference \\
\hline Wood & Sawdust, Chips, Twigs, Needles, Branches, Bark & {$[32-44]$} \\
\hline Vegetative Waste & Olive Pulp, Straw, Shells, Husks, Pith & {$[32,33,45-52]$} \\
\hline Charred Waste & $\begin{array}{c}\text { Charred-Olive Pulp, Corn Cobs, Vegetative Waste, Fruit } \\
\text { Cuttings, Straw }\end{array}$ & {$[37,44,52-55] \&$ own data } \\
\hline Shell Charcoal & Charred-Coconut Shells, Palm Kernel Shells & {$[56-67]$ \& own data } \\
\hline Wood Charcoal & Charred- Bamboo, Cypress, Lamtoro, Pine, Spruce, & Eucalyptus, Mallee \\
\hline Coal & Coal, Anthracite, Newcastle Blend Coal, Bitumite & {$[26,30,35,38-41,43,44,51,54,57,68-72] \&$ own data } \\
\hline Coke & Lignite Coke, Coke, Semi-Coke, Petroleum Coke, Coke Breeze & {$[3,22,30,35,37,41,43,44,54,55,60,64,68-70,73] \&$ own data } \\
\hline
\end{tabular}

The composition of coke or coal is commonly reported as a proximate analysis or ultimate analysis. The proximate analysis is subdivided into four categories: moisture-, ash-, volatile matter- and fixed carbon content. The ultimate analysis is subdivided into six categories: ash-, carbon-, hydrogen-, nitrogen-, sulfur- and oxygen content. Proximate and ultimate analyses from the references in Table 3 and own data are compared in this chapter. However, the standard analytical methods are described first briefly, to understand what the proximate and ultimate analysis represents.

The moisture content can be determined either by a two-stage method or a single-stage method. For the two-stage method, a sample is dried in air at temperatures below $40^{\circ} \mathrm{C}$, the mass loss of the sample is the free-moisture content, followed by crushing the sample and drying at $105^{\circ} \mathrm{C}$ to $110{ }^{\circ} \mathrm{C}$ under nitrogen or air to determine the residual moisture content. The single-stage method is conducted similar to the second stage of the previous method, a sample is crushed and either dried under nitrogen or air at $105^{\circ} \mathrm{C}$ to $110{ }^{\circ} \mathrm{C}$ to determine the mass loss [74].

The volatile matter content can be determined by heating a sample without contact to air at $900{ }^{\circ} \mathrm{C}$ for seven minutes. The mass loss minus the moisture content is the volatile matter content [75].

The ash content can be determined by burning a sample at $815{ }^{\circ} \mathrm{C}$ in air until the sample reaches a constant mass. The remaining mass is the ash content of the sample [76].

The fixed carbon content $\left(w_{t} \%_{C}\right.$ fix $)$ can be calculated by Equation (1) after the ash content $\left(w t \%_{A s h}\right)$, moisture content $\left(w_{t} \%_{M}\right)$ and volatile matter content $\left(w t \%_{V M}\right)$ are determined [77].

$$
w t \%_{C f i x, a d}=100 \%-\left(w t \%_{A s h, a d}+w t \%_{M, a d}+w t \%_{V M, a d}\right)
$$

$w t \%_{x, a d}$ : weight percent of proximate analysis value $x$ in air-dried sample

Instead of calculating the fixed carbon content, the total carbon content of a sample after the removal of volatile matter can be measured by a total combustion method. The fixed carbon content can then be calculated by Equation (2). However, if the ash in the sample contains carbonates, Equation (2) would yield a higher fixed carbon content compared to Equation (1).

$$
w t \% C f i x=\frac{w t \% C_{\text {after VM determination }} \cdot \mathrm{m}_{\text {after VM determination }}}{\mathrm{m}_{\text {initial sample }}}
$$

$\mathrm{m}_{\text {sample: }}$ sample mass in arbitrary units

Carbon, hydrogen and nitrogen are measured by complete combustion in oxygen at elevated temperatures. Interfering combustion products are removed and nitrogen oxides are reduced to $\mathrm{N}_{2}$, before $\mathrm{CO}_{2}, \mathrm{H}_{2} \mathrm{O}$ and $\mathrm{N}_{2}$ are analyzed by instrumental gas analysis procedures [78]. 
Sulfur can be in fuels as inorganic sulfates, inorganic sulfides and organic sulfur. The total sulfur content can be obtained by combusting a sample in an oxygen stream at $1350{ }^{\circ} \mathrm{C}$. Water vapor and solid matter are removed from the gas stream and the gas is afterward analyzed by a calibrated infrared absorption detector [79].

If the previous described values are available, the oxygen content can be calculated for an air-dried (ad) basis using Equation (3) [80].

$$
w t \%_{0, a d}=100 \%-\left(w t \%_{C, a d}+w t \%_{H, a d}+w t \%_{N, a d}+w t \%_{S, a d}+w t \%_{A s h, a d}+w t \%_{H}{ }_{2} \mathrm{O}, a d\right)
$$

${ }^{w}{ }^{\%} \%$,ad : weight percent of element $\mathrm{X}$ in air-dried sample

\subsection{Proximate Analysis}

Figure 3 shows box plots of the proximate analysis of referenced data from Table 3 and own data sorted by ascending mean fixed carbon contents. The fixed carbon content and volatile matter content are displayed on a dry and ash-free basis, to allow comparability between different studies. The ashand moisture content are displayed as received. In Figure 3, the cross inside the boxes displays the average value, the line in the box displays the median, the box reaches from the 25th percentile to the 75th percentile (interquartile range), the whiskers either include the maximum and minimum value of the dataset, or the last value within a maximum distance of 1.5 times the interquartile range. Outliers with a larger distance to the box are displayed as points.

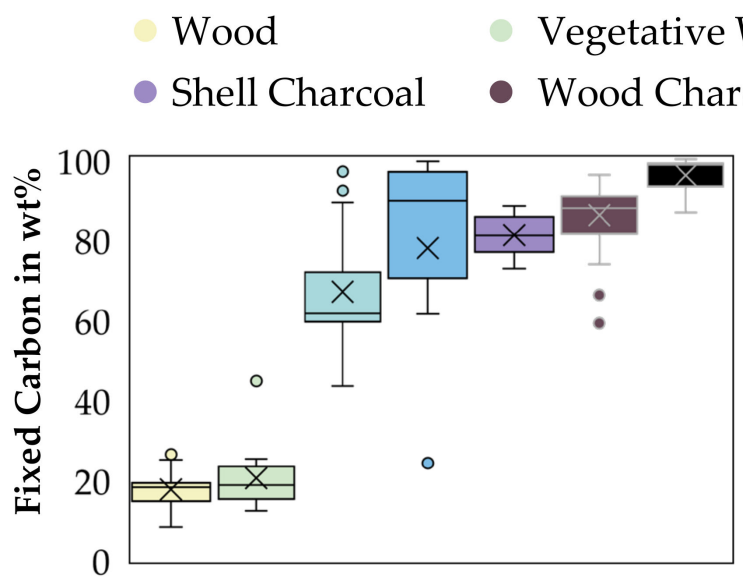

(a)

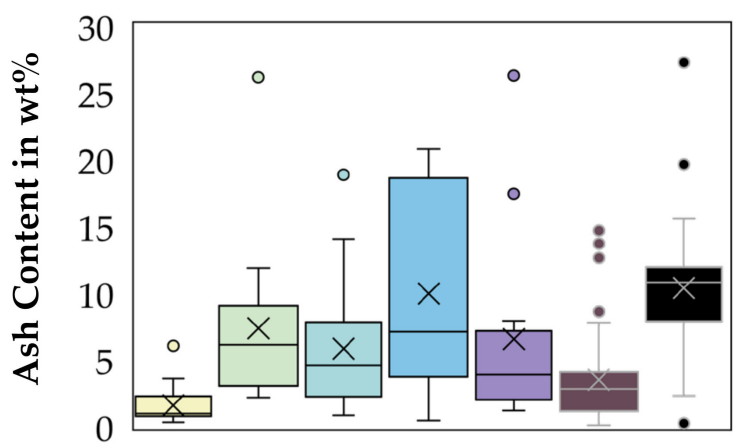

(c)

\section{Coal Charred Waste}

- Coke

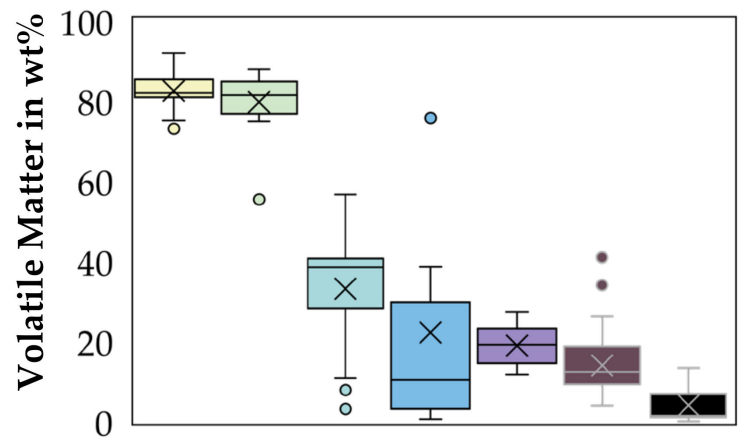

(b)

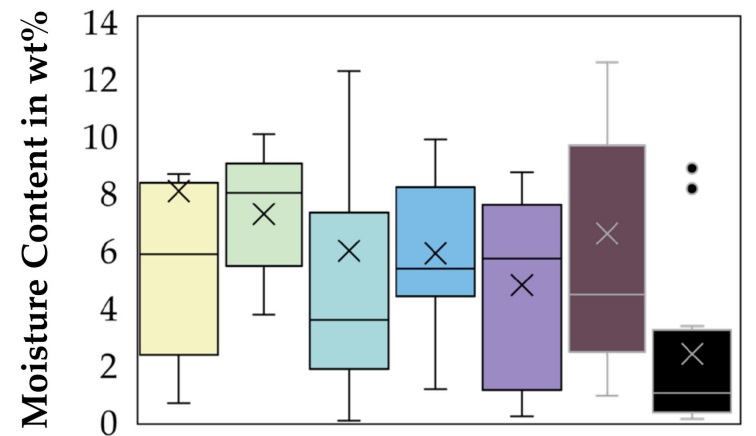

(d)

Figure 3. Box plots of parameters obtained by proximate analysis of different reducing agents sorted by ascending fixed carbon content. (a): Fixed carbon, dry and ash-free. (b): Volatile matter, dry and ash-free. (c): Ash content, as received. (d): Moisture content, as received.

Not surprisingly, raw biomass like wood or vegetative waste has the lowest fixed carbon content and highest volatile matter content. The fixed carbon content of charred vegetative waste, shell charcoal and wood charcoal are surpassing the fixed carbon content of coal, but have lower fixed carbon contents compared to coke. Generally, for metallurgical applications, a reducing agent with a higher fixed carbon has a better quality compared to a reducing agent with a lower fixed carbon content [81]. Another advantage of coke 
in regards to the fixed carbon content is the uniformity represented by the smallest box between the first quartile and third quartile. Shell charcoal and wood charcoal are deviating slightly more compared to coke, while especially the charred vegetative waste samples show a strong deviation in the fixed carbon content.

Wood and wood charcoal have the lowest mean ash content, while coke and charred vegetative waste have the highest ash content. In practice, the ash content should be low, since ash is a non-productive component of a reducing agent and can increase the amount of slag produced and alter the chemical composition of the slag [82]. Since the comparison of the ash content solely on the absolute basis is disregarding the amount of the reducing agent needed for a process, Table 4 is comparing the amount of ash per ton of fixed carbon. The upper quartile and lower quartile are also shown in the table.

Table 4. Mass of ash in relation to a constant fixed carbon amount in reducing agents.

\begin{tabular}{|c|c|c|c|c|c|c|c|}
\hline Reducing Agent & Wood & Vegetative Waste & Coal & Charred Waste & Shell Charcoal & Wood Charcoal & Coke \\
\hline $\begin{array}{l}\text { Mean mass of ash in kg per ton } \\
\text { fixed carbon }\end{array}$ & 91.6 & 393.7 & 91.3 & 117.3 & 83.4 & 41.1 & 110.4 \\
\hline $\begin{array}{l}\text { Upper quartile } \\
\text { in kg }\end{array}$ & 128.9 & 587.7 & 117.1 & 192.1 & 85.3 & 46.0 & 121.9 \\
\hline $\begin{array}{l}\text { Lower quartile } \\
\text { in } \mathrm{kg}\end{array}$ & 41.6 & 147.7 & 28.3 & 46.6 & 23.4 & 12.7 & 79.3 \\
\hline
\end{tabular}

Moreover, in numbers relative to the fixed carbon content, wood charcoal has the lowest amount of ash, however, raw wood has now a higher amount of ash compared to shell charcoal and coal. In relation to the fossil reference, shell charcoal and wood charcoal perform better compared to coal and coke in terms of the mean mass of ash per fixed carbon. Based on these numbers, the replacement of coke by wood charcoal would result in a $62.6 \%$ lower ash load for a metallurgical operation.

\subsection{Ultimate Analysis}

Part of an ultimate analysis of coal is the determination of the hydrogen-, carbon- and oxygen content. A common method to display those values is a diagram containing the atomic hydrogen to carbon ratio over the atomic oxygen to carbon ratio. Van Krevelen [83] proposed this method since principal reactions like decarboxylation (Decarboxy.), demethanation (Demeth.), dehydration (Dehydr.), dehydrogenation and oxidation are represented as straight lines in this diagram [83]. Figure 4 shows such a diagram containing the data of the samples mentioned in Table 3 and lines representing the pathway of the mentioned reactions. In addition to the individual values, the ellipses show the average absolute deviation of the mean values for each category, while the points represent individual data point.

Noticeable are higher variations in the atomic $\mathrm{O} / \mathrm{C}$ ratio for wood, coal and coke compared to the atomic $\mathrm{H} / \mathrm{C}$ ratio, while vegetative waste, charred vegetative waste, shell charcoal and wood charcoal have a higher deviation in the atomic $\mathrm{H} / \mathrm{C}$ ratio. The highest deviations are shown by vegetative waste and charred vegetative waste, which could impede their usage in metallurgical processes, as constant properties are desirable in industrial operations. The smallest deviations are shown by coke, followed by shell charcoal, coal and wood charcoal. Shell charcoal and wood charcoal exhibit a higher total carbon content compared to coal according to the Van Krevelen diagram. As shown by the proximate analysis in Figure 3, shell charcoal and wood charcoal also have a higher fixed carbon content compared to coal.

Sulfur is an unwanted impurity in steel [84] and since ferroalloys are used in the steel industry as a master alloy, maximum sulfur contents are regulated by international standards [85-89]. In carbothermic reduction processes, most of the sulfur input comes in the form of reducing agents, for example, nearly $90 \%$ of the sulfur in a high carbon ferrochromium process comes from the coke input [90]. Therefore, the sulfur content in reducing agents should be as low as possible. To compare the sulfur content, it is again 
shown in relation to a constant amount of fixed carbon in Table 5. The upper quartile and lower quartile are also shown in the table.

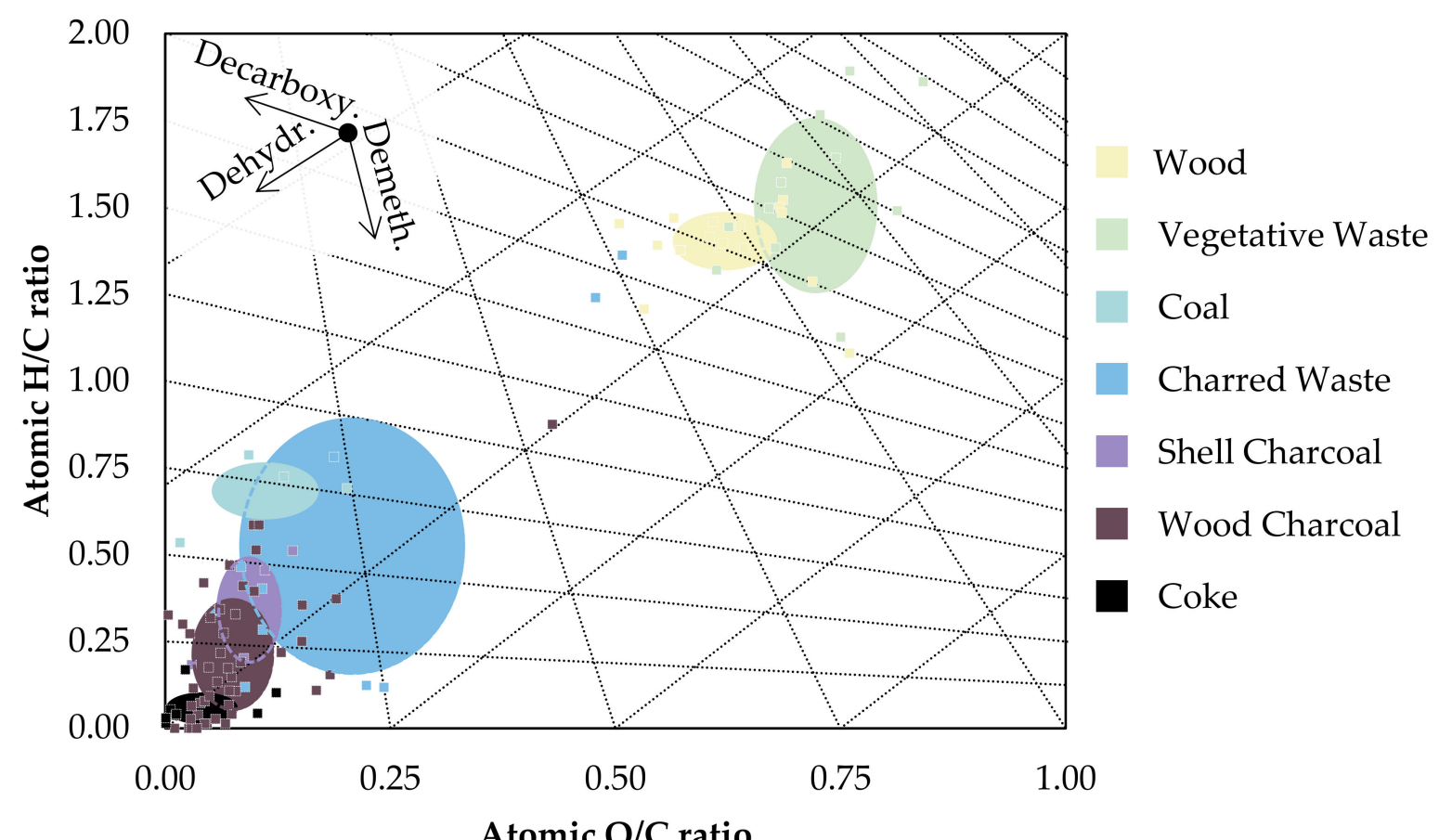

Figure 4. Van Krevelen diagram including different reducing agents used to produce ferroalloys in an industrial-scale or in research facilities.

Table 5. Mass of sulfur in relation to a constant fixed carbon amount in reducing agents.

\begin{tabular}{|c|c|c|c|c|c|c|c|}
\hline Reducing Agent & Wood & Vegetative Waste & Coal & Charred Waste & Shell Charcoal & Wood Charcoal & Coke \\
\hline $\begin{array}{l}\text { Mean mass of sulfur in } \mathrm{kg} \text { per ton } \\
\text { fixed carbon }\end{array}$ & 2.1 & 4.7 & 7.9 & 0.6 & 1.0 & 0.3 & 5.4 \\
\hline $\begin{array}{l}\text { Upper quartile } \\
\text { in } \mathrm{kg}\end{array}$ & 2.8 & 7.6 & 9.0 & 0.9 & 1.2 & 0.4 & 6.7 \\
\hline $\begin{array}{l}\text { Lower quartile } \\
\text { in } \mathrm{kg}\end{array}$ & 0.9 & 2.1 & 6.4 & 0.3 & 0.8 & 0.1 & 3.8 \\
\hline
\end{tabular}

According to Table 5, the sulfur content in the fossil reducing agents is the highest. Additionally noticeable is that the heat-treated reducing agents have a lower sulfur to fixed carbon ratio compared to the raw material. Wood charcoal has the lowest sulfur to fixed carbon ratio and a replacement of coke by wood charcoal would result in a $94 \%$ lower sulfur load for a metallurgical operation.

\section{Unit Operations Presented in this Review}

In the production route of the metals subject of this review, a considerable number of unit operations is used, often for more than one metal addressed here. Many unit operations included already have the potential to use bio-based carbon. One subchapter is dedicated to introduce the established conditioning processes sintering, briquetting, calcination or pre-reduction in a rotary kiln and the subsequent reduction smelting in a submerged arc furnace. In laboratory trials, other furnaces are also used like resistance- or induction furnaces, however, it is more likely that the presented state of art equipment is used for industrial applications. One subchapter is devoted to introduce innovative processes like segregation, and experiments using microwave heating or solar heating. Those processes are not carried out on an industrial-scale yet, but could be a breakthrough technology for the production of the considered metals. In the figures showing the schematic processes, the areas to substitute fossil carbon by bio-carbon reported are highlighted by a green dashed box. 


\subsection{Established Unit Operations Carried out in the Industry}

Figure 5 shows a schematic sketch of a sintering plant. Sintering is used to agglomerate ore, fines, and fluxes by using a carbon carrier like coke breeze or coal. The raw materials are mixed and a burner ignites the carbon carrier in the mixture. Wind boxes force air through the mixture while burning carbon supplies the energy for the process. The high temperature enables an agglomeration by surface melting. The sinter is finally crushed to lumps and charged into a smelting furnace. In this review, published research about the substitution of fossil carbon for the sintering of manganese and chromite ore is compiled.

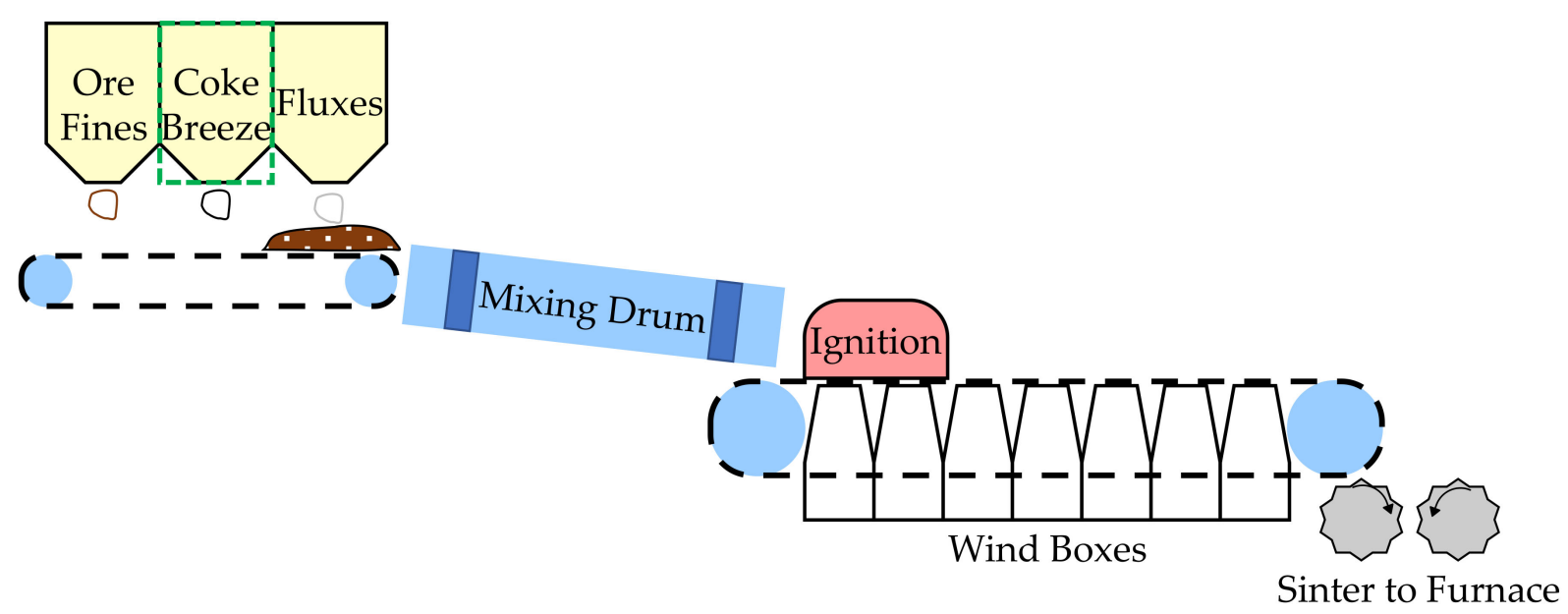

Figure 5. Schematic sintering process.

Another option for agglomeration is briquetting of raw material. Figure 6 shows a sketch of a briquetting process. Fine raw material is compacted by force into a lump briquette. Those briquettes can already contain a reducing agent like coke, but it is also possible to include bio-based carbon in this process. A further example of agglomeration is pelletizing using a pelletizing disk or pelletizing drum, which is not shown by a sketch in this review. The incorporation of bio-based carbon in agglomerates produced by briquetting or pelletizing has also been reported for the production of ferroalloys containing nickel, chromium, silicon and manganese and is addressed in this paper.

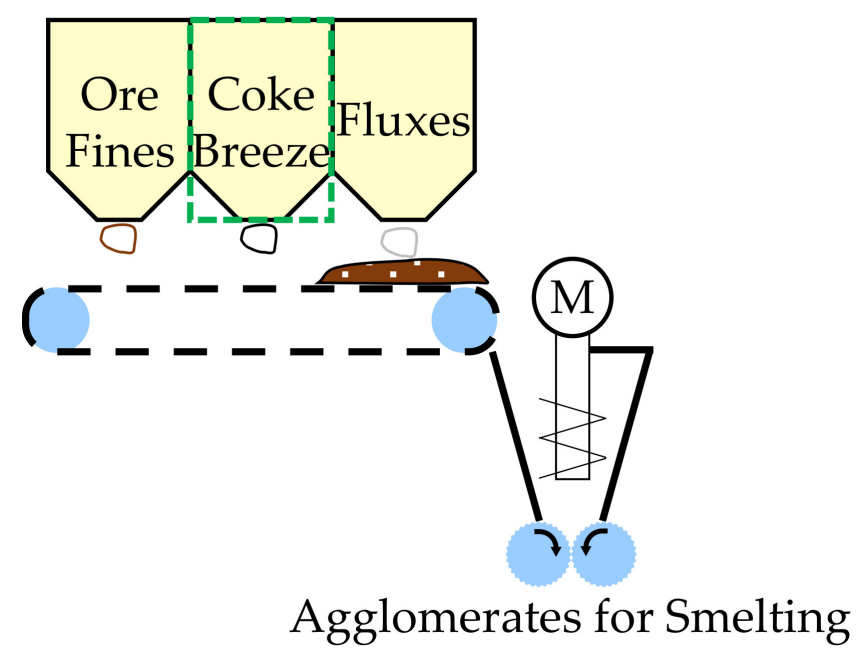

Figure 6. Schematic briquetting process.

Pre-reduction or solid-state reduction of ore is commonly carried out in a rotary kiln with a slight downward slope. It is typically heated by a gas-, oil-, or coal burner. Raw materials like ore, fines, coke breeze, coal and fluxes are either mixed and pelletized or directly charged at the higher side of the kiln. While the raw material is descending, it 
is heated and depending on the used mixture, oxides are either pre-reduced or reduced. The calcine is used as a feedstock for smelting for example in a submerged arc furnace. By pre-heating the calcine, the specific energy consumption in the smelting furnace is reduced and pre-reduction can minimize the amount of carbon carriers necessary for a full reduction of the feed in a furnace. Conditioning of ore for a subsequent hydrometallurgical treatment can also be carried out in a rotary kiln, for example to modify the mineralogical composition of ore. A schematic sketch of the calcination or pre-reduction operation is shown in Figure 7. Research carried out to substitute fossil carbon with bio-based carbon are presented in the chapters about nickel, chromium and manganese production and in the upgrading of ilmenite ore.

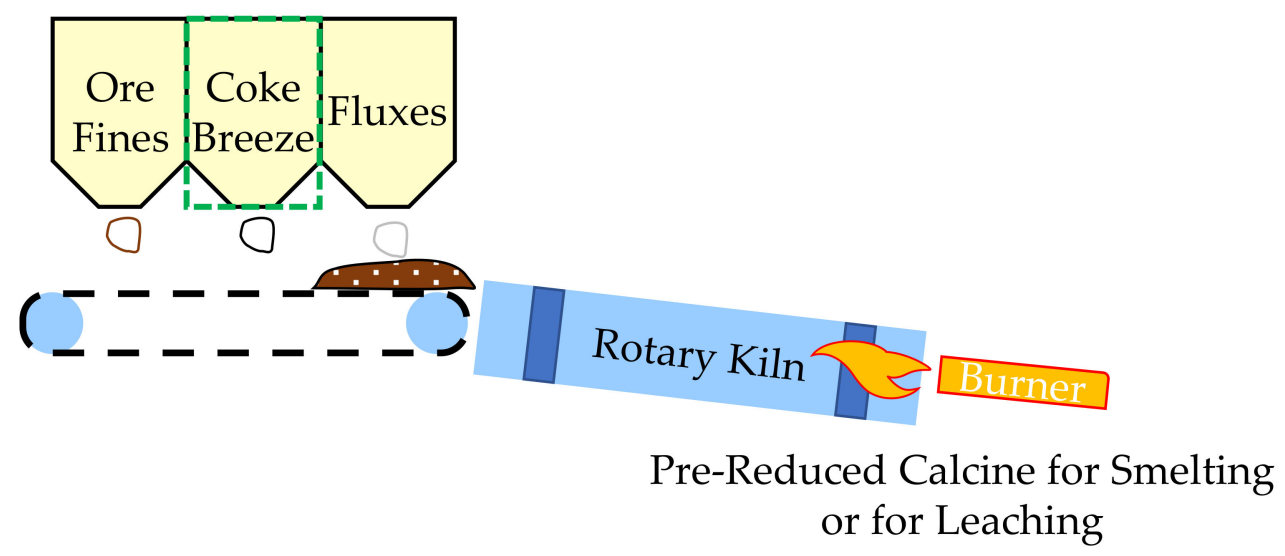

Figure 7. Schematic calcination process.

Common smelting reactors for the production of ferroalloys are submerged arc furnaces, refractory- or carbon-lined and heated by electricity conducted through electrodes into the furnace. Figure 8 shows a sketch of a submerged arc furnace with three electrodes. Other configurations are also common, for example with one top-electrode and a conductive hearth coupled with a bottom electrode or configurations with six electrodes. Those differences are not crucial for this review and therefore not further discussed. In those furnaces, ore, agglomerates or sinter are charged from the top with or without fluxes and carbon-containing materials like coke. Smelting processes using bio-based carbon are discussed for the production of nickel, chromium, silicon and manganese-containing alloys in this paper.

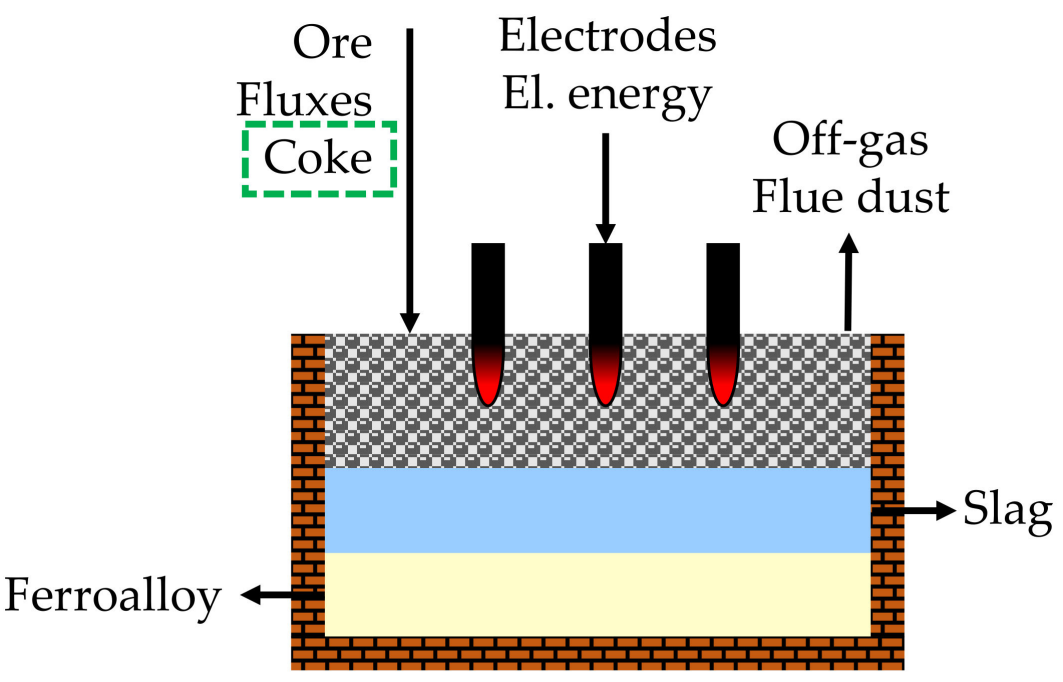

Figure 8. Schematic submerged arc furnace. 


\subsection{Innovative Unit Operations of Current Research Interest}

Segregation of primary concentrates is currently investigated to produce metal-rich particles, which can be separated from gangue material by using established mineral beneficiation methods. This is especially of interest, if the valuable metals in ore cannot be directly concentrated by current mineral processing. In a segregation process, ore is heated together with a carbon carrier and an additive for example in a rotary kiln, which enables the liberation of valuable metals by volatilization. Chlorides could be used for this process which would result in the formation of gaseous $\mathrm{HCl}$. The metal oxides then react with gaseous $\mathrm{HCl}$ according to Equation (4) [91,92].

$$
\mathrm{MeO}_{(\mathrm{s})}+2 \mathrm{HCl}_{(\mathrm{g})} \rightleftharpoons \mathrm{MeCl}_{2(\mathrm{~g})}+\mathrm{H}_{2} \mathrm{O}_{(\mathrm{g})}
$$

The generated water vapor is then reduced at solid carbon resulting in the formation of hydrogen according to Equation (5) [91].

$$
\mathrm{C}_{(\mathrm{s})}+2 \mathrm{H}_{2} \mathrm{O}_{(\mathrm{g})} \rightleftharpoons \mathrm{H}_{2(\mathrm{~g})}+\mathrm{CO}_{2(\mathrm{~g})}
$$

Hydrogen is then able to reduce the metal chloride according to Equation (6) while $\mathrm{HCl}$ is regenerated to react with leftover metal oxides again [91].

$$
\mathrm{MeCl}_{2(\mathrm{~g})}+\mathrm{H}_{2(\mathrm{~g})} \rightleftharpoons \mathrm{Me}_{(\mathrm{s})}+2 \mathrm{HCl}_{(\mathrm{g})}
$$

After the reaction is complete, residual gangue particles and carbon particles with deposited metal are produced. Those carbon particles with deposited metal are then collected by mineral processing and used in a smelting process, while the demetallized gangue is discarded. Figure 9 shows a schematic segregation process. This review presents research done about segregation processes using bio-based carbon for the enrichment of nickel and chromium resources.

\section{Segregation}

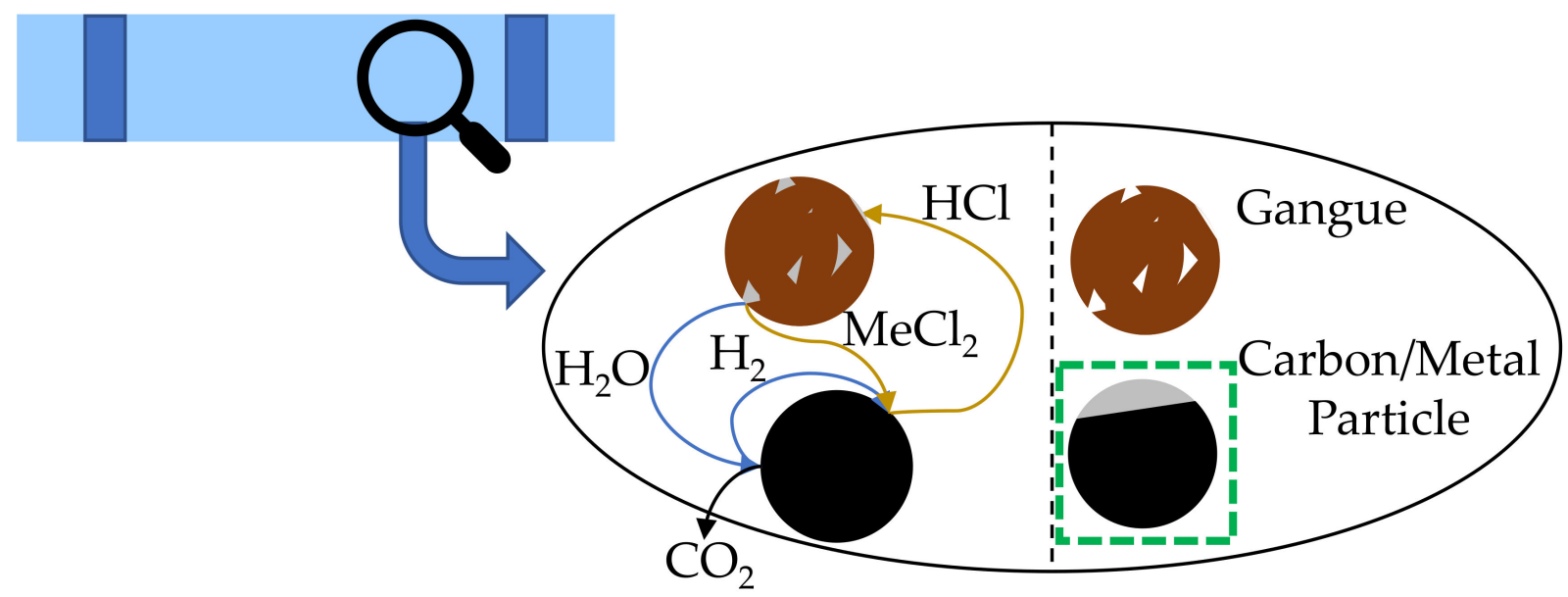

Figure 9. Schematic segregation process.

An option to avoid $\mathrm{CO}_{2}$ emissions generated to heat material, can be the usage of solar thermal energy or microwave heating by using renewable electricity. Currently, only laboratory-scale studies were found using those innovative heating sources coupled with the usage of bio-based carbon as reducing agent for metal oxides. A schematic set-up for the usage of solar heating and microwave heating is shown in Figure 10. These options are presented for the production of silicon and the upgrading of ilmenite, while microwave heating is already investigated for the pre-reduction of manganese ore and upgrading of ilmenite. 


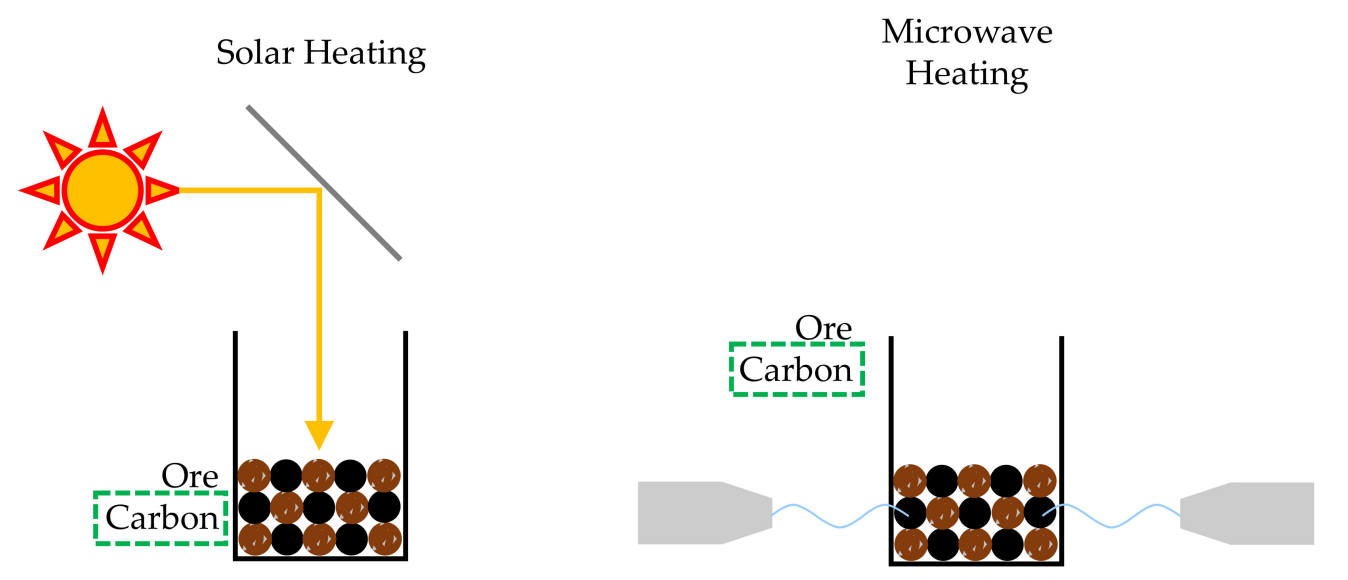

Figure 10. Schematic set-up for solar and microwave heated trials.

\section{Production of Nickel Alloys Using Bio-Based Carbon}

Research carried out to substitute fossil carbon in the production of nickel-containing alloys by bio-based carbon, either via solid-state reduction or smelting processes are presented in this chapter. In addition, life cycle assessments (LCA) investigating the replacement of fossil coal by bio-based carbon for the production of nickel are shown in this chapter.

\subsection{Solid-State Processes Using Bio-Based Carbon for the Production of Nickel Alloys}

The solid-state reduction chapter is divided into studies investigating the pre-reduction and the segregation of nickel resources.

\subsubsection{Pre-Reduction of Nickel Resources Using Bio-Based Carbon}

Pre-reduction and pre-heating of nickel ore are commonly used in the rotary kiln/electric furnace (RKEF) smelting process to lower the energy consumption in the electric furnace. Most commonly fossil carbon like anthracite, bituminous coal or lignite coal is used in the rotary kiln operation [93-99]. However, it is also possible to use bio-based carbon instead of fossil carbon in rotary kilns. This chapter presents some work carried out in this direction.

Already in 1960, the Hanna Nickel Smelting Co. in Oregon, USA presented the possibility of using wood waste in a rotary kiln to reduce trivalent iron into the divalent state. Back then Hanna Nickel used the Ugine reduction process. Crushed and screened ore was dried in an oil-fired rotary kiln and the hot calcine was smelted in an electric furnace. The molten ore was hydraulically tilted into a reaction ladle. After charging the molten ore, liquid ferronickel as seed metal and solid ferrosilicon as a reducing agent was fed into a reaction ladle. The content of the reaction ladle was poured into an empty ladle and back several times until the reduction was completed. Finally, the slag was transferred to a slag ladle for subsequent water granulation. Afterward, the ferronickel was transferred to a refining furnace [100]. Figure 11 shows a simplified process sheet of the Hanna Nickel Smelting Co [100].

Crushed and Screened Ore

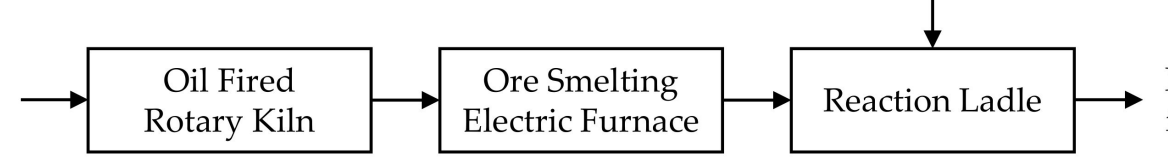

Metal and Slag for further Processing

Figure 11. Simplified process of the Hanna Nickel smelting operation (after [100]). 
As nearly $45 \%$ of ferrosilicon was used to reduce trivalent iron, tests were conducted to reduce the ferrosilicon consumption. The melting furnace consisted of a water-cooled steel shell and it was not possible to remove metal from the electric furnace in the original design. Therefore, approaches like adding reductants into the electric furnace were approached with caution. Furthermore, attempts to add carbon to the reaction ladle resulted in carbon boils or had no significant impact on ferrosilicon consumption. Instead, successful tests were carried out to add carbon or sawdust with the feed in the rotary kiln. In both cases, the ferrosilicon consumption decreased by $15 \%$ and the electrode consumption was reduced by $10-12 \%$, while sawdust had lower costs per pound of fixed carbon [100]. Those successful tests led to an installation of a sawdust system in the calcining operation already in 1960 [101].

Instead of using wood waste, a more recently investigated biomass-based reducing agent is shell charcoal like coconut or palm shell charcoal.

Shofi et al. [61] investigated a solid-state reduction process using sodium chloride, sodium sulfate and sodium carbonate as additives to produce a metallic concentrate from nickel laterites in a muffle furnace and to recover nickel by wet magnetic separation. Palm shell charcoal was the only reducing agent in this work, which does not allow a comparison with other reducing agents. The study showed the advantages of a sodium sulfate addition on the process. Adding $10 \mathrm{wt} \%$ of sodium sulfate and $5 \mathrm{wt} \%$ of palm shell charcoal at a reduction temperature of $1150{ }^{\circ} \mathrm{C}$ and a reduction time of $60 \mathrm{~min}$ yielded the highest nickel recovery of $73.2 \%$ and a nickel grade of $4.6 \mathrm{wt} \%$ in the concentrate. Furthermore, the grain size of the produced ferronickel particles was nearly three times higher $(\sim 30 \mu \mathrm{m})$ compared to the other additives [61].

Petrus et al. [56] investigated and compared the reduction behavior of anthracite coal and coconut shell charcoal for the roasting reduction of limonitic laterite. Laterite and the reducing agent were pelletized and treated in a muffle furnace at different temperatures and holding times. In the study, no ferronickel or wustite could be identified, instead, only a partial pre-reduction of iron oxides to magnetite occurred. A mineralogical comparison of the yielded products after a reduction time of $120 \mathrm{~min}$ at $900{ }^{\circ} \mathrm{C}$ yielded no significant difference in terms of the formation of olivine, quartz, magnetite and hematite for both reducing agents. However, kinetic analysis revealed, that according to a Jander model, the apparent activation energy slightly deviated with a value of $3.7092 \mathrm{~kJ} / \mathrm{mol}$ for the reduction with anthracite and $4.4370 \mathrm{~kJ} / \mathrm{mol}$ for the reduction with coconut shell charcoal, which was stated as a comparable performance by the authors [56].

Chen et al. [102] investigated the reduction of pelletized saprolite and limonite nickel ore with torrefied oil palm fiber at temperatures between $900{ }^{\circ} \mathrm{C}$ and $1400{ }^{\circ} \mathrm{C}$. The limonite ore was also treated with coal as a comparison at temperatures between $900{ }^{\circ} \mathrm{C}$ and $1100{ }^{\circ} \mathrm{C}$. Figure 12 shows the measured iron- and nickel content of the treated limonite ore for varying temperatures. The raw ore has an iron content of $41.1 \mathrm{wt} \%$ and a nickel content of $1.18 \mathrm{wt} \% \mathrm{Ni}$.

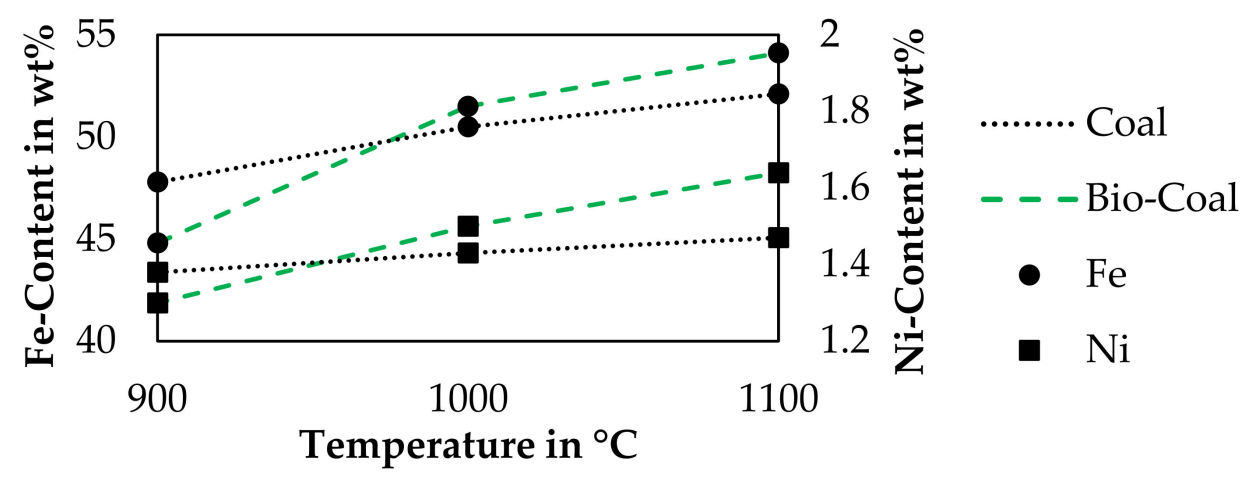

Figure 12. Iron- and nickel content after reduction of limonite with coal and bio-coal (based on data from [102]). 
The comparison of coal and the bio-coal sample showed slightly higher nickel- and iron contents for reduction temperatures of $1000{ }^{\circ} \mathrm{C}$ and $1100{ }^{\circ} \mathrm{C}$, whereas at a temperature of $900{ }^{\circ} \mathrm{C}$ coal yielded a higher iron- and nickel content in the sample. Higher reaction temperatures were not used for the comparison and were only carried out with bio-coal. The X-ray diffraction patterns presented by Chen et al. [102] of ore samples reduced with this type of bio-coal revealed, that at reduction temperatures above $1000^{\circ} \mathrm{C}$, the main phase in the reduced limonite samples is iron, whereas, for saprolite samples, the first peaks attributed to metallic phases occurred over $900{ }^{\circ} \mathrm{C}$ already. Chen et. al. [102] described, that at temperatures between $800{ }^{\circ} \mathrm{C}$ and $1100{ }^{\circ} \mathrm{C}$, the pellets formed a dense shell and a loose core. The soft melting temperature was determined to be $1200^{\circ} \mathrm{C}$, where small metal particles were formed for the first time. At $1400{ }^{\circ} \mathrm{C}$ a separation between iron and oxides occurred [102].

Nurjaman et al. [58] investigated the production of metallic concentrates from laterite ores with a nickel content of $1.4 \mathrm{wt} \%$ using sodium sulfate as an additive and anthracite coal or palm shell charcoal as a reducing agent. Magnetic separation was employed to remove the tailings from magnetic ferronickel particles. Both reducing agents were suitable to produce metallic concentrates, however, the nickel grade in the concentrate produced with anthracite was higher $(6.1 \mathrm{wt} \%)$ compared to the concentrate produced using palm shell charcoal $(4.6 \mathrm{wt} \%)$. This was explained by the higher sulfur content in anthracite compared to palm shell charcoal, which leads to an additional generation of FeS particles and a decreased iron metallization [58].

Swamy et al. [103] studied the extraction of nickel from chromitiferous overburden concentrate granules with $\mathrm{CO}_{2}-\mathrm{CO}-\mathrm{N}_{2}$ gas mixtures in a vertical bed reactor. In this setup, the addition of only $2.5 \mathrm{wt} \%$ charcoal increased the nickel extraction by $11 \%$ to $19 \%$ compared to trials without charcoal addition. Nickel extractions slightly above $90 \%$ were obtained [103]. However, no comparison with other reducing agents like fossil coal or coke was carried out in the study.

Further research proposed the utilization of palm kernel shell charcoal as a partial substitute in nickel rotary kilns [59], rice husks as a reducing agent for limonite ore [46], lamtoro charcoal [57,71,104], palm kernel shells [47,105-107], palm kernel shell charcoal $[62,108]$ or coconut shell charcoal $[57,63,109]$ as a reducing agent for laterite ores.

\subsubsection{Segregation Processes Using Nickel Resources and Bio-Based Carbon}

Oxidic nickel ores have been treated by using the segregation process (see chapter 3.2), where minerals are chlorinated at elevated temperatures and volatile nickel- and iron chlorides deposit on a carbon surface. The generated metal-carbon particles can later be separated from gangue material by flotation or magnetic separation. Compared to the sole pre-reduction presented in the previous chapter, the additional usage of chlorides aids the liberation of valuable metals from the gangue matrix. In the 1980s, pilot-scale trials with a capacity of one metric ton of ore per hour were conducted successfully with nickel recoveries over $90 \%$ and nickel grades of $60 \mathrm{wt} \%$ in the concentrate. Based on those trials, energy savings compared to a smelting process of $25-30 \%$ were estimated [110]. However, due to decreasing nickel prices the plant was closed [92].

Grimsey et al. [111] investigated the segregation process using different layers of a laterite ore deposit. As the mineralogical composition of the ore was the main investigated parameter in the study, carbon- and calcium chloride addition was not varied, but two reducing agents were compared. Metallurgical coke with a specific surface area of $4.3 \mathrm{~m}^{2} / \mathrm{g}$ and activated coconut carbon with a specific surface area of $1160 \mathrm{~m}^{2} / \mathrm{g}$ were used in the study. In all cases, the recovery through segregation using activated coconut carbon was lower compared to metallurgical coke. The nickel recovery dropped from $80 \%$ to $67 \%$ at $900{ }^{\circ} \mathrm{C}$ for limonite, from $71 \%$ to $67 \%$ at $950{ }^{\circ} \mathrm{C}$ for nontronite and from $65 \%$ to $48 \%$ at $950{ }^{\circ} \mathrm{C}$ for garnierite. The decreased nickel yield for activated coconut carbon was explained by the occurring in situ reduction of nickel due to its reactivity. The higher surface area of activated carbon led to a lower oxygen partial pressure compared to metallurgical coke 
and under these conditions, metallic nickel formed directly to some extent and was not volatilized and segregated on the carbon particles. Those fine metallic nickel inclusions were difficult to recover from the calcine via magnetic separation [111]. Even though the recovery efficiency for nickel was lower in this study using the biomass-based reducing agent, the reduction to metallic nickel occurred fast as lower reaction time was needed to decrease the oxygen partial pressure to values low enough to reduce metallic nickel due to an increased rate of the Boudouard reaction [111]. Therefore, if the target is sole to pre-reduce ore in a solid-state reaction, the activated charcoal carbon could have an advantage compared to metallurgical coke.

\subsection{Smelting Processes Using Bio-Based Carbon to Produce Nickel Alloys}

This subchapter covers the usage of bio-based carbon for the production of nickel alloys like ferronickel and nickel pig iron. The main difference between those alloys is the concentration of nickel in the final product. While nickel pig iron contains $1-15 \mathrm{wt} \%$ nickel, ferronickel contains 20-40 $\mathrm{wt} \%$ nickel [112].

Compared to the solid-state reduction processes, only a few studies were published investigating the opportunity to use bio-based carbon for the smelting of nickel ores. Three experimental studies were reported about the smelting of nickel laterite ore from Poomala, Indonesia $[60,113,114]$. Supriyatna and Sihotang et al. $[113,114]$ investigated the effect of various palm kernel shell charcoal additions and the smelting time for the production of nickel pig iron in a laboratory-scale electric arc furnace using $9.7 \mathrm{~kg}$ of ore per trial. Nickel recovery of $92.53 \%$ was obtained for the best parameters with an addition of $20.6 \mathrm{wt} \%$ of palm kernel shell charcoal and a smelting time of 90 min [113,114]. Andika et al. [60] compared the usage of standard coke (62.97 wt $\%$ fixed carbon), coal (37.25 wt $\%$ fixed carbon) and coconut shell charcoal (55.02 wt\% fixed carbon). An electric arc furnace using $30 \mathrm{~kg}$ of ore per trial was used to produce nickel pig iron as well. Even though the fixed carbon content varied in the reducing agents, in each trial $7 \mathrm{~kg}$ of a reducing agent was used. The nickel extraction with coconut shell charcoal was inferior compared to the usage of coal and coke, with the highest obtained nickel extraction for coke. However, the iron yield was the highest for coconut shell charcoal, also the obtained metal mass was the highest using coconut shell charcoal [60].

Even though there are not a lot of studies about smelting trials with bio-based carbon for the production of ferronickel, the reduction of greenhouse gas emissions by substituting coal with bio-based carbon was already evaluated in two "cradle-to-gate" life cycle assessments (LCA) [115,116].

Figure 13 compares the global warming potential (GWP) as reported by Bartzas et al. [116] and by Norgate et al. [115] for a baseline scenario and a green scenario replacing 50\% of fossil reducing agents by bio-based carbon. Additionally, the primary energy demand (PED) reported for both scenarios by Bartzas et al. [116] is included.

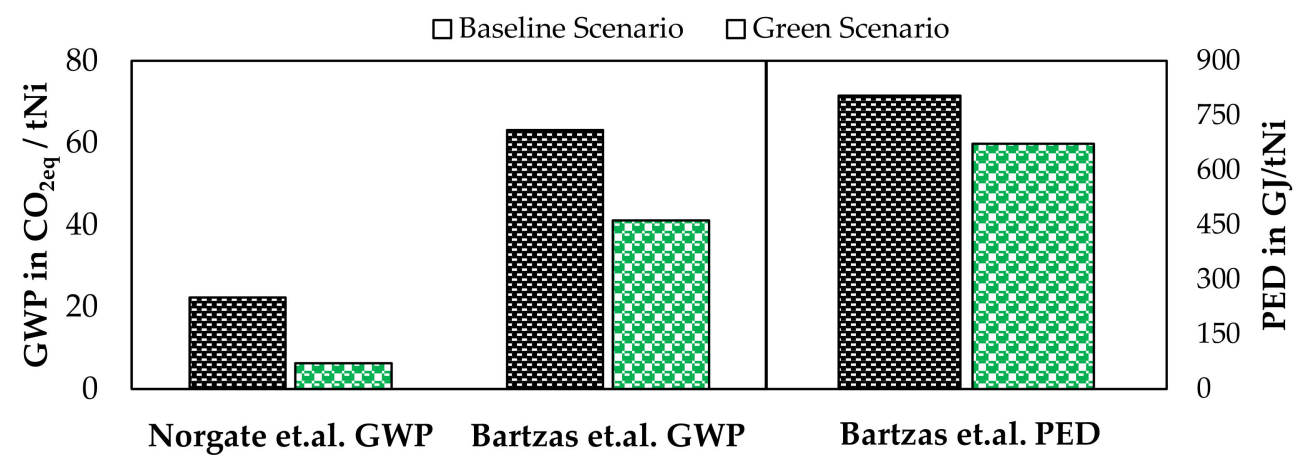

Figure 13. GWP and PED of the pyrometallurgical nickel production using fossil and bio-based carbon (based on Data by $[115,116])$. 
The LCA of Norgate et al. [115] compared different production routes for nickel and proposed several possibilities to reduce the specific greenhouse gas (GHG) emissions. One suggestion was the replacement of coal with biochar. An LCA of the biochar production has already been published previously by the author [117] and used as a basis for the smelting of ferronickel. For ferronickel smelting, typically 3.9 tons of coal are used per ton of ferronickel resulting in $22.4 \mathrm{t} \mathrm{CO}_{2 \mathrm{eq}} / \mathrm{t} \mathrm{Ni}$. A complete replacement of coal by the proposed biochar would reduce the GWP to $12.3 \mathrm{tCO}_{2 \mathrm{eq}} / \mathrm{t} \mathrm{Ni}$, not considering the credits of by-products obtained from biochar production (bio-oil and electricity). If those by-product credits are also included in the calculation, a partial replacement of $70 \%$ coal by biochar would result in a GWP of $0 \mathrm{t} \mathrm{CO}_{2 \mathrm{eq}} / \mathrm{t} \mathrm{Ni}$. Even without by-product credits, a complete replacement of biochar leads to a lower GWP compared to the other presented options by Norgate et al. One of these options was the recovery of waste heat from the slag, which yielded a GWP of slightly above $20 \mathrm{tCO}_{2 \mathrm{eq}} / \mathrm{t} \mathrm{Ni}$. The second option was the use of a bath smelting operation with more efficient utilization of the embodied energy in the off-gas due to post-combustion in the furnace, which allowed savings in electrical energy and results in a GWP of $13.7 \mathrm{t} \mathrm{CO}_{2 \mathrm{eq}} / \mathrm{t} \mathrm{Ni}$ [115]. Since the investigated bath smelting option used coal, a replacement by biochar could decrease the GWP in a bath smelting furnace even more.

Bartzas et al. [116] conducted an LCA of the ferronickel production using a typical Greek laterite ore as a feedstock. One investigated scenario was the replacement of 50\% of the commonly used coal and lignite by biochar derived from agricultural waste and assuming that $50 \%$ of the total electricity consumption is sourced from renewable energy. A second scenario was the partial utilization of the slag in the construction industry. The baseline scenario without any changes results in a GWP of $12.6 \mathrm{t} \mathrm{CO}_{2 \mathrm{eq}} / \mathrm{t}$ FeNi. The partial usage of biochar and electricity from renewable sources reduced the GWP by $4.38 \mathrm{tCO}_{2 \mathrm{eq}} / \mathrm{t}$ FeNi. Without the assumption of using electricity from renewable sources, the savings in GHG emissions are 18\% compared to the baseline scenario. The optimized usage of slag in the construction industry reduced the GWP by $13 \%$ and was therefore inferior compared to the replacement of coal and lignite by biochar. The PED decreased by $17.1 \%$ in the green scenario compared to the baseline scenario. In the green scenario, nearly $36 \%$ of the PED were covered by biomass and biochar. Another side benefit of biochar usage is the lower acidification potential. Due to the lower sulfur content in biochar compared to coal and lignite, savings of $0.018 \mathrm{t} \mathrm{SO}_{2 \mathrm{eq}} / \mathrm{t}$ FeNi were reported for the scenario using $50 \%$ biochar and $50 \%$ of electricity from renewable sources [116].

\section{Production of Chromium Alloys Using Bio-Based Carbon}

Research for substituting fossil carbon was also carried out in the production of chromium. Bio-based carbon was used for investigating mainly the solid-state process, compared to nickel while only limited research was carried out in smelting operations to generate chromium alloys. An LCA about chromium production using bio-based carbon was not published to our knowledge.

\subsection{Solid-State Processes Using Bio-Based Carbon for the Production of Chromium Alloys}

Solid-state research was dedicated to pre-reduction and segregation. This also includes investigations with a focus on agglomeration processes like pelletizing followed by thermal treatment and sintering studies carried out in semi-industrial and industrial-scale.

\subsubsection{Pre-Reduction and Agglomeration of Chromium Resources Using Bio-Based Carbon}

First publications about the usage of bio-based carbon for the solid-state reduction of chromite were already published in the 1960s. Jochens et al. [118] investigated the possibility of selectively reducing iron to metal or carbide in a laboratory-scale fluosolid reactor. Afterward, iron is removed by leaching with sulfuric acid to increase the chromium to iron ratio in the furnace feed. Experiments were carried out with wood charcoal as a reducing agent, chromite ore as raw material, and nitrogen as fluidizing gas. Temperatures between 
$1000{ }^{\circ} \mathrm{C}$ and $1250{ }^{\circ} \mathrm{C}$ were investigated. Even though the fluidizing itself worked stable, only a small increase in chromium to iron ratio was observed. A probable explanation was an insufficient contact between charcoal and chromite. As a modification, oxygen was added to the nitrogen gas to enable the generation of carbon monoxide in the reactor, but the trials were still not successful. Instead, non-renewable town gas was used as a fluidizing gas, which yielded satisfactory results increasing the chromium to iron ratio from 1.6-1.8 up to 3 and higher [118]. A renewable alternative to town gas in this process could be biomass-derived syngas, which was already used for direct reduction of iron by Guo et al. [119].

Khan $[120,121]$ conducted isothermal pre-reduction and reduction experiments with several chromite ores pelletized with charcoal, coal or without reducing agents in a $\mathrm{CO}-\mathrm{CO}_{2}$ atmosphere. A resistance-heated thermogravimetric setup was chosen to determine the reduction rates at $1350-1600{ }^{\circ} \mathrm{C}$ [121] and at $1500{ }^{\circ} \mathrm{C}$ and $1600{ }^{\circ} \mathrm{C}$ [120]. At $1600{ }^{\circ} \mathrm{C}$ the reduction rate of the charcoal was higher compared to the trials with coal, at $1500{ }^{\circ} \mathrm{C}$, one chromite sample showed a higher reduction rate with charcoal and two chromite samples showed a higher reduction rate with coal [120]. Figure 14 shows the degree of reaction of three chromite ore samples studied by Khan [121]. In isothermal reduction trials at $1550{ }^{\circ} \mathrm{C}$, charcoal resulted in a significantly higher degree of reaction using the "CR Ore", the degree of reaction for "CG Ore" was the same using charcoal and coal. The degree of reaction for the "CB Ore" was significantly higher using charcoal in the beginning, but after $45 \mathrm{~min}$, coal yielded a higher degree of reaction [121]. The ores differed in chromium and iron content, "CR Ore" had the lowest chromium content and highest iron content, followed by "CG Ore". "CB Ore" had the highest chromium content and the lowest iron content. Furthermore, the oxidation state of iron differed, "CB Ore" and "CR Ore" contained iron mostly in the trivalent state, while "CG Ore" contained iron mostly in the divalent state [121].

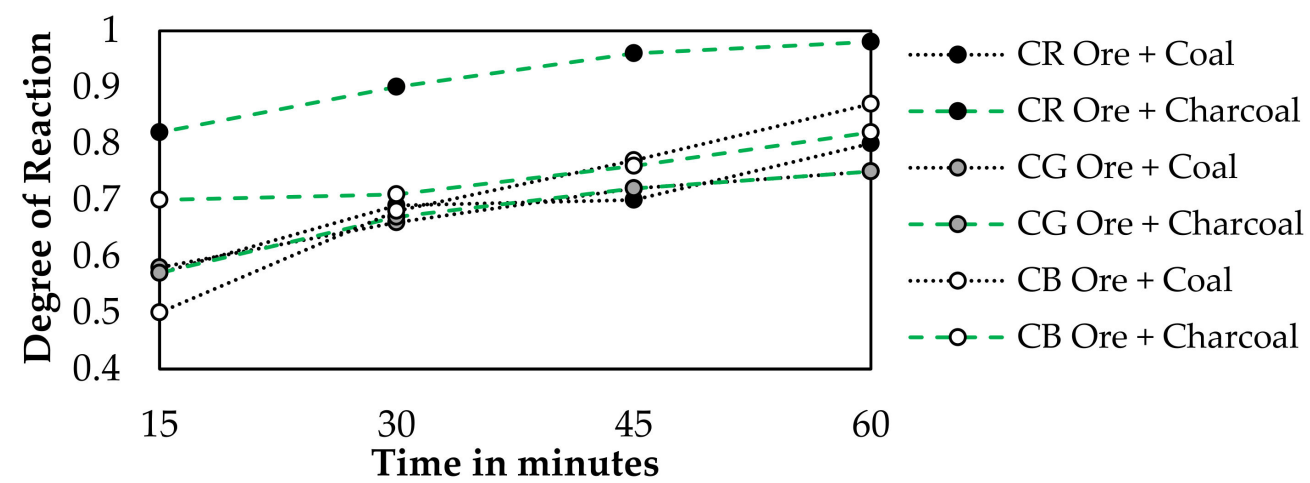

Figure 14. Time-dependent degree of reaction of various chromite ores at $1550{ }^{\circ} \mathrm{C}$ with coal and charcoal (based on data by Khan [121]).

Nurjaman et al. [64] investigated the beneficiation and smelting of low-grade chromite sands from Indonesia. The raw chromite sand had a chromium to iron ratio of 0.9 , which could be increased to 1.31 by magnetic separation. A second beneficiation step was carried out by reduction roasting at $1100{ }^{\circ} \mathrm{C}$ with coconut shell charcoal $(69.91 \mathrm{wt} \%$ fixed carbon content) and limestone as an additive. Magnetic separation of the pre-reduced chromite sand yielded a chromium to iron ratio of 1.60 . Thirty $\mathrm{kg}$ of beneficiated concentrate were smelted per trial in a three-phase submerged arc furnace and additional trials were carried out with the as-received low-grade chromite sand. The reducing agent for the electric arc furnace process was coke instead of coconut shell charcoal in the study. The smelting of raw ore yielded ferrochromium with $35.2 \mathrm{wt} \%$ chromium and $53.2 \mathrm{wt} \%$ iron. The highest grade obtained was $50.7 \mathrm{wt} \%$ chromium in the alloy and an iron content of $47.7 \mathrm{wt} \%$ smelting beneficiated ore [64]. 
Sommerfeld et al. [122] examined the pre-reduction of magnesia-rich chromite ore in a laboratory-scale conducting isothermal pre-reduction trials between $1000^{\circ} \mathrm{C}$ and $1300^{\circ} \mathrm{C}$. As renewable reducing agents, coconut shell charcoal, olive pomace charcoal, corn cob charcoal and bamboo charcoal were examined, while fossil lignite coke was used as a reference. Since at $1000{ }^{\circ} \mathrm{C}$ and $1150{ }^{\circ} \mathrm{C}$ the pre-reduction was below $34.3 \%$ in the best case using olive pomace charcoal, a focus was on the trials at $1300^{\circ} \mathrm{C}$. At this temperature, the pre-reduction of the four renewable reducing agents yielded similar results at reaction times of $360 \mathrm{~min}$ between $65.4 \%$ using coconut shell charcoal and $61.0 \%$ using bamboo charcoal. Lignite coke only yielded a degree of reaction of $51.9 \%$. However, it has to be noted, that at lower reaction times up to $90 \mathrm{~min}$ the pre-reduction also differed more using bio-based reducing agents. The highest pre-reduction for lower holding times was reached using olive pomace charcoal, followed by coconut shell charcoal, corn cob charcoal and bamboo charcoal. Still, as only pre-reduction was carried out in a laboratory-scale, it is still unclear how those reducing agents will influence the processing in a larger scale, since the renewable reducing agents contained a higher amount of chlorine than coke, which could increase the wear of off-gas treatment plants. Furthermore, the metal quality could be influenced by the renewable reducing agents, as the phosphorous content was elevated in the ash of the charcoal samples compared to the lignite coke. However, as a benefit the bio-based charcoals contained a significantly lower portion of sulfur [122].

Another option to include biomass in the production route of ferrochromium is the replacement of coke or coal during the sintering operation to agglomerate chromite fines, which was already investigated several times recently for the sintering of iron ore [123-134] and the pelletizing of iron ore $[34,35,48,54,119,135]$. However, there are also difficulties to overcome when charcoal is used for sintering. Lopes [136] described trials at Ferbasa carried out in the 1980s with a semi-industrial sintering plant producing 2000 metric tons of sinter. Sintering of chromite fines generally leads to positive effects like more stable submerged arc furnace operation, reduced dust emission, lower energy and charcoal consumption and increased productivity. But difficulties attributed to the usage of charcoal were stated. Due to the high reactivity of charcoal lower maximum temperatures were reached in the sintering bed, which makes sintering of ores with a high softening point like chromite difficult, also the low density of charcoal leads to a higher volume of the sintering charge and larger voids in the sinter decreased the mechanical stability [136]. Nearly thirty years later, Rocha et al. [72] presented results from an industrial sintering test also carried out at Ferbasa. The sintering equipment had a capacity of 10 tons sinter per batch. Chromite lumps were used as a false great and chromite concentrate and ore fines were used as chromium carriers. FeSiCr slag was used as a flux and charcoal was used as a carbon carrier, coke or coal was not added. Due to the high ash content in the used charcoal, a liquid phase formed easily, which increased the sintering yield. The addition of FeSiCr slag as a flux in the sintering operation had a positive effect as well. The trial with $\mathrm{FeSiCr}$ slag and $6.5 \mathrm{wt} \%$ charcoal in the blend yielded the same technical performance compared to a trial with $9.5 \mathrm{wt} \%$ charcoal without $\mathrm{FeSiCr}$ slag. This can be explained by entrained metal droplets in the slag, that are oxidized in the high-temperature zone of the sintering strand [72].

Sakaranaho et al. [137] investigated the substitution of coke breeze by charcoal in chromite pellets in 2018. Fine chromite concentrate with a mean size of $200 \mu \mathrm{m}$ is normally pelletized with fine coke and coke dust from off-gas filters. Laboratory trials were carried out with a batch size of $550 \mathrm{~g}$. Chromite, coke $(85.21 \mathrm{wt} \% \mathrm{C}, 0.741 \mathrm{wt} \% \mathrm{~S})$ and birch charcoal (96.18 wt\% C, $0.006 \mathrm{wt} \%$ S), bentonite and water were pelletized in the study. Different ratios of coke and charcoal, varying carbon additions and varying particle sizes were variable parameters in this article. Green pellets were then burned in a resistance-heated furnace with a constant air supply. The cold compression strength (CCS) and electrical conductivity of the pellets were measured to evaluate the quality of the pellets. The CCS decreased with an increased share of charcoal in the mixture. A mixture of $50 \%$ charcoal resulted in a CCS $7.7 \%$ lower than the reference trial where only coke was used. Higher 
charcoal ratios in the fuel mixture decreased the CCS more drastically, a charcoal ratio of $75 \%$ reduced the CCS by $40.7 \%$. Particle size and increasing carbon additions were also investigated, but the effect on the CCS was not as significant as the ratio of coke to charcoal in the mixture. The relative permittivity of the pellets at room temperature decreases when charcoal is added in the mixture, furthermore, it was stated, that the decrease is lower if the reduction degree of pellets is higher. The authors concluded, that the significant potential in reduced $\mathrm{SO}_{\mathrm{x}}$ emissions, due to the lower sulfur content in charcoal, justifies the replacement of $50 \%$ coke by charcoal, as the reduction in CCS was still low in that case [137].

\subsubsection{Segregation Processes Using Chromium Resources and Bio-Based Carbon}

Similar to the segregation studies already mentioned for the treatment of nickel, Yu et al. [91] investigated the segregation process using chromite ore. $\mathrm{CaCl}_{2}$ was used as a chlorine-containing additive and charcoal and petroleum coke were used as reducing agents, both with a similar total carbon content of $85.3 \mathrm{wt} \%$ and $85.1 \mathrm{wt} \%$ respectively. The focus of the study was not to investigate yields or metallization degrees, instead, the mechanism of segregation was investigated. By comparing the results of trials using petroleum coke and charcoal, it was stated, that the highly reactive nature, porous structure and higher surface area of charcoal lead to an enhanced chloridization and metallization accompanied by the formation of monocrystalline hexagonal $\mathrm{M}_{7} \mathrm{C}_{3}$-type whiskers, which were not observed when petroleum coke was used. Figure 15 shows the morphology of FeCr- and carbide particles produced by Yu et. al. [91] using charcoal $(\mathrm{a}-\mathrm{c})$ and petroleum coke $(\mathrm{d}-\mathrm{f})$ as a reducing agent.
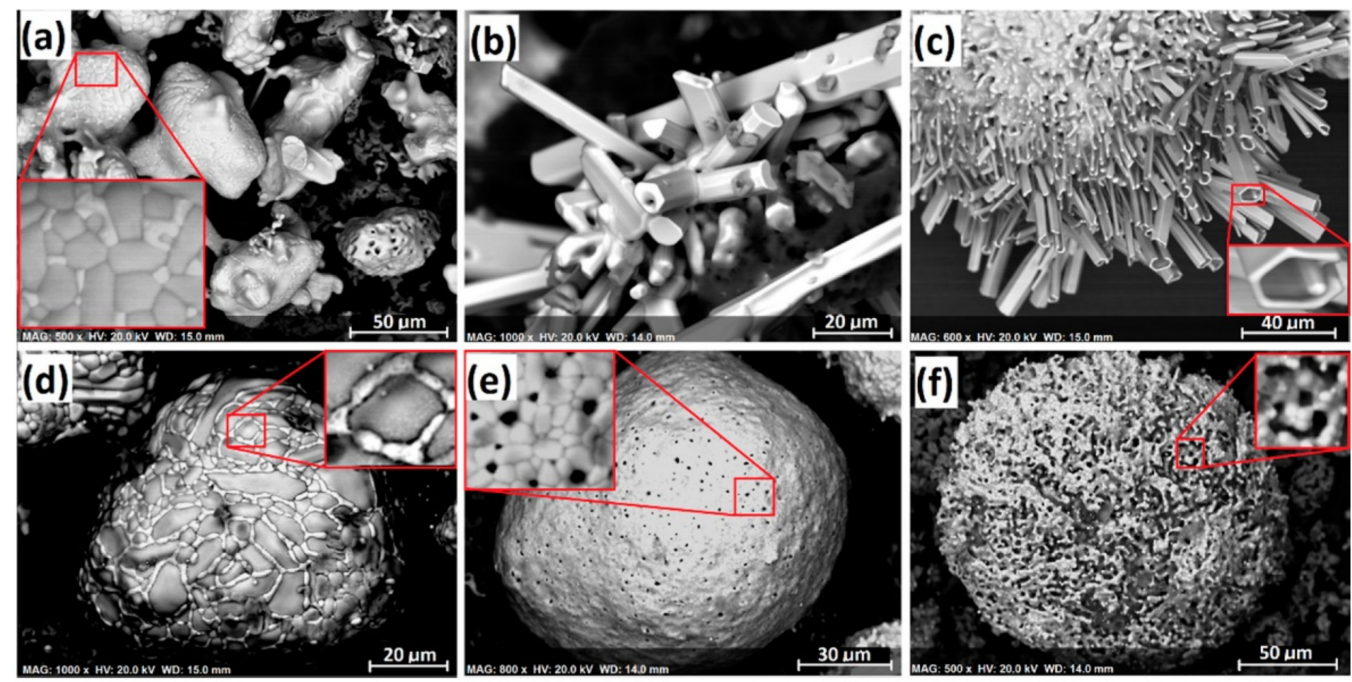

Figure 15. Morphologies of $\mathrm{FeCr}$ - and carbide particles produced by segregation using charcoal $(\mathbf{a}-\mathbf{c})$ and petroleum coke (d-f) by Yu et. al. [91].

The presence of siliceous gangue was also listed as a promoting factor of the whisker formation. Segregation of iron and chromium on carbon particles was also observed using petroleum coke and since the metallization degree was not investigated [91], it cannot be stated that the higher reactivity leads to higher yields. Especially, if the results of Grimsey et al. [111] for the segregation of nickel laterite are considered, where the usage of activated charcoal resulted in lower yields compared to metallurgical coke [111].

\subsection{Smelting Processes Using Bio-Based Carbon to Produce Chromium Alloys}

Balango et al. [65] smelted calcinated chromite ore and nickel laterite in a vertical resistance heated furnace. The aim was to investigate the simultaneous smelting of nickel and chromium-bearing ores to produce a crude $\mathrm{Fe}-\mathrm{Ni}-\mathrm{Cr}$ alloy in one furnace as proposed previously by Yape et al. [138]. In the study of Balango et al. [65], ore mixtures with different proportions of laterite and chromite from The Philippines were reduced by coconut charcoal 
with a fixed carbon content of $72.46 \mathrm{wt} \%$, other reducing agents were not considered in the study. Metal yields up to $99.62 \%$ were reported using a mixture containing $50 \%$ chromite and $50 \%$ laterite resulting in a crude alloy containing $11.20 \mathrm{wt} \%$ of chromium and $1.78 \mathrm{wt} \%$ of nickel. Using higher shares of laterite in the blend resulted in alloys with higher nickel contents and lower chromium contents, but the yield decreased to $69.70 \%$ using higher laterite shares in the raw material blend [65].

Furthermore, it is also possible to use wood chips in the production of $\mathrm{FeSiCr}$. Machulec et al. [36] reported that wood chips can be used to adjust the resistance of the charge and to enhance gas permeability [36]. As the main reducing agent in this study, hard coal was used [36], therefore, it can be assumed, that the wood chips were not added to substitute fossil carbon, but to improve the mentioned physical properties of the charge.

\section{Production of Ferrosilicon and Silicon Alloys Using Bio-Based Carbon}

Charcoal and wood chips are already commonly used as additives for the production of silicon alloys in submerged arc furnaces, as it leads to good ventilation of the charge [139]. Compared to the previously discussed metals, pre-reduction or solid-state reduction using biocarbon has not been investigated to our knowledge and literature review. But smelting processes using bio-based carbon and the production of pellets and composites containing bio-based carbon are thoroughly reported recently. As an innovative approach, the production of silicon using solar thermal energy and bio-based carbon under vacuum is presented as well in this chapter. In addition, an LCA investigating the replacement of fossil coal by bio-based carbon for the production of silicon is also shown, while an LCA about the ferrosilicon process using bio-based carbon was not published to our knowledge.

\subsection{Smelting Processes Using Bio-Based Carbon to Produce Silicon Alloys}

The production of ferrosilicon using only bio-based carbon as a carbon carrier is already state of art and in an industrial-scale, as Elkem is operating a furnace in Paraguay with a capacity of $11,000 \mathrm{mt}$ with bio-based carbon. In addition, hydroelectric power is used, which leads to a near carbon-neutral operation $[140,141]$. The established facilities of Elkem in Norway already used 20\% bio-carbon in 2019 and Elkem aims for a further increase in the reducing agent mixture up to $40 \%$ by 2030 for their Norwegian smelters. However, the sourcing of the bio-carbon is named as a challenge and the replacement of $40 \%$ fossil fuel would lead to a demand for bio-carbon, which equals $7 \%$ of the annual forest extraction in Norway [141].

One further problem to overcome is the increased amount of energy leaving the furnace in the off-gas due to higher volatile contents in raw materials like wood chips compared to coke or charcoal [142].

Liu et al. [37] conducted trials in an 8 MVA submerged arc furnace to produce silicon while substituting a share of the fossil reducing agents with alternative carbon materials. Vegetative plant waste from the Yunnan Province was heated in a low oxygen environment to generate waste carbon material samples for the submerged arc furnace trials with a fixed carbon content of $78.5 \mathrm{wt} \%$. Three batches were investigated in the study, while in one batch $20 \%$ of the regular fossil reducing agents (coal and petroleum coke) were replaced by waste carbon material. The specific $\mathrm{CO}_{2}$ emission decreased by $0.817-0.865 \mathrm{t}$ per ton of silicon (19.1-20.0\%) for the batch with waste carbon material. The electric energy consumption was $13.81 \mathrm{MWh} / \mathrm{t}$ of silicon in the batch with waste carbon material, which was similar to the two reference batches. The highest silicon yield was also observable in the trial with waste carbon material resulting in a yield of $94.5 \%$, while the maximum yield of the reference campaigns were $86 \%$ in both cases. Another presented indicator was the carbon efficiency, which slightly increased from 0.447 and 0.446 in the reference trials up to 0.45 in the campaign using waste carbon material. This was explained by the enhanced fluidity of the burden promoted by $\mathrm{CaO}$ present in the ash of the waste carbon material. As a consequence, the contact area of the material increased and the reactions were more intense [37]. Those results show in conclusion, that treated vegetative waste can be included 
in an industrial process without impairing main technical performance indicators and some performance indicators can even be slightly increased.

Monsen et al. [26] used Brazilian charcoal to produce ferrosilicon in a $150 \mathrm{~kW}$ pilotscale submerged arc furnace. A stable furnace operation was achieved and a metal yield of 89.3\% was reported, close to industrial figures, while a reference trial with English gas coke only achieved a yield $7 \%$ lower. The higher yield using charcoal was especially attributed to the better SiO-reactivity of charcoal compared to coke. The electric power consumption for charcoal was $10 \mathrm{kWh} / \mathrm{kg} \mathrm{FeSi}$, which was $2 \mathrm{kWh} / \mathrm{kg}$ lower compared to the English gas coke, but $2 \mathrm{kWh} / \mathrm{kg}$ higher compared to industrial trials. The production of silicon was also assayed in this work, showing that a purer silicon product could be produced by using Brazilian or European charcoal with silicon contents of $99.0 \%$ and $98.7 \%$ respectively, which was significantly higher than the used reference coke. The silicon content in the metal obtained from the reference trial was only $95.9 \%$. This was explained by the lower ash content in the charcoal samples compared to coke [26], which can be considered a general advantage of bio-based carbon as shown by the general comparison from Figure 3 and Table 4.

Li et al. [69] investigated the carbothermal reduction of pellets containing quartz and different carbon sources at temperatures between $1625^{\circ} \mathrm{C}$ and $1675^{\circ} \mathrm{C}$ to study the reactions occurring in the low-temperature zone of submerged arc furnaces. The reactivity of the carbon-containing material to $\mathrm{SiO}$ and quartz was the focus in this study, showing that the reactivities match well for charcoal and coal, while carbon black, coke and preheated coal showed an inferior matching of the reactivities. As a lower matching leads to $\mathrm{SiO}-$ losses through the off-gas, a high matching of reactivities is preferred. Charcoal showed a good SiO-reactivity and quartz/carbon reactivity, therefore it was recommended to use charcoal as the main carbon source for the production of silicon [69].

Hasannezhad et al. [143] compared the usage of coal and wood charcoal to produce FeSi in an SAF with a power rating of 17 MVA in 2020. Figure 16 shows the average specific energy consumption and silicon yield of the trials using coal and charcoal.

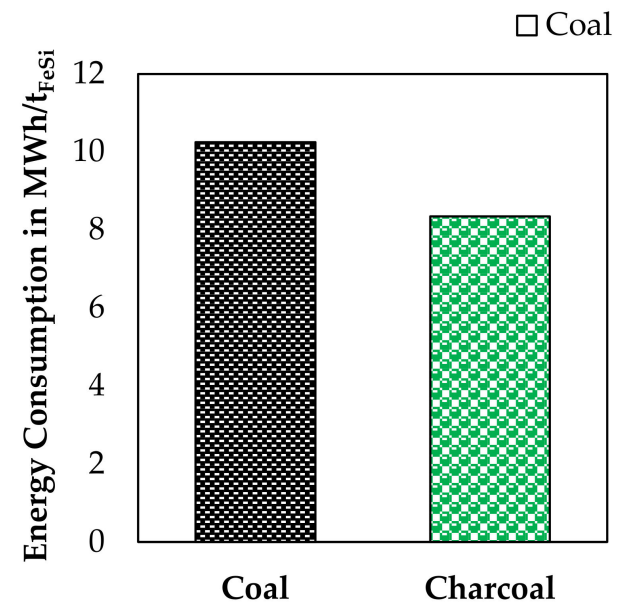

(a)

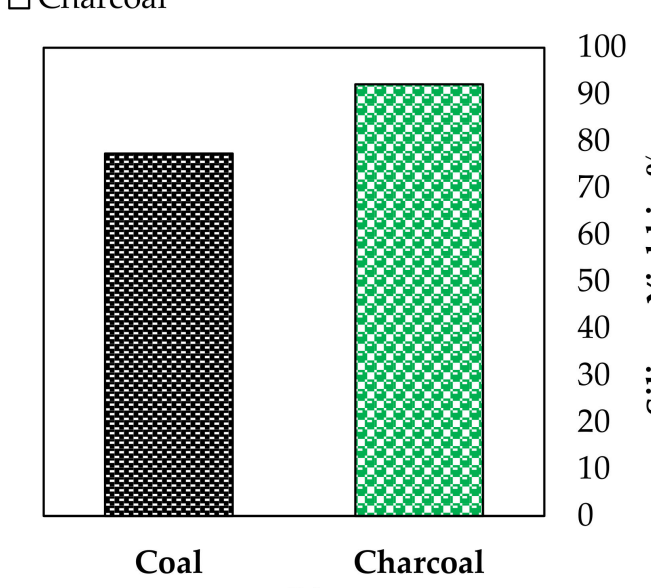

(b)

Figure 16. Electrical energy consumption (a) and silicon yield (b) for the production of FeSi using coal and charcoal (based on data from [143]).

For both indicators, charcoal yielded significantly better results compared to the usage of coal. The increased yield using charcoal was explained by the higher apparent porosity of charcoal $(30.62 \%)$ compared to coal $(1.51 \%)$. The higher porosity enhances the reaction of silicon monoxide gas with carbon to form silicon carbide in the process. Furthermore, the increased furnace efficiency was explained by a higher specific electrical resistance of charcoal $(\sim 17,900-87,000 \Omega \cdot \mathrm{cm})$ compared to coal $(\sim 0-40,000 \Omega \cdot \mathrm{cm})$ in the investigated temperature range of $350-650{ }^{\circ} \mathrm{C}$ for resistivity measurements. This leads to a reaction 
cavity with a higher thermal concentration compared to the usage of coal and a colder top layer of the charge allowing silicon monoxide gas to condense [143].

\subsection{Production of Agglomerates Containing Biomass for the Application in Silicon Furnaces}

As already described in the introduction, the replacement of coke by biomass-based reducing agents in submerged arc furnaces is accompanied by many challenges, especially the diffuse composition and the inferior mechanical properties. To overcome those obstacles, a considerable amount of research was carried out to design biochar composites or pellets with properties suitable for direct use in submerged arc furnaces. Most of those studies focused on the silicon or ferrosilicon production process, but those results may also be transferable to other submerged arc furnace processes as well.

Riva et al. [38] investigated the production of densified biochar made from Norwegian spruce suitable for the production of silicon and ferrosilicon alloys. Spruce samples were pyrolyzed at different temperatures in this work and pelletized in a compact hot pellet press adding different amounts of pyrolysis oil from a fast pyrolysis process, lignosulphonate as a binder and water. The compacted pellets were then heat treated and analyzed. The usage of pyrolysis oil showed to be an efficient way to use this by-product from pyrolysis and further enhance the mechanical properties like density, mechanical durability and tensile strength of the pellets [38]. The usage of non-condensable gas components was not assayed in the study by Riva et al. [38], but commonly heating values of biomass gases are comparable to coal gas and could be used for energy conversion [144] or as a reducing agent in metallurgical applications [145]. Furthermore, $\mathrm{CO}_{2}$ reactivity tests showed that the mass loss curve of the pellets was smoother compared to untreated biochar samples originated from the same feedstock. However, it was stated that the reactivity of the biomass pellets was still higher compared to fossil carbon sources [38]. Based on this work, Riva et al. [146] conducted a life cycle assessment to investigate the potential $\mathrm{CO}_{2}$ emission savings replacing coke with the produced biocarbon pellets from the previous study [38]. As a reference scenario, the production process of Elkem Solar Silicon was used [147]. The $\mathrm{CO}_{2}$ equivalent generated during the production of biocarbon pellets was stated as $0.672 \mathrm{~kg} \mathrm{CO}$ eq per $\mathrm{kg}$ of biocarbon pellets considering the feedstock, pyrolysis and pelletizing process. This was slightly higher than the $\mathrm{CO}_{2 \mathrm{eq}}$ for the production of coke. Yet, substituting coke with bio-based carbon leads to a reduction in the emission of $10 \mathrm{~kg}$ $\mathrm{CO}_{2 \text { eq }}$ per kg compared to the reference of Elkem Solar Silicon. Furthermore, optimization of the pyrolysis plant and operation conditions could additionally decrease the $\mathrm{CO}_{2 \mathrm{eq}}$ of the biocarbon pellet production process [146]. Figure 17 shows the comparison of the GHG-emissions of solar silicon as presented by $[146,147]$ for four scenarios. Usage of fossil reductants and biocarbon is considered in combination with the GHG-emissions using a European electricity mix (UCTE mix) and a Norwegian energy mix with a significant lower $\mathrm{CO}_{2}$ footprint.

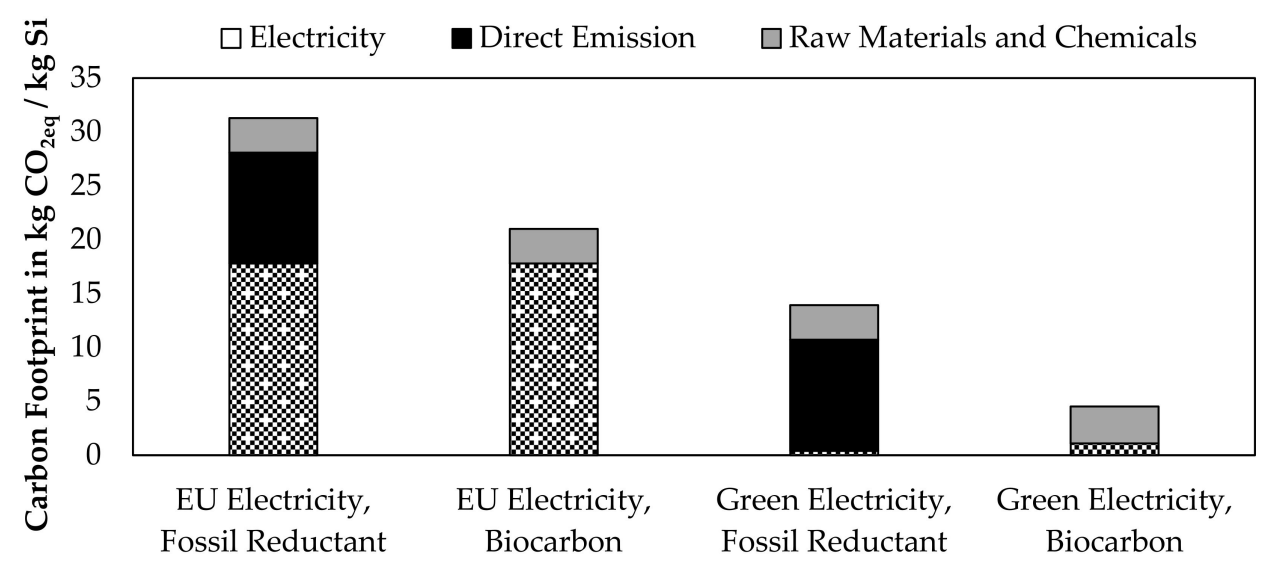

Figure 17. GHG emissions of Solar Silicon for varying electricity mixes and biocarbon usage. Modified from $[146,147]$. 
As shown by Figure 17, besides the avoidance of direct emissions, the usage of electricity with a lower $\mathrm{CO}_{2}$ footprint is vital to decrease the GHG emissions of the production process.

Riva et al. [40] published a further study to improve the proposed process [39] and to investigate the self-heating risk of the produced pellets, which could be kept low, if suitable temperatures are used for the pyrolysis process or the second heat treatment operation [40].

Surup et al. investigated [41] the production of charcoal during high-temperature pyrolysis to substitute metallurgical coke. In this work, spruce and oak chips were pyrolyzed at temperatures between $800{ }^{\circ} \mathrm{C}$ and $1600{ }^{\circ} \mathrm{C}$ in a slow pyrolysis reactor. The assayed $\mathrm{CO}_{2}$ reactivity by thermogravimetric analysis showed that the $\mathrm{CO}_{2}$ reactivity of both kinds of wood was similar and independent of the heat treatment temperature or wood origin. Compared to metallurgical coke, the $\mathrm{CO}_{2}$ reactivity of charcoal was higher. Further investigation of the samples by transmission electron microscopy showed, that higher heat treatment temperatures enhanced the graphitization of the char structure and that oak char was more graphitic than spruce char, while lower temperatures resulted in structures similar to amorphous carbon. An increase in the heat treatment temperature can lead to a graphitized structure similar to coke which could yield a lower reactivity of char [41]. It can be assumed, that those results lead to further investigations using higher temperatures, which were also published by Surup et al. [32]. Different woody biomasses and straws were treated in a slow pyrolysis reactor at temperatures between $1300{ }^{\circ} \mathrm{C}$ and $2800{ }^{\circ} \mathrm{C}$ in this work. $\mathrm{CO}_{2}$ - and $\mathrm{O}_{2}$ reactivity were assayed by thermogravimetric analysis and the results showed, that the main influence was the heat treatment conditions and that the feedstock conditions were less relevant. The nanostructure of biochar was investigated by Raman spectroscopy and transmission electron microscopy, showing that higher treatment temperatures lead to graphite structures. Temperatures above $2400{ }^{\circ} \mathrm{C}$ lead to reactivities similar to metallurgical coke. Furthermore, trials were carried out with the addition of bio-oil to investigate a co-pyrolysis process, showing promising results to produce biocarbon with similar $\mathrm{CO}_{2}$ reactivities compared to metallurgical coke [32] In another study by Surup et al. [148], the co-pyrolysis of softwood and hardwood with recirculated tar was investigated at temperatures up to $1600^{\circ} \mathrm{C}$. By co-pyrolysis it was possible to obtain biocarbon pellets with increased hardness and electrical resistivity at room temperature similar to metallurgical coke, but the reactivity of biocarbon pellets was higher compared to metallurgical coke [148]. Incorporation of raw materials into composite pellets containing pyrolyzed biomass and tar as a binder can also be an option. Surup et al. [149] investigated properties like electrical conductivity and $\mathrm{CO}_{2}$ reactivity of composite pellets containing either quartz or manganese ore as feedstock for the production of silicon or manganese alloys, but the higher $\mathrm{CO}_{2}$ reactivity of the composite pellets compared to metallurgical coke [149] are still a disadvantage, as a high $\mathrm{CO}_{2}$ reactivity will increase the power- and coke consumption due to an enhanced Boudouard reaction in the top of the reaction shaft [150]. To investigate the electrical resistivity at high temperatures similar to the conditions in a submerged arc furnace, Surup et al. [68] presented a set-up to measure the electrical resistivity of a carbonaceous bed at temperatures up to $1700{ }^{\circ} \mathrm{C}$ [68]. Charcoal, coal, semi-coke used for the production of silicon and ferrosilicon as well as metallurgical coke used for the production of silicomanganese were investigated in the study. While increasing the temperature, the electrical resistivity of charcoal decreased several magnitudes and approached the electrical resistivity of semi-coke and coal, but the electrical resistivity of charcoal remained higher compared to the metallurgical coke sample. Examining the bulk density and particle size of the samples showed, that the impact of the bulk density was higher than the impact of the particle size. Before and after the electrical resistivity tests, the compression strength and durability in a tumbling test of the samples were investigated. The durability of coke, coal and semi-coke decreased after the heat treatment, whereas the durability of the charcoal samples increased, however, the highest durability was still shown by metallurgical coke. The compression strength of metallurgical coke stayed the same after heat treatment, whereas all other samples showed an increasing compression strength after heat treatment. The observed thermal shrinkage 
for charcoal was the highest in this study and the thermal shrinkage of metallurgical coke was the lowest. Applying those results to a submerged arc furnace process, it is assumed that the charcoal will inhibit electrical conductivity in the upper zone of the furnace and after a descent of the burden and an increase in temperature, the electrical properties approach that of metallurgical coke, while the charcoal still has slightly better electrical properties. The mechanical properties are inferior to metallurgical coke, but during the descent of the burden, the charcoal can withstand compression strengths between 400 and $1600 \mathrm{kPa}$. The maximum compression pressure on the carbon bed in a submerged arc furnace for manganese production was estimated by the authors with $150 \mathrm{kPa}$ and therefore the charcoal samples could be a suitable alternative reducing agent [68].

An innovative method to obtain charcoal for metallurgical applications and feedstock for value-added chemicals is the integration of supercritical $\mathrm{CO}_{2}\left(\mathrm{scCO}_{2}\right.$-)extraction followed by pyrolysis as investigated by Surup et al. [42]. With $\mathrm{scCO}_{2}$ extraction of low-value forestry residues like pinewood needles, bark and branches it was possible to extract more than half of value-added compounds of the raw material. Furthermore, the influence of the $\mathrm{scCO}_{2}$ extraction on the physical properties and charcoal yield was insignificant, however, the production of tar during pyrolysis was reduced. The $\mathrm{CO}_{2}$ reactivity of bark and branches was similar for raw samples and samples treated by $\mathrm{scCO}_{2}$ extraction. The charcoal of non-treated needles was slightly less reactive compared to the charcoal produced with needles after $\mathrm{scCO}_{2}$ extraction [42].

Compared to the presented results obtained by pyrolysis of biomass, hydrothermal carbonization can be a suitable technic for biomass upgrading for metallurgical purposes. Surup et al. [45] investigated the hydrothermal carbonization and torrefaction of olive pulp and characterized the properties of the samples relevant for the metallurgical industry. The $\mathrm{CO}_{2}$ reactivity of hydrothermal carbonized olive pulp was similar to the $\mathrm{CO}_{2}$ reactivity of biochar made of olive pulp at $900{ }^{\circ} \mathrm{C}$, while for hydrothermal carbonization temperatures around $200-250^{\circ} \mathrm{C}$ were already sufficient. Therefore, hydrothermal carbonization could be a viable option using only modest temperatures to produce biochar. The mechanical stability of the hydrothermal carbonized samples however was insufficient, a second heat treatment at $400{ }^{\circ} \mathrm{C}$ was necessary to obtain mechanical stability suitable for ferroalloy applications. The torrefaction trials in this work only yielded biochar with inferior $\mathrm{CO}_{2}$ reactivity and inferior mechanical stability compared to hydrothermal carbonization [45].

\subsection{Solar Thermal Production of Silicon Using Bio-Based Carbon}

An even more sustainable and innovative method to reach $\mathrm{CO}_{2}$ neutrality is the usage of biocarbon as a reducing agent in a reactor powered by solar energy. Loutzenhiser et al. [151] investigated the reduction of alumina and silica in a vacuum distillation set-up powered by a high-flux solar simulator using beech charcoal to produce aluminum and silicon respectively. Due to the pressure of $10^{-3}$ bar, it was possible to reduce alumina and silica and evaporate the metallic elements. By the evaporation, contamination of the product by carbides or oxycarbides can be avoided. After the trials, a considerable amount of evaporated and condensed metallic aluminum or silicon was found on the crucible walls while the residue in the crucible contained aluminum carbides, aluminum oxycarbides or silicon carbide. An optimization of the setup or process was not carried out in this research [151], but the usage of a solar reactor can be an interesting option to reduce greenhouse gas emissions for the production of metals. It has to be mentioned that this research took place in a gram-scale.

\section{Production of Manganese Alloys Using Bio-Based Carbon}

Research carried out to substitute fossil carbon in the production of manganese alloys by bio-based carbon addressing solid-state processes, agglomeration and smelting processes are presented in this chapter. An LCA about manganese production using bio-based carbon was not published to our knowledge. 


\subsection{Solid-State Processes Using Bio-Based Carbon for the Production of Manganese Alloys}

A considerable amount of research was carried out investigating pre-reduction processes. A special role in regards to the pre-reduction is the reduction-roasting process, in which pyrolusite from low-grade manganese ore is pre-reduced and afterward subjected to leaching, a whole subchapter is dedicated to this process step. Another possibility is the usage of pre-reduced manganese-containing kiln for the production of ferromanganese ore silicomanganese in a submerged arc furnace. Both processing routes are shown in Figure 18. Sintering studies are also included in this chapter.
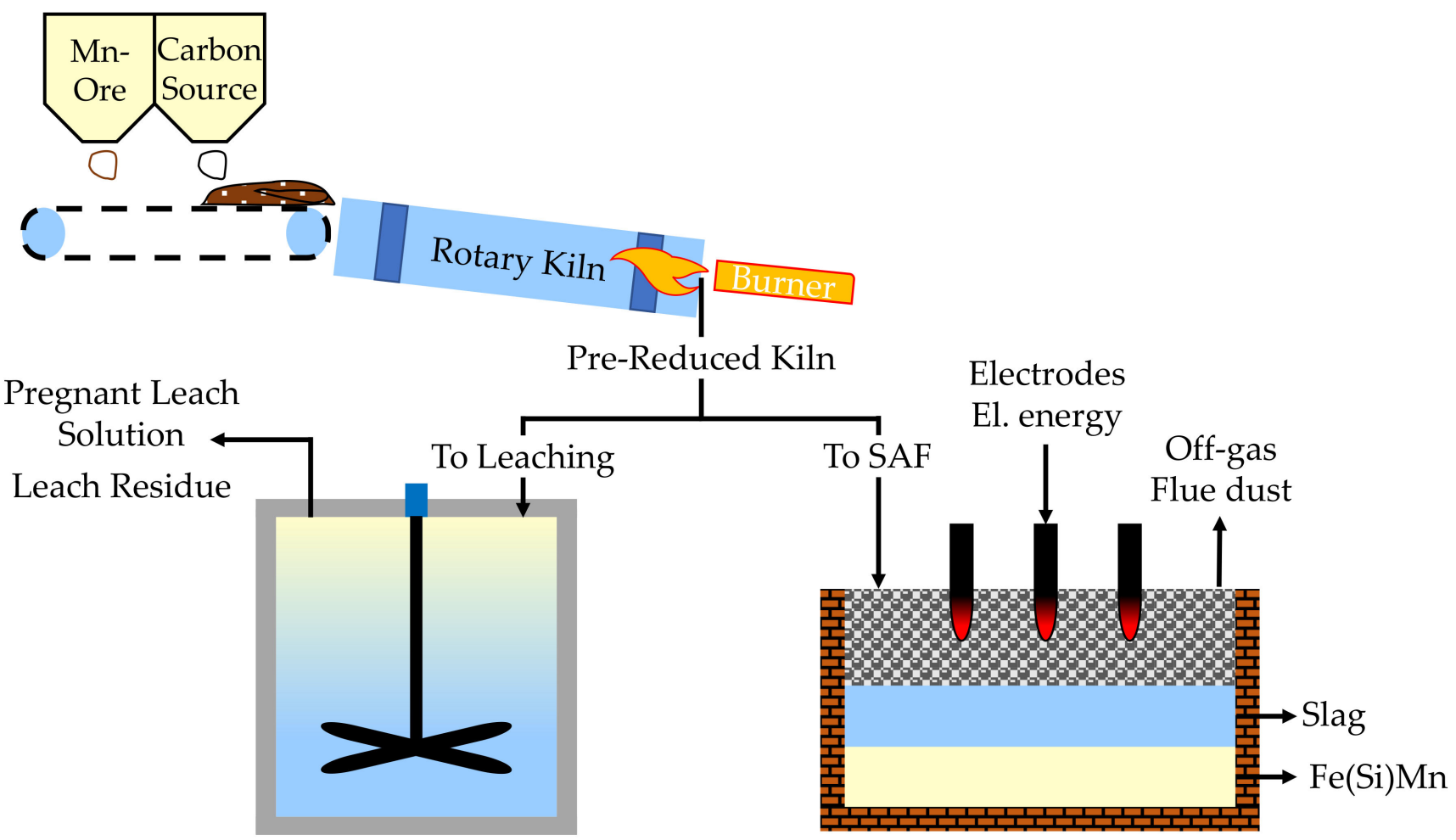

Figure 18. Possible processes to treat pre-reduced manganese kiln.

7.1.1. Pre-Reduction and Agglomeration of Manganese Resources Using Bio-Based Carbon

Pre-reduction in an external furnace is not a common practice for producing ferromanganese in a submerged arc furnace, because the reduction of higher manganese oxides in the submerged arc furnace by ascending gases containing carbon monoxide is an exothermic reaction $[152,153]$. However, mass and energy calculations showed that by increasing the raw material temperature the electric energy consumption in a submerged arc furnace could still be significantly reduced. The specific electrical energy consumption can be decreased by $80 \mathrm{kWh} /$ ton if the raw material is heated by $100{ }^{\circ} \mathrm{C}$ additionally. The larger share of the electrical energy saving is attributed to the increased temperature of the raw material, while the enhanced pre-reduction only contributes slightly to the electrical energy savings. Charging raw material heated to $600{ }^{\circ} \mathrm{C}$ into a submerged arc furnace reduces the electrical energy consumption by $20 \%$. The total $\mathrm{CO}_{2}$ emission can be reduced as well using a pre-heating operation. However, this highly depends on the electricity and the fuel used in the pre-treatment unit. Commonly, rotary kilns are used in the metallurgical industry for pre-reduction $[154,155]$. It is possible to use exhaust gases from submerged arc furnaces for pre-treatment, but often additional fuel is necessary. If the fuel in the rotary kiln is fossil carbon and the electric energy is sourced from renewable sources or nuclear energy, the $\mathrm{CO}_{2}$ emissions are higher if a pre-treatment is carried out. If the electrical energy is sourced by burning fossil coal and fossil coal is used in a rotary kiln as well, smelting the hot calcine in a submerged arc furnace would be more energy efficient. Using coke in the pre-treatment unit would lead to the highest $\mathrm{CO}_{2}$ emissions, whereas coal and 
natural gas would result in lower $\mathrm{CO}_{2}$ emissions, biocarbon would show the lowest $\mathrm{CO}_{2}$ emission [153]. However, those are theoretical considerations and experimental studies using biocarbon in a rotary kiln to produce pre-treated manganese feed for submerged arc furnace applications were not carried out to our best knowledge.

During beneficiation of manganese ores, finely dispersed particles are generated which are then transferred to the off-gas if used in an electric furnace. Therefore, agglomeration of those fines is necessary. One possible way is to sinter the fines [43]. The main function of sintering machines is to agglomerate fines, in addition, it is possible to reduce the oxides, even if this secondary effect is limited [155]. Kieush et. al. [43] carried out a laboratory study using coke breeze and mixtures of coke breeze with $25 \%$ woody biomass or prepyrolyzed wood as fuel for sintering manganese ore, manganese concentrate, fluxes and returns. It was observed that the yield of sinter with a size over $10 \mathrm{~mm}$ and the specific sintering capacity decreased by substituting coke breeze with biomass. However, replacing $25 \%$ of coke breeze with biomass pyrolyzed at $1000^{\circ} \mathrm{C}$ lead to a higher sintering velocity and using $25 \%$ of biomass pyrolyzed over $600{ }^{\circ} \mathrm{C}$ yielded a higher sinter strength compared to using only coke breeze. As improvements, it was suggested to use biomass with a lower reactivity compared to the used biomass or larger particles of biofuel to increase the share of bio-based carbon usable in the mixture, without decreasing the effectiveness of the process [43].

Zhang et. al. [156] carried out a study in a laboratory-scale to sinter low-grade manganese ore. One part of the study was the replacement of coke with biomass fuel. It was stated that the tumbling index decreased while replacing coke with biomass charcoal. Using only coke resulted in a tumbling index of $61 \%$, while using $40 \%$ biomass in the fuel mixture yielded a tumbling index of $56 \%$. The highest sinter yield of $84 \%$ was observed when $20 \%$ of biomass was used in the fuel mixture while the trial carried out with coke resulted in a yield of $80 \%$. The highest productivity of $1.6 \mathrm{t} \cdot\left(\mathrm{m}^{-2} \mathrm{~h}^{-1}\right)$ was observed when $30 \%$ of biomass was used compared to $1.5 \mathrm{t} \cdot\left(\mathrm{m}^{-2} \mathrm{~h}^{-1}\right)$ when only coke is used. Using a higher share of biomass lead to a significant decrease in productivity. An observed benefit was the decrease in $\mathrm{SO}_{2}$ emission and $\mathrm{NO}_{\mathrm{x}}$ emission using biomass charcoal as a substitute for coke [156].

\subsubsection{Reduction-Roasting Processes of Low-Grade Manganese Ore Using Bio-Based Carbon}

A considerable amount of research was published investigating the usage of biomass to reduce low-grade manganese ores in the reduction-roasting process, which differs from the pre-reduction process, since the pre-reduced feed is used for hydrometallurgical processing afterward in the reduction-roasting process as shown in Figure 18. By reducing $\mathrm{MnO}_{2}$ to $\mathrm{MnO}$ in a roasting step, the manganese oxide becomes soluble in sulfuric acid and the leach liquor can further be processed to produce electrolytic manganese. Compared to conventional reducing agents like lignite [33] or anthracite [157] biomass or biomass charcoal showed a higher reduction degree and the possibility to use lower temperatures in the roasting process. Table 6 shows the studies carried out investigating the reduction roasting processing of manganese ore and highlights the special emphasis of each study.

Furthermore, one study was carried out with a reduction roasting step using palm kernel shell charcoal, however in this case the reaction temperature exceeded $1000^{\circ} \mathrm{C}$ and it was not directly aimed to generate a concentrate for leaching [66]. 
Table 6. Studies carried out investigating the reduction roasting process.

\begin{tabular}{|c|c|c|c|}
\hline Study & Reducing Agent & Furnace and Reduction Temperature & Special Emphasis \\
\hline [158] & Dry moso bamboo & Tubular Furnace, $500^{\circ} \mathrm{C}$ & Investigation of reoxidation during cooling \\
\hline [33] & $\begin{array}{l}\text { Rice straw, sawdust, wheat stalk, maize } \\
\text { straw, bamboo, lignite }\end{array}$ & $\begin{array}{c}\text { Tubular furnace, } 200-900^{\circ} \mathrm{C} \text { and } \\
\text { nonisothermal TGA }\end{array}$ & Kinetics and XRD-analysis * \\
\hline [159] & $\begin{array}{c}\text { Dry bamboo scrap, hemicellulose, } \\
\text { cellulose, lignin }\end{array}$ & Tubular furnace, $200-500{ }^{\circ} \mathrm{C}$ & $\begin{array}{l}\text { Reaction mechanism, kinetics, XRD-, SEM-, } \\
\text { EDS-analysis * }\end{array}$ \\
\hline [160] & Wheat stalk & Tubular furnace, $300-550{ }^{\circ} \mathrm{C}$ & Kinetics, XRD-, SEM-, EDS-analysis * \\
\hline [157] & Black charcoal, anthracite & Muffle furnace, $600-850{ }^{\circ} \mathrm{C}$ & $\begin{array}{c}\text { Comparison of charcoal and anthracite, } \\
\text { XRD-analysis * }\end{array}$ \\
\hline [161] & Pine charcoal & Muffle furnace, $500-850^{\circ} \mathrm{C}$ & XRD-analysis * \\
\hline [162] & Sawdust & Muffle furnace, $350-600^{\circ} \mathrm{C}$ & XRD-analysis, leaching parameters * \\
\hline [49] & Straw & Muffle furnace, $200-600^{\circ} \mathrm{C}$ & Reaction mechanism, kinetics, XRD-analysis * \\
\hline [163] & Cornstalk & Muffle furnace & Leaching parameters \\
\hline [50] & Walnut shell & Microwave heating reactor, STA * & $\begin{array}{l}\text { TG-DTG-DSC of biomass and ore mixtures, } \\
\text { XRD- and SEM-analysis, reaction mechanism * }\end{array}$ \\
\hline [164] & $\begin{array}{l}\text { Raw biomass: poplar, pine, ageratina } \\
\text { adenophora, rapeseed shell, walnut shell }\end{array}$ & Dielectric test system, STA, $25-800^{\circ} \mathrm{C} *$ & Dielectric properties, reaction mechanism \\
\hline [165] & Walnut shell & Dielectric test system, STA, $25-800{ }^{\circ} \mathrm{C} *$ & $\begin{array}{c}\text { Dielectric properties, thermochemical } \\
\text { characteristics }\end{array}$ \\
\hline [166] & Hemicellulose, cellulose, lignin & STA, $25-800^{\circ} \mathrm{C}^{*}$ & FT-IR analysis, kinetics, XRD-analysis * \\
\hline [167] & Hemicellulose, lignin & STA, $25-800^{\circ} \mathrm{C}^{*}$ & Kinetics, XRD-analysis * \\
\hline
\end{tabular}

* XRD: X-ray diffraction; SEM: Scanning electron microscopy; EDS: Energy dispersive X-ray spectroscopy; TGA: Thermogravimetric analyzer; TG: Thermogravimetry; DTG: Differential thermogravimetry; DSC: Differential scanning calorimetry; STA: Simultaneous thermal analysis; FT-IR: Fourier-transform infrared spectroscopy.

\subsection{Smelting Processes Using Bio-Based Carbon to Produce Manganese Alloys}

Replacing fossil fuels with bio-based carbon has been already elaborated as a promising option to reduce greenhouse gas emissions for the production of manganese alloys. Eramet Norway stated in their sustainability report from 2016, that "it will probably be possible to use biocarbon to replace current reductants without requiring any major changes to current processes" [168]. They also stated that there are still a few challenges to overcome, without specifying those in detail. A research project was announced, which used residues from paper production to produce biofuel and solid biochar. The biochar should then be able to replace fossil reductants for the production of manganese alloys [168]. In the sustainability reports from 2017 and 2018, biocarbon was mentioned again. According to Eramet Norway, they "identified the replacement of fossil carbon material with biocarbon as one of the most promising technologies for a major reduction of $\mathrm{CO}_{2}$ emissions from the smelting process" $[169,170]$. Pilot-scale tests for the introduction of bio-based carbon into the process were already planned for $2020 / 2021$, however, as a challenge, the structural weakness of biocarbon was mentioned, since manganese smelters are normally not designed to handle bio-based carbon [171]. At the beginning of the century, the silicomanganese industry in Norway had no experience using charcoal and as charcoal needed to be imported from other countries, the cost was higher and no process improvements were expected in the manganese industry, so it seemed unfeasible to use charcoal [150]. Back in 2004, Monsen et al. [150] investigated the use of charcoal, industrial coke and reactive coke during the production of silicomanganese. It was stated that charcoal and coke have a similar slag-reactivity, if both are pre-calcined at $1600{ }^{\circ} \mathrm{C}$, the $\mathrm{CO}_{2}$ reactivity of charcoal however was significantly higher compared to coke, which is undesirable as this will lead to an increase in carbon and power consumption. In addition to those tests, pilot-scale tests were carried out as well. One outcome was that charcoal resulted in higher resistance in the coke-bed compared to coke. The comparison of power consumption showed, that industrial coke resulted in the highest power consumption compared to reactive coke and charcoal, but those differences were mostly attributed to the lower silicon contents in the alloys obtained in the trials with reactive coke and charcoal. The metal production using charcoal was the highest in this set of experiments, which was explained by the high reactivity of charcoal and the low silicon content in the alloy. If a reductant is not used to reduce silicon, it is available for the reduction of manganese in this specific case [150]. In an additional experiment by the authors, they were also able to produce 
a silicomanganese with a silicon content of $18 \mathrm{wt} \%$ by using a mixture containing $50 \%$ charcoal and 50\% coke, adjusted by the total carbon content. This was achieved by a higher moisture content of the charge, which leads to less burning carbon in the colder top layers of the furnace burden [30]. In the first publication, only a silicon content of $12.9 \mathrm{wt} \%$ was obtained when charcoal and coke mixtures were used as a reducing agent [150]. In addition to the pilot-scale experiments, a considerable amount of laboratory-scale investigations were carried out by the researchers from Trondheim, Norway to cover topics like reaction mechanism and reduction kinetics while using charcoal as an alternative reductant to treat ferromanganese slag $[67,70,172-174]$.

Braga et al. [175] investigated the reduction behavior of Brazilian manganese ore and concentrate with wood charcoal. The aim was to study the performance of selfreducing composites. It was expected, that inside the composites manganese is reduced by gas-solid reactions, and therefore slow metal-slag reactions can be avoided. Pellets of manganese-containing raw materials with wood charcoal and Portland cement as a binder were produced. They were tested in a thermogravimetric system. Temperatures between $800{ }^{\circ} \mathrm{C}$ and $1350{ }^{\circ} \mathrm{C}$ were used. It was observed that increasing the temperature from $800{ }^{\circ} \mathrm{C}$ to $950{ }^{\circ} \mathrm{C}$ significantly increased the reduction behavior, whereas a further temperature increase only changed the behavior slightly. In the study, ferromanganese particles were even observed at $950{ }^{\circ} \mathrm{C}$, at $1200^{\circ} \mathrm{C}$ also some slag particles were identified. An additional trial at $1400{ }^{\circ} \mathrm{C}$ showed that the pellets do not disintegrate. The metallization degree from those small-scale trials with pellets at $1250{ }^{\circ} \mathrm{C}$ and a reaction time of $15 \mathrm{~min}$ was assayed by SEM and metallization of $90 \%$ and $40 \%$ was observed for iron and manganese respectively. Due to the metallization and thermal stability of the pellets, it was expected, that a high metallization can be obtained when the pellets are charged into a submerged arc furnace, before the raw materials are molten and dissolved into the slag and metal. As a verification, a smelting test was carried out with one kilogram of composite pellets. Pellets were charged into a liquid iron bath at $1500{ }^{\circ} \mathrm{C}$ in an induction furnace. This trial yielded a manganese reduction above $95 \%$ based on a chemical analysis and mass balance. A scaleup was carried out in a 7.5 MVA electric smelting furnace to produce commercial-grade Fe-Si-Mn. Seventy-five percent of the charge were manganese ore lumps and charcoal, whereas the rest of the feed were self-reducing briquettes. A $10 \%$ increase in production capacity and electric energy savings of $380 \mathrm{kWh} / \mathrm{t}$ Fe-Si-Mn, due to smoother operation, enhanced gas distribution, improved electrical yield and an increased reduction rate were observed compared to the usage of manganese lump ore [175]. A comparison with coke or coal was not carried out, therefore, it was not investigated if those improvements were possible due to the usage of charcoal or because the self-reducing composites were superior compared to lump ore.

A completely different approach to produce ferromanganese not from virgin raw materials but waste materials was investigated by Yeşiltepe et al. [176]. They smelted battery paste from alkaline batteries with mill scale and waste coffee grounds in a laboratory tube furnace. Those residues were blended, pelletized and reduced in a laboratory-scale furnace. In those studies, ferromanganese with roughly $35 \%$ manganese was produced. Zinc oxide could be recovered from the flue dust to produce another valuable product. According to the authors, there were still losses of manganese in the slag, due to the low reaction temperature [176]. By combining three residues, this study showed how mixed end-of-life residues and industrial residues can be treated to produce valuable products.

Supriyatna et al. [51] investigated the reduction of Indonesian low-grade manganese ore with charcoal and palm kernel shell biomass in a mini electric arc furnace. In those studies, it was possible to produce ferromanganese with manganese contents between $70.9 \mathrm{wt} \%$ and $77.0 \mathrm{wt} \%$. The highest manganese extraction was obtained using palm kernel shell biomass and was around $50 \mathrm{wt} \%$. Comparing the same ratios of reductants, the manganese extraction using palm kernel shell biomass was higher compared to charcoal in all trials [51]. 


\section{Upgrading of Ilmenite Ore Using Bio-Based Carbon}

One common resource to produce $\mathrm{TiO}_{2}$ is ilmenite, a mineral with the formula $\mathrm{FeO} \cdot \mathrm{TiO}_{2}$. To remove iron and to increase the titanium content in a slag precursor, two common processes exist. Metallic iron is either produced via solid-state reduction of ilmenite with carbon. The metallic iron can be removed by leaching to increase the $\mathrm{TiO}_{2}$-content. The second option is the reduction of iron with carbon in a liquid state, $\mathrm{TiO}_{2}$ is enriched in a slag phase for further processing and the metallic iron is a product, while in the first process it is a waste product [177]. The smelting of ilmenite is commonly carried out in electric arc furnaces running in open arc mode [178]. Equation (7) is the reaction occurring during the solid-state reduction while Equation (8) is the reaction occurring during the smelting process.

$$
\begin{aligned}
& \mathrm{FeO} \cdot \mathrm{TiO}_{2(\mathrm{~s})}+\mathrm{C}_{(\mathrm{s})} \rightleftharpoons \mathrm{Fe}_{(\mathrm{s})}+\mathrm{TiO}_{2(\mathrm{~s})}+\mathrm{CO}_{(\mathrm{g})} \\
& \mathrm{FeO} \cdot \mathrm{TiO}_{2(\mathrm{l})}+\mathrm{C}_{(\mathrm{s})} \rightleftharpoons \mathrm{Fe}_{(\mathrm{l})}+\mathrm{TiO}_{2(\mathrm{l})}+\mathrm{CO}_{(\mathrm{g})}
\end{aligned}
$$

To our knowledge, no studies were carried out investigating the smelting of ilmenite ore to obtain an iron alloy and titanium-rich slag utilizing bio-based carbon. Instead, solid-state processes were investigated using ilmenite ore and bio-based carbon. An LCA about ilmenite upgrading using bio-based carbon was not published to our knowledge.

Other applications of biomass associated with titanium are possible as well, for example, the carburizing of titanium with pyrolyzed plant biomass [179]. However, upgrading of titanium is outside the scope of this review and not further evaluated.

Setiawan et al. [67] investigated the reduction of ilmenite ore using charred palm kernel shells in a solar simulator furnace and a tube resistance furnace. Indonesian ilmenite ore and locally sourced palm kernel shells were used as raw materials in the study. A reaction temperature of $1200^{\circ} \mathrm{C}$ was applied in the solar simulator furnace and temperatures of $1000{ }^{\circ} \mathrm{C}, 1100{ }^{\circ} \mathrm{C}$ and $1200{ }^{\circ} \mathrm{C}$ were used in the tube resistance furnace as a comparison. In the tube resistance furnace trials, it was observed that metallic iron and rutile already formed at $1000{ }^{\circ} \mathrm{C}$. However, intense peaks of ilmenite were still observable in an x-ray diffraction analysis. Furthermore, chromite spinels were observed at $1000^{\circ} \mathrm{C}$. Increasing the reduction temperature leads to a decrease of the ilmenite content and vanishing chromite spinels, instead, pseudobrookite was present in the samples reduced at higher temperatures. At $1200{ }^{\circ} \mathrm{C}$, no remaining ilmenite was identified by $\mathrm{x}$-ray diffraction. Compared to the trial in the tube resistance furnace at $1200{ }^{\circ} \mathrm{C}$, the solar simulator trial at $1200{ }^{\circ} \mathrm{C}$ resulted in a slightly higher pseudobrookite content, also chromite spinels were still observed in the solar simulator trial. EDX-analysis revealed that the tube resistance furnace leads to a globular iron morphology, whereas the solar simulator furnace leads to a streak morphology of iron. This was explained by the local overheat caused by the solar heat flux [67]. By combining the natural energy source of solar energy with a bio-based reducing agent with a low carbon impact, this approach could be a valuable option to reduce the carbon footprint of ilmenite treatment.

In a separate study, Setiawan et al. [180] investigated the use of palm kernel shell charcoal for the reduction of Indonesian ilmenite while using sulfur and sodium sulfate as an additive. Samples were reduced in a tube resistance furnace at $1200^{\circ} \mathrm{C}$. Palm kernel shell charcoal was able to crack the spinel and reduce iron oxides to produce metallic iron. With the usage of sulfur and sodium sulfate, it was possible to increase the particle size of iron compared to a trial without additives. This was explained by the formation of liquid FeS, which will dissolve metal particles. In addition, sodium reacted with silica minerals forming sodium silicate phases with a low melting point. The largest particle size was obtained when sodium sulfate was used which eases the separation of iron and titanium-containing oxides by a magnetic separator [180].

Guo et al. [181] examined the microwave absorbing characteristics of oxidized ilmenite ore from China with coconut-based activated carbon, coke and graphite. By comparing the attenuation and frequency of different ratios of ore to carbonaceous material it was stated that the addition of carbonaceous material improved the microwave absorbing char- 
acteristics of the samples, while the highest attenuation was observed for the mixtures with coconut-based charcoal [181]. Therefore, if microwave heating is considered as an energy source in a process, bio-based reductants are an option with good absorbing characteristics.

George et al. [52] investigated the usage of coconut pith to reduce Indian ilmenite beach sand. Coconut pith was placed in a stainless-steel reaction tube, above the pith was a layer of ilmenite sand followed by another layer of pith. The reaction tube was placed in a furnace and temperatures between $800{ }^{\circ} \mathrm{C}$ and $1100{ }^{\circ} \mathrm{C}$ were applied, the reaction times in the furnace varied between thirty minutes and five hours. After the trial, excess pith was separated by putting the sample in water and removing floating carbon. The settled ilmenite was dried and subjected to hydrochloric leaching to remove iron. A reaction time of one hour was already sufficient to reduce $50 \%$ of iron into the metallic state and after three hours no ferric iron was present in the ilmenite sample. The reduction efficiency increased while increasing the temperature, however, above $1050^{\circ} \mathrm{C}$ the metallization is only slightly increasing if the temperature is raised. By treating a sample with coconut pith at about $1050{ }^{\circ} \mathrm{C}$ for three hours and leaching with $20 \%$ hydrochloric acid for one hour at $80^{\circ} \mathrm{C}$, it was possible to produce rutile samples containing less than $3 \%$ iron [52].

Langberg et al. [44] explored the use of mallee charcoal in the metallurgical industry. Mallee trees can be harvested with a short rotation and were planted in Western Australia to offset the increasing soil salinity due to the increased stock of shallow-rooted crops in that area. One tested process to use charcoal derived from mallee trees was the rotary kiln process to reduce ilmenite. The charcoal in the study was produced by slow pyrolysis. A comparison with coal was carried out in regards to $\mathrm{CO}_{2}$ reactivity and ash composition. The produced mallee charcoal showed a significantly lower ash content than coal, but the ash content of charcoal from bark or leaf and twig was in the same magnitude as coal. The ash of the charcoal showed significantly higher levels of alkaline compounds like $\mathrm{Na}_{2} \mathrm{O}$ and $\mathrm{K}_{2} \mathrm{O}$, but the sulfur content was significantly lower compared to coal. The $\mathrm{CO}_{2}$ reactivity of the investigated coal sample was an order of magnitude lower compared to the mallee charcoal, while the $\mathrm{CO}_{2}$ reactivity of charcoal from mallee bark or leaf and twig charcoal was between two and three times higher compared to wood charcoal. Reduction tests with ilmenite were carried out in a stainless-steel drum placed in a muffle furnace at $1100{ }^{\circ} \mathrm{C}$. By comparing the metallization rate of different carbon carriers, the mallee charcoal showed a higher reduction rate in the test compared to coal and could therefore increase the productivity of rotary kilns. Technical issues and obstacles to overcome were mentioned in the publication as following. Due to the low density of charcoal negative effects on productivity could be possible if the mixing with the ilmenite feed is insufficient. Also, volatile alkaline oxides could react with $\mathrm{SO}_{2}$ and form sulfur accretions in the off-gas lines [44].

Zhao et al. [55] investigated the reduction temperature and different reducing agents to produce a metallic concentrate and titanium enriched oxides by in a solid-state direct reduction and magnetic separation of low-grade titanomagnetite beach sand from Indonesia. The beach sand was pelletized with a binder and dried. The pellets were placed in a bed of the reducing agent contained in a graphite crucible, due to the embedment of ore in a reducing agent, the evolving gas from the reducing agent is reacting with the ore and the direct reaction with the carbon-containing material is limited. The reduction was carried out in a furnace at temperatures between $120{ }^{\circ} \mathrm{C}$ and $1400{ }^{\circ} \mathrm{C}$ using devolatilized bitumite. Furthermore, at $1200{ }^{\circ} \mathrm{C}$ wheat straw char and coke were used as a reducing agent. Gasification tests of the reducing agents in $\mathrm{CO}_{2}$ atmosphere showed that the reactivity of wheat straw char and bitumite was similar, with a slightly higher reactivity of bitumite. The lowest $\mathrm{CO}_{2}$ reactivity was again observed for coke. In the reduction experiments, it was observed, that an increase in the reduction temperature decreased the recovery of iron and the $\mathrm{TiO}_{2}$ content of the titanium concentrate. Roasted samples were investigated by SEM and EDS, samples treated at $1200^{\circ} \mathrm{C}$ showed a porous structure that could increase the diffusion of reducing gases, while at higher temperatures larger iron particles and connected iron crystals were observed, which could decrease the diffusion 
of reducing gas. Furthermore, unreduced titanomagnetite and wustite were observed in the central area of pellets at higher reducing temperatures. Therefore, a reduction temperature of $1200{ }^{\circ} \mathrm{C}$ was used for further experiments. The best result was obtained by using bitumite with an iron recovery of $91.83 \%$ after magnetic separation. The total iron content in the magnetic iron concentrate was $90.28 \%$ and the $\mathrm{TiO}_{2}$-content was $0.91 \%$. The $\mathrm{TiO}_{2}$-recovery in the titanium concentrate was $91.19 \%$ and the $\mathrm{TiO}_{2}$ content was $46.01 \%$, which was significantly higher than the $\mathrm{TiO}_{2}$-content in the raw beach sand containing only $11.42 \%$. Wheat straw char lead to similar results, even though wheat straw char was slightly inferior compared to bitumite in regards to the iron recovery and iron content in the magnetic concentrate and $\mathrm{TiO}_{2}$-recovery and $\mathrm{TiO}_{2}$-content in the non-magnetic fraction. Coke yielded the worst results and again titanomagnetite and wustite were observed in the samples due to insufficient reducing atmosphere. Therefore, for reduction using evolved reducing gases from the reducing agent bitumite was presented as the best option. Wheat straw char still yielded better results compared to coke [55].

\section{Conclusion and Outlook}

Bio-based carbon is a promising alternative to replace fossil carbon in the production of metals. In particular for the production of ignoble metals like chromium, manganese and silicon, it seems that the transition to a hydrogen-based industry is not feasible, since the reduction of those metals only takes place if the partial pressure of water vapor are very low.

Due to the faster carbon cycle compared to fossil carbon, bio-based carbon can be considered $\mathrm{CO}_{2}$ neutral. However, there are still some issues to overcome if bio-based carbon should replace fossil carbon in conventional production routes. In particular, the higher $\mathrm{CO}_{2}$ reactivity, lower density and diffuse composition of bio-based carbon sources seem to be a technical challenge. Research to use alternative reducing agents reviewed in this paper dates back to the 1960s and even though the topic is still intensively investigated, there are still unit operations not covered extensively. Table 7 shows relevant unit operations for the investigated metals and ilmenite upgrading and a qualitative estimate of the amount of research carried out and the scale of the trials.

Table 7. Scale and amount of research investigating relevant unit operations.

\begin{tabular}{|c|c|c|c|c|c|c|}
\hline \multirow[b]{2}{*}{ Unit Operation } & \multirow[b]{2}{*}{ Category } & \multicolumn{5}{|c|}{ Metal Product or Process } \\
\hline & & FeNi & $\mathrm{FeCr}$ & Si\&FeSi & FeMn\&SiMn & $\begin{array}{l}\text { Ilmenite } \\
\text { Upgrading }\end{array}$ \\
\hline \multirow{2}{*}{$\begin{array}{c}\text { Pelletizing \& } \\
\text { Briquetting }\end{array}$} & Amount & - & + & - & $-*$ & - \\
\hline & Scale & o & Laboratory & o & $\mathrm{o}$ & o \\
\hline \multirow{2}{*}{ Sintering } & Amount & - & + & - & + & - \\
\hline & Scale & $\mathrm{o}$ & Industrial & o & Laboratory & o \\
\hline \multirow{2}{*}{$\begin{array}{c}\text { Pre-Reduction } \\
\& \\
\text { Solid-State } \\
\text { Reduction }\end{array}$} & Amount & ++ & + & - & ++ & + \\
\hline & Scale & Industrial & Laboratory & o & Laboratory & Laboratory \\
\hline \multirow{2}{*}{ Smelting } & Amount & + & + & ++ & + & - \\
\hline & Scale & $\begin{array}{l}\text { Enhanced } \\
\text { Laboratory }\end{array}$ & $\begin{array}{l}\text { Enhanced } \\
\text { Laboratory }\end{array}$ & Industrial & Industrial & o \\
\hline LCA & Amount & ++ & - & + & - & - \\
\hline
\end{tabular}

*: One study investigated smelting of manganese ore and charcoal composites, as the focus was on the smelting process, it was not included in the pelletizing and briquetting category. ++: significant amount of studies reviewed; +: little amount of studies reviewed; -: no studies reviewed; o: not applicable, since no research was found. 
Most studies presented in this review investigated solid-state processes while smelting processes were the minority. Even the focus regarding the solid-state processes differed for the investigated metals. Studies investigating solid-state processes to produce nickel, manganese and upgraded ilmenite mostly focused on pre-reduction and reduction processes. For chromium, a similar amount of pre-reduction and agglomeration studies were carried out, while the sintering process with bio-based carbon was even investigated on an industrial-scale. The smelting process to produce ferronickel and ferrochromium has only been investigated in an enhanced laboratory-scale until this point, and even the amount of research available is rather low. Smelting of silicon using bio-based carbon is already an industrial practice and a lot of research investigating an industrial-scale is also available. Smelting of manganese alloys was also carried out on an industrial-scale and also in a pilot-scale, but less research compared to the production of silicon is available. Smelting of ilmenite ore with bio-based carbon was not published to our knowledge.

The potential reduction of $\mathrm{CO}_{2}$ emissions by using bio-based carbon was already determined in life cycle assessments (LCA) for nickel $[115,116]$ (Figure 13) and silicon [146] (Figure 17), however, detailed life cycle assessments for ferrochromium, ferromanganese and ilmenite upgrading were not found.

Besides the usage of bio-based carbon in established unit operation, research was carried out to investigate novel processes. Table 8 summarizes novel processes or special emphasis of research to produce the investigated metals and for ilmenite upgrading.

Table 8. Novel processes and special emphasis investigated for the production of metals and ilmenite upgrading.

\begin{tabular}{|c|c|c|c|c|}
\hline \multicolumn{5}{|c|}{ Metal Product or Process } \\
\hline FeNi & $\mathrm{FeCr}$ & Si\&FeSi & FeMn\&SiMn & $\begin{array}{l}\text { Ilmenite } \\
\text { Upgrading }\end{array}$ \\
\hline Segregation & Segregation & $\begin{array}{c}\text { Production of suitable bio-based carbon, } \\
\text { usage of solar energy }\end{array}$ & Reduction-roasting & $\begin{array}{l}\text { Usage of solar energy, } \\
\text { usage of microwaves }\end{array}$ \\
\hline
\end{tabular}

The segregation process was investigated to produce nickel and chromium metalcarbon particles, which can be recovered by flotation or magnetic separation. Solar energy as a green energy source in combination with bio-based carbon was used to produce silicon and to upgrade ilmenite, while for ilmenite microwaves were used as well in combination with bio-based carbon. To overcome the previously mentioned mechanical disadvantages of bio-based carbon, a lot of research investigated the production of biobased carbon agglomerates to substitute fossil carbon in submerged arc furnaces for silicon and ferrosilicon processes. Those results may also be applicable to produce other alloys in submerged arc furnaces. Besides pre-reduction and sintering studies, one characteristic for manganese was a large number of articles about the reduction-roasting process to dress low-grade manganese ores for further hydrometallurgical treatment.

To achieve the transition from fossil carbon carriers to bio-based carbon, it will be necessary to further investigate the processes not extensively covered until now as shown in Table 7. As a further motivation to quantify the potential benefits of bio-based carbon compared to fossil carbon, detailed LCAs to produce ferrochromium, manganese alloys and ilmenite upgrading are necessary. Especially since the presented LCAs for nickel and silicon have already shown that bio-based carbon can significantly reduce the carbon footprint of ferroalloys.

Besides the needed research to close knowledge gaps, it could already be a helpful first step to partially substitute fossil carbon by bio-based carbon to promote the transition of an industry heavily dependent on metallurgical coke to a more sustainable reducing agent. Especially since a small amount of bio-based carbon in the fuel mix is not impairing the well-known processes severely. According to studies about sintering and agglomeration presented here in this review, a partial substitution of around $25 \%$ of fossil reducing agents by bio-based carbon is often possible, without weakening the quality of agglomerates for further treatment. 
Based on the review and besides the need to investigate the unit operations not covered until now (Table 7), there are three additional points, which need further investigation and are relevant for all unit operations presented in this article:

- Determination of metal qualities obtainable using biomass, since biomass can contain more phosphorous, but less sulfur compared to fossil reducing agents

- Gas emissions, especially monitoring $\mathrm{NO}_{x^{-}}, \mathrm{SO}_{2}$ - and chlorine emissions

- Improvement of bio-based carbon in regards to density, mechanical strength and $\mathrm{CO}_{2}$ reactivity

Even more challenging will be the up-scaling of novel technologies like solar thermal, microwave heating or the segregation process using bio-based carbon from a laboratoryscale to a demonstration-scale and then to an industrial-scale. Especially, as this research is only in the early stage. However, those potential breakthrough technologies could significantly contribute to a more sustainable ferroalloy industry.

Supplementary Materials: The following are available online at https:/ /www.mdpi.com/article/10.3390/ min11111286/s1, Figure S1: Equilibrium partial pressure of $\mathrm{CO}$ and equilibrium $\mathrm{H}_{2} \mathrm{O}$ to $\mathrm{H}_{2}$ ratio for the selected reduction reactions. (a) pre-reduction with carbon; (b) reduction with carbon; (c) prereduction with hydrogen; (d) reduction with hydrogen.

Author Contributions: Conceptualization, M.S. and B.F.; methodology, M.S.; writing—original draft preparation, M.S.; writing-review and editing, B.F.; visualization, M.S.; supervision, B.F. All authors have read and agreed to the published version of the manuscript.

Funding: This research received no external funding.

Data Availability Statement: No new data were created or analyzed in this study. Data sharing is not applicable to this article.

Conflicts of Interest: The authors declare no conflict of interest.

\section{References}

1. Pachauri, R.K.; Allen, M.R.; Barros, V.R.; Broome, J.; Cramer, W.; Christ, R.; Church, J.A.; Clarke, L.; Dahe, Q.; Dasgupta, P.; et al. Climate change 2014: Synthesis report; Intergovernmental Panel on Climate Change: Geneva, Switzerland, 2015; ISBN 978-92-9169-143-2.

2. Fick, G.; Mirgaux, O.; Neau, P.; Patisson, F. Using Biomass for Pig Iron Production: A Technical, Environmental and Economical Assessment. Waste Biomass Valorization 2014, 5, 43-55. [CrossRef]

3. Monsen, B.; Lindstad, T.; Tuset, J.K. $\mathrm{CO}_{2}$ Emissions from the Production of Ferrosilicon and Silicon metal in Norway. In Proceedings of the 56th Electric Furnace Conference Proceedings, Electric Furnace Conference, New Orleans, LA, USA, 15-18 November 1998; Iron and Steel Society: Warrendale, PA, USA, 1998; pp. 371-378.

4. Bale, C.W.; Bélisle, E.; Chartrand, P.; Decterov, S.A.; Eriksson, G.; Gheribi, A.E.; Hack, K.; Jung, I.-H.; Kang, Y.-B.; Melançon, J.; et al. FactSage Thermochemical Software and Databases, 2010-2016. Calphad 2016, 54, 35-53. [CrossRef]

5. Kumar, M.; Gupta, R.C. Industrial Uses of Wood Char. Energy Sources 1998, 20, 575-589. [CrossRef]

6. da Silviera, R.C.; do Carmo, W.F.; Neto, M.V.B. Utilization of Charcoal by the Ferro Alloy Industry in Brazil. Technical Analysis. In Proceedings of the Fourth International Ferroalloys Congress, INFACON IV, Rio de Janeiro, Brazil, 1986, 31 August-3 September; pp. 482-500.

7. Dobrynin, D.; Jarlebring, N.Y.; Mustalahti, I.; Sotirov, M.; Kulikova, E.; Lopatin, E. The forest environmental frontier in Russia: Between sustainable forest management discourses and 'wood mining' practice. Ambio 2021, 50, 2138-2152. [CrossRef] [PubMed]

8. Kiruki, H.; van der Zanden, E.H.; Zagaria, C.; Verburg, P.H. Sustainable woodland management and livelihood options in a charcoal producing region: An agent-based modelling approach. J. Environ. Manage. 2019, 248, 109245. [CrossRef] [PubMed]

9. Watson, J.E.M.; Evans, T.; Venter, O.; Williams, B.; Tulloch, A.; Stewart, C.; Thompson, I.; Ray, J.C.; Murray, K.; Salazar, A.; et al. The exceptional value of intact forest ecosystems. Nat. Ecol. Evol. 2018, 2, 599-610. [CrossRef] [PubMed]

10. Suopajärvi, H.; Umeki, K.; Mousa, E.; Hedayati, A.; Romar, H.; Kemppainen, A.; Wang, C.; Phounglamcheik, A.; Tuomikoski, S.; Norberg, N.; et al. Use of biomass in integrated steelmaking-Status quo, future needs and comparison to other low-CO $\mathrm{C}_{2}$ steel production technologies. Appl. Energy 2018, 213, 384-407. [CrossRef]

11. Mousa, E.; Wang, C.; Riesbeck, J.; Larsson, M. Biomass applications in iron and steel industry: An overview of challenges and opportunities. Renew. Sustain. Energy Rev. 2016, 65, 1247-1266. [CrossRef]

12. Quader, M.A.; Ahmed, S.; Ghazilla, R.A.R.; Ahmed, S.; Dahari, M. A comprehensive review on energy efficient $\mathrm{CO}_{2}$ breakthrough technologies for sustainable green iron and steel manufacturing. Renew. Sustain. Energy Rev. 2015, 50, 594-614. [CrossRef]

13. Suopajärvi, H.; Kemppainen, A.; Haapakangas, J.; Fabritius, T. Extensive review of the opportunities to use biomass-based fuels in iron and steelmaking processes. J. Clean. Prod. 2017, 148, 709-734. [CrossRef] 
14. Rosenfeld, D.C.; Böhm, H.; Lindorfer, J.; Lehner, M. Scenario analysis of implementing a power-to-gas and biomass gasification system in an integrated steel plant: A techno-economic and environmental study. Renew. Energy 2020, 147, 1511-1524. [CrossRef]

15. Mandova, H.; Leduc, S.; Wang, C.; Wetterlund, E.; Patrizio, P.; Gale, W.; Kraxner, F. Possibilities for $\mathrm{CO}_{2}$ emission reduction using biomass in European integrated steel plants. Biomass Bioenerg. 2018, 115, 231-243. [CrossRef]

16. Suopajärvi, H.; Pongráczb, E.; Fabritiusa, T. The potential of using biomass-based reducing agents in the blast furnace: A review of thermochemical conversion technologies and assessments related to sustainability. Renew. Sustain. Energy Rev. 2013, 25, 511-528. [CrossRef]

17. Gupta, R.C. Woodchar as a Sustainable Reductant for Ironmaking in the 21st Century. Min. Proc. Ext. Met. Rev. 2003, 24, 203-231. [CrossRef]

18. Wei, R.; Zhang, L.; Cang, D.; Li, J.; Li, X.; Xu, C.C. Current status and potential of biomass utilization in ferrous metallurgical industry. Renew. Sustain. Energy Rev. 2017, 68, 511-524. [CrossRef]

19. Schulte, R.F.; Tuck, C.A. U.S. Geological Survey 2016 Minerals Yearbook: Ferroalloys [Advanced Release]; United States Geological Survey: Reston, VA, USA, 2020.

20. Schnebele, E.K. U.S. Geological Survey 2017 Minerals Yearbook: Silicon [Advanced Release]; United States Geological Survey: Reston, VA, USA, 2020.

21. Fenton, M.D.; Tuck, C.A. U.S. Geological Survey 2016 Minerals Yearbook: Iron and Steel [Advanced Release]; United States Geological Survey: Reston, VA, USA, 2019.

22. Lindstad, T.; Olsen, S.E.; Tranell, G.; Færden, T.; Lubetsky, J. Greenhouse Gas Emissions from Ferroalloy Production. In Proceedings of the Eleventh International Ferroalloys Congress, INFACON XI, New Delhi, India, 18-21 February 2007; pp. 457-466.

23. Climate Watch, Washington DC. 2020. Available online: https:/ / www.climatewatchdata.org (accessed on 27 February 2021).

24. Ritchie, H.; Roser, M. Global Greenhouse Gas Emissions by Sector. Available online: https:/ / ourworldindata.org/emissions-bysector (accessed on 27 February 2021).

25. United Nations, Department of Economic and Social Affairs. International Standard Industrial Classification of All Economic Activities (ISIC), Rev.4; United Nations: New York, NY, USA, 2008; ISBN 9789211615180.

26. Monsen, B.; Grønlin, M.; Nygaard, L.; Tveit, H. The Use of Biocarbon in Norwegian Ferroalloy Production. In Proceedings of the Ninth International Ferroalloys Congress, INFACON IX, Quebec City, Qc, Canada, 3-6 June 2001; pp. 268-276.

27. Monsen, B.; Olsen, S.E.; Lindstad, T. $\mathrm{CO}_{2}$-emissions from the production of manganese and chromium alloys in Norway. In Proceedings of the 56th Electric Furnace Conference Proceedings, New Orleans, LA, USA, 15-18 November 1998; Iron and Steel Society: Warrendale, PA, USA, 1998; pp. 363-369.

28. Saidur, R.; Abdelaziz, E.A.; Demirbas, A.; Hossain, M.S.; Mekhilef, S. A review on biomass as a fuel for boilers. Renew. Sustain. Energy Rev. 2011, 15, 2262-2289. [CrossRef]

29. Hu, Q.; Shao, J.; Yang, H.; Yao, D.; Wang, X.; Chen, H. Effects of binders on the properties of bio-char pellets. Appl. Energy 2015, 157, 508-516. [CrossRef]

30. Monsen, B.; Tangstad, M.; Solheim, I.; Syverstsen, M.; Ishak, R.; Mitgaard, H. Charcoal for Manganese Alloy Production. In Proceedings of the Eleventh International Ferroalloys Congress, INFACON XI, New Delhi, India, 2007., 18-21 February.

31. Noumi, E.S.; Rousset, P.; de Cassia Oliveira Carneiro, A.; Blin, J. Upgrading of carbon-based reductants from biomass pyrolysis under pressure. J. Anal. Appl. Pyrolysis 2016, 118, 278-285. [CrossRef]

32. Surup, G.R.; Foppe, M.; Schubert, D.; Deike, R.; Heidelmann, M.; Timko, M.T.; Trubetskaya, A. The effect of feedstock origin and temperature on the structure and reactivity of char from pyrolysis at $1300-2800{ }^{\circ} \mathrm{C}$. Fuel 2019, 235, 306-316. [CrossRef]

33. Zhang, H.; Zhu, G.; Yan, H.; Li, T.; Feng, X. Thermogravimetric Analysis and Kinetics on Reducing Low-Grade Manganese Dioxide Ore by Biomass. Metall. Mater. Trans. B 2013, 44, 878-888. [CrossRef]

34. Guo, D.; Hu, M.; Pu, C.; Xiao, B.; Hu, Z.; Liu, S.; Wang, X.; Zhu, X. Kinetics and mechanisms of direct reduction of iron ore-biomass composite pellets with hydrogen gas. Int. J. Hydrogen Energ. 2015, 40, 4733-4740. [CrossRef]

35. Konishi, H.; Ichikawa, K.; Usui, T. Effect of Residual Volatile Matter on Reduction of Iron Oxide in Semi-charcoal Composite Pellets. ISIJ Int. 2010, 50, 386-389. [CrossRef]

36. Machulec, B.; Gil, S.; Bialik, W.; Kozłowski, S. Production of ultrapure ferrosilicon chrome with controlled contents of carbon and other chemical elements for manufacturing of innovative metallic materials. In Proceedings of the Conference ProceedingsMETAL 2019, 28th International Conference on Metallurgy and Materials, Brno, Czech Republic, 22-24 May 2019 ; pp. 117-122.

37. Liu, J.; Chen, Z.; Ma, W.; Wei, K.; Ding, W. Application of a Waste Carbon Material as the Carbonaceous Reductant During Silicon Production. Silicon 2018, 10, 2409-2417. [CrossRef]

38. Riva, L.; Surup, G.R.; Buø, T.V.; Nielsen, H.K. A study of densified biochar as carbon source in the silicon and ferrosilicon production. Energy 2019, 181, 985-996. [CrossRef]

39. Riva, L.; Nielsen, H.K.; Skreiberg, Ø.; Wang, L.; Bartocci, P.; Barbanera, M.; Bidini, G.; Fantozzi, F. Analysis of optimal temperature, pressure and binder quantity for the production of biocarbon pellet to be used as a substitute for coke. Appl. Energy 2019, 256, 113933. [CrossRef]

40. Riva, L.; Cardarelli, A.; Andersen, G.J.; Buø, T.V.; Barbanera, M.; Bartocci, P.; Fantozzi, F.; Nielsen, H.K. On the self-heating behavior of upgraded biochar pellets blended with pyrolysis oil: Effects of process parameters. Fuel 2020, 278, 118395. [CrossRef]

41. Surup, G.R.; Nielsen, H.K.; Heidelmann, M.; Trubetskaya, A. Characterization and reactivity of charcoal from high temperature pyrolysis $\left(800-1600{ }^{\circ} \mathrm{C}\right)$. Fuel 2019, 235, 1544-1554. [CrossRef] 
42. Surup, G.R.; Hunt, A.J.; Attard, T.; Budarin, V.L.; Forsberg, F.; Arshadi, M.; Abdelsayed, V.; Shekhawat, D.; Trubetskaya, A. The effect of wood composition and supercritical $\mathrm{CO}_{2}$ extraction on charcoal production in ferroalloy industries. Energy 2020, 193, 116696. [CrossRef]

43. Kieush, L.; Boyko, M.; Koveria, A.; Yaholnyk, M.; Poliakova, N. Manganese Sinter Production with Wood Biomass Application. Key Eng. Mater. 2020, 844, 124-134. [CrossRef]

44. Langberg, D.E.; Somerville, M.A.; Freeman, D.E.; Washington, B.M. The use of Mallee charcoal in metallurgical reactors. In Proceedings of the Green Processing 2006. 3rd International Conference on the Sustainable Processing of Minerals, Newcastle, Australia, 5-6 June 2006; pp. 69-75.

45. Surup, G.R.; Leahy, J.J.; Timko, M.T.; Trubetskaya, A. Hydrothermal carbonization of olive wastes to produce renewable, binder-free pellets for use as metallurgical reducing agents. Renew. Energy 2020, 155, 347-357. [CrossRef]

46. Maksum, A.; Husein, M.K.E.; Permana, S.; Rustandi, A.; Soedarsono, J.W. A preliminary study on the reduction of limonite ore by using rice husk as a reducing agent. IOP Conf. Ser. Mater. Sci. Eng. 2018, 316, 12050. [CrossRef]

47. Rahayu, D.; Maksum, A.; Soedarsono, J.W. Effects of reduction time on carbothermic reduction of lateritic nickel ore using palm kernel shell as green reducing agent. IOP Conf. Ser. Earth Environ. Sci. 2018, 105, 12037. [CrossRef]

48. Rashid, R.Z.A.; Salleh, H.M.; Ani, M.H.; Yunus, N.A.; Akiyama, T.; Purwanto, H. Reduction of low grade iron ore pellet using palm kernel shell. Renew. Energy 2014, 63, 617-623. [CrossRef]

49. Zhao, Y.; Zhu, G.; Cheng, Z. Thermal analysis and kinetic modeling of manganese oxide ore reduction using biomass straw as reductant. Hydrometallurgy 2010, 105, 96-102. [CrossRef]

50. Li, K.; Chen, G.; Chen, J.; Peng, J.; Ruan, R.; Srinivasakannan, C. Microwave pyrolysis of walnut shell for reduction process of low-grade pyrolusite. Bioresour. Technol. 2019, 291, 121838. [CrossRef]

51. Supriyatna, Y.I.; Zulhan, Z.; Triapriani, Y. The ferromanganese production using Indonesian low-grade manganese ore using charcoal and palm kernel shell as reductant in mini electric arc furnace. IOP Conf. Ser. Mater. Sci. Eng. 2018, 285, 12022. [CrossRef]

52. George, A.; Kelukutty, V.S.; Radhika, L.G.; Mohandas, P.N.; Rohatgi, P.K. Rutile from ilmenite using coconut pith as a reductant. J. Mater. Sci. 1984, 19, 1522-1529. [CrossRef]

53. Agirre, I.; Griessacher, T.; Rösler, G.; Antrekowitsch, J. Production of charcoal as an alternative reducing agent from agricultural residues using a semi-continuous semi-pilot scale pyrolysis screw reactor. Fuel Process. Technol. 2013, 106, 114-121. [CrossRef]

54. El-Tawil, A.A.; Ahmed, H.M.; Ökvist, L.S.; Björkman, B. Self-Reduction Behavior of Bio-Coal Containing Iron Ore Composites. Metals 2020, 10, 133. [CrossRef]

55. Zhao, Y.-Q.; Sun, T.-C.; Zhao, H.-Y.; Chen, C.; Wang, X.-P. Effect of reductant type on the embedding direct reduction of beach titanomagnetite concentrate. Int. J. Miner. Metall. Mater. 2019, 26, 152-159. [CrossRef]

56. Petrus, H.T.B.M.; Putera, A.D.P.; Sugiarto, E.; Perdana, I.; Warmada, I.W.; Nurjaman, F.; Astuti, W.; Mursito, A.T. Kinetics on roasting reduction of limonitic laterite ore using coconut-charcoal and anthracite reductants. Miner. Eng. 2019, 132, 126-133. [CrossRef]

57. Rasyid, M.H.A.; Rhamdani, A.R.; Putera, A.D.P.; Petrus, H.T.B.M. Study on biomass performance in reduction of nickel laterite from Pomalaa, Sulawesi Tenggara. AIP Conf. Proc. 2016, 1755, 50007. [CrossRef]

58. Nurjaman, F.; Sa'adah, A.; Shofi, A.; Apriyana, W.; Suharno, B. The Effect of Additives and Reductors in Selective Reduction Process of Laterite Nickel Ore. Jsmi 2018, 20, 8. [CrossRef]

59. Pamungkas, B.C.; Hadi, H. Potential of Biomass Utilization in Rotary Kiln of Nickel Processing Plant. IOP Conf. Ser. Mater. Sci. Eng. 2019, 588, 12006. [CrossRef]

60. Andika, R.; Astuti, W.; Syafriadi; Nurjaman, F. Effect of flux addition and reductant type in smelting process of Indonesian limonite ore in electric arc furnace. IOP Conf. Ser. Mater. Sci. Eng. 2019, 478, 12007. [CrossRef]

61. Shofi, A.; Rahmahwati, A.; Nurjaman, F.; Suharno, B. Effect of reduction temperature and sodium-based additives on nickel upgrading process of laterites ores. IOP Conf. Ser. Mater. Sci. Eng. 2019, 541, 12002. [CrossRef]

62. Sugiarto, E.; Putera, A.D.P.; Petrus, H.T.B.M. Kinetic study of nickel laterite reduction roasting by palm kernel shell charcoal. IOP Conf. Ser. Earth Environ. Sci. 2017, 65, 12027. [CrossRef]

63. Abidin, F.; Harjanto, S.; Kawigraha, A.; Permatasari, N.V. Characterization on particle size distribution of reduced lateritic nickel ore using biomass carbon reduction. IOP Conf. Ser. Mater. Sci. Eng. 2019, 602, 12080. [CrossRef]

64. Nurjaman, F.; Subandrio, S.; Ferdian, D.; Suharno, B. Effect of basicity on beneficiated chromite sand smelting process using submerged arc furnace. AIP Conf. Proc. 2018, 1964, 020009. [CrossRef]

65. Balangao, J.K.B.; Podiotan, F.J.; Ambolode, A.E.C.; Anacleto, N.M.; Namoco, C.S. Production of Iron-Chromium-Nickel Metal Alloys Via Reduction of Mixed Chromite Ore from Zambales and Laterite Ore from Taganito, Surigao del Norte under Argon Atmosphere. Indian J. Sci. Technol. 2018, 11, 1-11. [CrossRef]

66. Suharto; Nurjaman, F.; Shofi, A.; Sudibyo; Milandia, A.; Rismananda, M.H. Analysis of the effect of temperature on the reduction roasting process of Lampung manganese ore using palm kernel shell charcoal. IOP Conf. Ser. Earth Environ. Sci. 2020, 483, 12012. [CrossRef]

67. Setiawan, A.; Shaw, M.; Torpy, A.; Pownceby, M.I.; Harjanto, S.; Rhamdhani, M.A. Solar Carbothermic Reduction of Ilmenite Using Palm Kernel Shell Biomass. JOM 2020. [CrossRef]

68. Surup, G.R.; Pedersen, T.A.; Chaldien, A.; Beukes, J.P.; Tangstad, M. Electrical Resistivity of Carbonaceous Bed Material at High Temperature. Processes 2020, 8, 933. [CrossRef]

69. Li, F.; Tangstad, M.; Ringdalen, E. Carbothermal Reduction of Quartz and Carbon Pellets at Elevated Temperatures. Metall. Mater. Trans. B 2018, 49, 1078-1088. [CrossRef] 
70. Gaal, S.; Berg, K.; Tranell, G.; Olsen, S.E.; Tangstad, M. An investigation into aspects of liquid phase reduction of manganese and silica containing slag. In Proceedings of the VII International Conference Molten Slags, Fluxes \& Salts, Cape Town, South Africa, 25-28 January 2004; pp. 651-658.

71. Petrus, H.T.B.M.; Diga, A.; Rhamdani, A.R.; Warmada, I.W.; Yuliansyah, A.T.; Perdana, I. Lamtoro charcoal (l. leucocephala) as bioreductor in nickel laterite reduction: Performance and kinetics study. J. Phys. Conf. Ser. 2017, 817, 12065. [CrossRef]

72. Rocha, M.G.; Silva, A.S.d.; Mourao, M.B.; Kurauchi, M.H.N.; Takano, C. Fundamental aspects of sintering of chromites concentrates. Min. Proc. Ext. Met. 2014, 123, 251-256. [CrossRef]

73. Safarian, J.; Tranell, G.; Kolbeinsen, L.; Tangstad, M.; Gaal, S.; Kaczorowski, J. Reduction Kinetics of MnO from High-Carbon Ferromanganese Slags by Carbonaceous Materials in Ar and CO Atmospheres. Metall. Mater. Trans. B 2008, 39, 702-712. [CrossRef]

74. International Organization for Standardization. Hard Coal-Determination of Total Moisture; (ISO 589:2008(E)); ISO: Geneva, Switzerland, 2008.

75. International Organization for Standardization. Hard Coal and Coke-Determination of Volatile Matter; (ISO 562:2010(E)); ISO: Geneva, Switzerland, 2010.

76. International Organization for Standardization. Solid Mineral Fuels—Determination of Ash; (ISO 1171:2010(E)); ISO: Geneva, Switzerland, 2010.

77. International Organization for Standardization. Coal_Proximate Analysis; (ISO 17246:2010(E)); ISO: Geneva, Switzerland, 2010.

78. International Organization for Standardization. Solid Mineral Fuels-Determination of Total Carbon, Hydrogen and Nitrogen ContentInstrumental Method; (ISO 29541:2010(E)); ISO: Geneva, Switzerland, 2010.

79. International Organization for Standardization. Solid Mineral Fuels—Determination of Sulfur by IR Spectrometry; (ISO 19579:2006(E)); ISO: Geneva, Switzerland, 2006.

80. International Organization for Standardization. Coal and Coke-Calculation of Analyses to Different Bases; (ISO 1170:2020(E)); ISO: Geneva, Switzerland, 2020.

81. Adrados, A.; de Marco, I.; López-Urionabarrenechea, A.; Solar, J.; Caballero, B.M.; Gastelu, N. Biomass Pyrolysis Solids as Reducing Agents: Comparison with Commercial Reducing Agents. Materials 2016, 9, 3. [CrossRef]

82. Díez, M.A.; Alvarez, R.; Barriocanal, C. Coal for metallurgical coke production: Predictions of coke quality and future requirements for cokemaking. Int. J. Coal Geol. 2002, 50, 389-412. [CrossRef]

83. van Krevelen, D.W. Graphical-statistical method for the study of structure and reaction processes of coal. Fuel 1950, 29, 260-284.

84. Schrama, F.N.H.; Beunder, E.M.; van den Berg, B.; Yang, Y.; Boom, R. Sulphur removal in ironmaking and oxygen steelmaking. Ironmak. Steelmak. 2017, 44, 333-343. [CrossRef]

85. ASTM International. Standard Specification for Ferrosilicon; (A100-07(2018)); ASTM International: West Conshohocken, PA, USA, 2018.

86. ASTM International. Standard Specification for Ferromanganese; (A99-03(2019)); ASTM International: West Conshohocken, PA, USA, 2019.

87. ASTM International. Standard Specification for Silicomanganese; (A483/A483M-10(2020)); ASTM International: West Conshohocken, PA, USA, 2020.

88. ASTM International. Standard Specification for Nickel; (B39-79(2018)); ASTM International: West Conshohocken, PA, USA, 2018.

89. ASTM International. Standard Specification for Ferrochromium; (A101-04(2019)); ASTM International: West Conshohocken, PA, USA, 2019.

90. Dai, W.; Shu, L. On Sulfur Control in HC FeCr Production. In Proceedings of the Seventh International Ferroalloys Congress, INFACON VII, Trondheim, Norway, 11-14 June 1995; pp. 287-296.

91. Yu, D.; Paktunc, D. Calcium Chloride-Assisted Segregation Reduction of Chromite: Influence of Reductant Type and the Mechanism. Minerals 2018, 8, 45. [CrossRef]

92. Grimsey, D.E.; Grimsey, E.J.; Ibana, D.C. Fundamental aspects of the recovery of nickel, cobalt and iron from nontronite laterite using the segregation process. Can. Metall. Q. 2020, 59, 169-179. [CrossRef]

93. Ogura, T.; Kuwayama, K.; Ono, A.; Yamada, Y. Production of Fe-Ni by the rotary kiln-electric furnace process at Hyuga Smelter. Int. J. Miner. Process. 1987, 19, 189-198. [CrossRef]

94. Li, G.; Jia, H.; Luo, J.; Peng, Z.; Zhang, Y.; Jiang, T. Ferronickel Preparation from Nickeliferous Laterite by Rotary KilnElectric Furnace Process. In Proceedings of the Characterization of Minerals, Metals, and Materials 2016, Nashville, TN, USA, 14-18 November 2016; Springer International Publishing: Berlin/Heidelberg, Germany, 2016; pp. 143-149.

95. Keskinkilic, E. Nickel Laterite Smelting Processes and Some Examples of Recent Possible Modifications to the Conventional Route. Metals 2019, 9, 974. [CrossRef]

96. Liu, P.; Li, B.; Cheung, S.C.P.; Wu, W. Material and energy flows in rotary kiln-electric furnace smelting of ferronickel alloy with energy saving. Appl. Therm. Eng. 2016, 109, 542-559. [CrossRef]

97. Chen, Y.-Q.; Zhao, H.-L.; Wang, C.-Y. Two-stage reduction for the preparation of ferronickel alloy from nickel laterite ore with low Co and high MgO contents. Int. J. Miner. Metall. Mater. 2017, 24, 512-522. [CrossRef]

98. Mehmetaj, B.; Boom, R. Ferronickel production in Kosova-Past performance and new opportunities. Steel Res. Int. 2001, 72, 428-433. [CrossRef]

99. Swinbourne, D.R. Understanding ferronickel smelting from laterites through computational thermodynamics modelling. Min. Proc. Ext. Met. 2014, 123, 127-140. [CrossRef]

100. Coleman, E.E.; Vedensky, D.N. Ferro-Nickel Production in Oregon. JOM 1960, 12, 197-201. [CrossRef]

101. United States Congress. Senate. Committee on Armed Services. Inquiry Into the Strategic and Critical Material Stockpiles of the United States: Hearings Before the National Stockpile and Naval Petroleum Reserves Subcommittee of the Committee on Armed Services, United States Senate, Eighty-Seventh Congress, Second Session; U.S. Government Printing Office: Washington, DC, USA, 1962. 
102. Chen, G.-J.; Hwang, W.-S.; Liu, S.-H.; Shiau, J.-S. The Effect of Bio-Coal on the Carbothermic Reduction of Laterite Ores. Mater. Trans. 2015, 56, 550-555. [CrossRef]

103. Swamy, Y.V.; Murthy, B.V.R.; Reddy, B.R. Extraction of nickel from chromitiferous overburden by roasting with a $\mathrm{CO}^{-\mathrm{CO}_{2}-\mathrm{N}_{2}}$ gas mixture. Mining Metall. Explor. 2000, 17, 223-227. [CrossRef]

104. Rhamdani, A.R.; Petrus, H.T.B.M.; Fahrurrozi, M. Characterization of nickel laterite reduction from Pomalaa, Sulawesi Tenggara. AIP Conf. Proc. 2015, 1699, 50012. [CrossRef]

105. Adzhani, S.; Hidayanti, R.; Maksum, A.; Permana, S.; Soedarsono, J.W. The influence of palm kernel shell mass ratio as a reducing agent in the lateritic nickel ore carbothermic reduction process. IOP Conf. Ser. Earth Environ. Sci. 2018, 105, 12016. [CrossRef]

106. Hidayanti, R.; Permana, S.; Maksum, A.; Soedarsono, J.W. Study on the effects of temperature in the carbothermic reduction laterite ore using palm kernel shell as reducing agent. IOP Conf. Ser. Earth Environ. Sci. 2018, 105, 12015. [CrossRef]

107. Shofi, A.; Supriyatna, Y.I.; Prasetyo, A.B. Selective Reduction of Southeast Sulawesi Nickel Laterite using Palm Kernel Shell Charcoal: Kinetic Studies with Addition of $\mathrm{Na}_{2} \mathrm{SO}_{4}$ and $\mathrm{NaCl}$ as Additives. Bull. Chem. React. Eng. Catal. 2020, 15, 501-513. [CrossRef]

108. Suharno, B.; Ilman, N.P.; Shofi, A.; Ferdian, D.; Nurjaman, F. Study of Low-Grade Nickel Laterite Processing Using Palm Shell Charcoal as Reductant. Mater. Sci. Forum 2020, 1000, 436-446. [CrossRef]

109. Putera, A.D.P.; Sugiarto, E.; Sutijan; Warmada, I.W.; Petrus, H.T.B.M. Coconut Shell Charcoal as a Bioreductor in Roasting Process of Nickel Laterite from Pomalaa, Southeast Sulawesi: Performance and Kinetics Study. Mater. Sci. Forum 2017, 901, 182-189. [CrossRef]

110. Ericson, A.S.; Svensson, J.; Ishii, K. Development of the MINPRO-PAMCO Nickel Segregation Process. JOM 1984, 36, 42-46. [CrossRef]

111. Grimsey, D.E.; Grimsey, E.J.; Ibana, D.C. Key factors affecting nickel recovery during the segregation of laterite ores. Can. Metall. Q. 2017, 56, 401-409. [CrossRef]

112. Rao, M.; Li, G.; Jiang, T.; Luo, J.; Zhang, Y.; Fan, X. Carbothermic Reduction of Nickeliferous Laterite Ores for Nickel Pig Iron Production in China: A Review. JOM 2013, 65, 1573-1583. [CrossRef]

113. Sihotang, I.H.; Supriyatna, Y.I.; Ismail, I.; Sulistijono. The effect of smelting time and composition of palm kernel shell charcoal reductant toward extractive Pomalaa nickel laterite ore in mini electric arc furnace. AIP Conf. Proc. 2018, 1945, 20023. [CrossRef]

114. Supriyatna, Y.I.; Sihotang, I.H.; Sudibyo. Preliminary Study of Smelting of Indonesian Nickel Laterite Ore using an Electric Arc Furnace. Mater. Today. Proc. 2019, 13, 127-131. [CrossRef]

115. Norgate, T.; Jahanshahi, S. Assessing the energy and greenhouse gas footprints of nickel laterite processing. Miner. Eng. 2011, 24, 698-707. [CrossRef]

116. Bartzas, G.; Komnitsas, K. Life cycle assessment of ferronickel production in Greece. Resour. Conserv. Recy. 2015, 105, 113-122. [CrossRef]

117. Norgate, T.; Langberg, D. Environmental and Economic Aspects of Charcoal Use in Steelmaking. ISIJ Int. 2009, 49, 587-595. [CrossRef]

118. Jochens, P.R.; Howat, D.D. The application of the fluo-solids reactor to the pyrometallurgical beneficiation of South African chromite. J. S. Afr. Inst. Min. Metall. 1964, 65, 236-253.

119. Guo, D.; Li, Y.; Cui, B.; Chen, Z.; Luo, S.; Xiao, B.; Zhu, H.; Hu, M. Direct reduction of iron ore/biomass composite pellets using simulated biomass-derived syngas: Experimental analysis and kinetic modelling. Chem. Eng. J. 2017, 327, 822-830. [CrossRef]

120. Khan, D.M.A. Pre-Reduction of Chromite by Thermogravimetric (TG) Analysis. Mater. Sci. Forum 2013, 760, 23-32. [CrossRef]

121. Khan, D.M.A. Reduction Kinetics of Chromite Pellets. Mater. Sci. Forum 2013, 760, 85-94. [CrossRef]

122. Sommerfeld, M.; Friedrich, B. Towards Green Ferroalloys: Replacement of Fossil Reductants in the Pre-Reduction Process of Chromite by Bio-Based Alternatives. In Proceedings of the REWAS 2022, Anaheim, CA, USA, 27 February-3 March 2022.

123. Zandia, M.; Martinez-Pachecob, M.; Fray, T.A.T. Biomass for iron ore sintering. Miner. Eng. 2010, 23, 1139-1145. [CrossRef]

124. Gan, M.; Fan, X.-H.; Jiang, T.; Chen, X.-L.; Yu, Z.-Y.; Ji, Z.-Y. Fundamental study on iron ore sintering new process of flue gas recirculation together with using biochar as fuel. J. Cent. South Univ. 2014, 21, 4109-4114. [CrossRef]

125. Kawaguchi, T.; Hara, M. Utilization of Biomass for Iron Ore Sintering. ISIJ Int. 2013, 53, 1599-1606. [CrossRef]

126. Liu, C.; Zhang, Y.; Zhao, K.; Xing, H.; Kang, Y. Effect of biomass on reaction performance of sintering fuel. J. Mater. Sci. 2019, 54, 3262-3272. [CrossRef]

127. Cheng, Z.; Yang, J.; Zhou, L.; Liu, Y.; Wang, Q. Characteristics of charcoal combustion and its effects on iron-ore sintering performance. Appl. Energy. 2016, 161, 364-374. [CrossRef]

128. Fan, X.; Ji, Z.; Gan, M.; Chen, X.; Li, Q.; Jiang, T. Influence of charcoal replacing coke on microstructure and reduction properties of iron ore sinter. Ironmak. Steelmak. 2016, 43, 5-10. [CrossRef]

129. Gan, M.; Fan, X.; Ji, Z.; Chen, X.; Jiang, T.; Yu, Z. Effect of distribution of biomass fuel in granules on iron ore sintering and NOx emission. Ironmak. Steelmak. 2014, 41, 430-434. [CrossRef]

130. Murakami, K.; Sugawara, K.; Kawaguchi, T. Analysis of Combustion Rate of Various Carbon Materials for Iron Ore Sintering Process. ISIJ Int. 2013, 53, 1580-1587. [CrossRef]

131. Lu, L.; Adam, M.; Kilburn, M.; Hapugoda, S.; Somerville, M.; Jahanshahi, S.; Mathieson, J.G. Substitution of Charcoal for Coke Breeze in Iron Ore Sintering. ISIJ Int. 2013, 53, 1607-1616. [CrossRef]

132. Gan, M.; Fan, X.; Chen, X.; Ji, Z.; Lv, W.; Wang, Y.; Yu, Z.; Jiang, T. Reduction of Pollutant Emission in Iron Ore Sintering Process by Applying Biomass Fuels. ISIJ Int. 2012, 52, 1574-1578. [CrossRef]

133. Jha, G.; Soren, S.; Mehta, K.D. Life cycle assessment of sintering process for carbon footprint and cost reduction: A comparative study for coke and biomass-derived sintering process. J. Clean. Prod. 2020, 259, 120889. [CrossRef]

134. Findorák, R.; Legemza, J.; Fröhlichová, M.; Fabriciová, G.; Džupková, M. New Utilization of Specific Biomass: Lignin in the Iron Ore Sintering Process. Metals 2020, 10, 1170. [CrossRef] 
135. Liu, Z.; Bi, X.; Gao, Z.; Liu, W. Carbothermal Reduction of Iron Ore in Its Concentrate-Agricultural Waste Pellets. Adv. Mater. Sci. Eng. 2018, 2018, 1-6. [CrossRef]

136. Lopes, G.D.O. Chrome Ore Fines Sintering in Ferbasa. In Proceedings of the Fourth International Ferroalloys Congress, INFACON IV, Rio de Janeiro, Brazil, 31 August-3 September 1986; pp. 147-156.

137. Sakaranaho, M.; Heikkilä, A.; Suopajärvi, H.; Päätalo, M.; Fabritius, T. Charcoal Use in Chromite Pellets - Effect on Sintering Process, Pellet Properties, and Electrical Conductivity. Steel Res. Int. 2018, 89, 1700260. [CrossRef]

138. Yape, E.O.; Anacleto, N.M. Direct Smelting of Chromite and Laterite Ores with Carbon under Argon Atmosphere. Adv. Mat. Res. 2013, 849, 170-176. [CrossRef]

139. Handbook of Extractive Metallurgy; Habashi, F. (Ed.) Wiley-VCH: Weinheim, Germany, 1997; ISBN 3527287922.

140. Annual Report 2018; Elkem ASA: Oslo, Norway, 2018. Available online: https://www.elkem.com/globalassets/corporate/ documents/elkem-annual-report-2018-print-and-tablet2.pdf (accessed on 25 March 2020).

141. Annual Report 2019; Elkem ASA: Oslo, Norway, 2019; Available online: https://www.elkem.com/globalassets/corporate/ documents/annual-report-2019-web2.pdf (accessed on 25 March 2020).

142. Kamfjord, N.E.; Myrhaug, E.H.; Wittgens, B. Energy Balance of a 45 MW (Ferro-) Silicon Submerged Arc Furnace. In Proceedings of the Twelfth International Ferroalloys Congress, INFACON XII, Helsinki, Finland, 6-9 June 2010; pp. 729-738.

143. Hasannezhad, H.; Meysami, A. Comparison of Biomass and Coal in the Recovery Process of silicon in an Electric Arc Furnace. JOM 2021, 73, 1030-1036. [CrossRef]

144. Raveendran, K.; Ganesh, A. Heating value of biomass and biomass pyrolysis products. Fuel 1996, 75, 1715-1720. [CrossRef]

145. CPichler, C.; Antrekowitsch, J. Pyrolysis Gas as a Renewable Reducing Agent for the Recycling of Zinc- and Lead-Bearing Residues: A Status Report. JOM 2017, 69, 999-1006. [CrossRef]

146. Riva, L.; Nielsen, H.K.; Buø, T.V.; Zhuo, H.; Yang, Q.; Yang, H.; Skreiberg, Ø.; Wang, L.; Bartocci, P.; Barbanera, M.; et al. LCA Analysis of Biocarbon Pellet Production to Substitute Coke. Dteees 2019. [CrossRef]

147. De Wild-Scholten, M.J.; Gløckner, R.; Odden, J.O.; Halvorsen, G.; Tronstad, R. LCA Comparison of the Elkem Solar Metallurgical Route and Conventional Gas Routes to Solar Silicon. In Proceedings of the 23rd European Photovoltaic Solar Energy Conference, Valencia, Spain, 1-5 September 2008; pp. 1225-1229.

148. Surup, G.R.; Vehus, T.; Eidem, P.-A.; Trubetskaya, A.; Nielsen, H.K. Characterization of renewable reductants and charcoal-based pellets for the use in ferroalloy industries. Energy 2019, 167, 337-345. [CrossRef]

149. Surup, G.R.; Nielsen, H.K.; Großarth, M.; Deike, R.; van den Bulcke, J.; Kibleur, P.; Müller, M.; Ziegner, M.; Yazhenskikh, E.; Beloshapkin, S.; et al. Effect of operating conditions and feedstock composition on the properties of manganese oxide or quartz charcoal pellets for the use in ferroalloy industries. Energy 2020, 193, 116736. [CrossRef]

150. Monsen, B.; Tangstad, M.; Mitgaard, H. Use of Charcoal in Silicomanganese Production. In Proceedings of the Tenth International Ferroalloys Congress, INFACON X, Cape Town, South Africa, 1-4 February 2004; pp. 392-404.

151. Loutzenhiser, P.G.; Guglielmini, E.; Frei, A.; Steinfeld, A. Vacuum Distillation of Aluminum and Silicon Via Carbothermal Reduction of Their Oxides with Concentrated Solar Energy. In Proceedings of the Energy Technology 2011, Carbon Dioxide and Other Greenhouse Gas Reduction Metallurgy and Waste Heat Recovery, TMS 2011 Annual Meeting \& Exhibition, San Diego, CA, USA, 27 Feburary-3 March 2011; pp. 175-181.

152. Olsen, S.E.; Tangstad, M.; Lindstad, T. Production of Manganese Ferroalloys; Tapir Akademisk Forlag: Trondheim, Norway, 2007; ISBN 9788251921916.

153. Tangstad, M.; Ichihara, K.; Ringdalen, E. Pretreatment Unit in Ferromanganese Production. In Proceedings of the Fourteenth International Ferroalloys Congress, INFACON XIV, Kiev, Ukraine, 31 May-4 June 2015.

154. Abdel Halim, K.S.; Bahgat, M.; Morsi, M.B.; El-Barawy, K. Pre-reduction of manganese ores for ferromanganese industry. Ironmak. Steelmak. 2011, 38, 279-284. [CrossRef]

155. Teguri, D.; Saito, K.; Miyauchi, Y. Manganese ore pre-reduction using a rotary kiln to manufacture super-low-phosphorus ferromanganese. In Proceedings of the Infacon XV: International Ferro-Alloys Congress, R.T. Jones, P. den Hoed, E M.W. Erwee. Infacon XV: International Ferro-Alloys Congress; Cape Town, South Africa, 25-28 February 2018, pp. 183-196.

156. Zhang, Y.; Luo, W.; You, Z.; Su, Z.; Li, G.; Jiang, T. Optimizing the Sintering Process of Low-Grade Ferromanganese Ores. In Proceedings of the 4th International Symposium on High-Temperature Metallurgical Processing, San Antonio, TX, USA, 3-7 March 2013; Jiang, T., Ed.; Wiley: Hoboken, NJ, USA, 2013; pp. 527-534.

157. Zhang, Y.; Zhao, Y.; You, Z.; Duan, D.; Li, G.; Jiang, T. Manganese extraction from high-iron-content manganese oxide ores by selective reduction roasting-acid leaching process using black charcoal as reductant. J. Cent. South Univ. 2015, 22, 2515-2520. [CrossRef]

158. Zhang, H.; Zhu, G.; Yan, H.; Zhao, Y.; Chen, F.; Wang, W. An investigation on stability of biomass reduced manganese dioxide ore. Acta Metall. Sin. Engl. 2012, 25, 435-442. [CrossRef]

159. Zhang, H.; Zhu, G.; Yan, H.; Li, T.; Zhao, Y. The Mechanism on Biomass Reduction of Low-Grade Manganese Dioxide Ore. Metall. Mater. Trans. B 2013, 44, 889-896. [CrossRef]

160. Zhang, H.; Zhu, G.; Yan, H.; Zhao, Y.; Li, T.; Feng, X. Reduction of low-grade manganese dioxide ore pellets by biomass wheat stalk. Acta Metall. Sin. Engl. 2013, 26, 167-172. [CrossRef]

161. Zhang, Y.; Duan, D.; You, Z.; Li, G.; Fan, X.; Jiang, T. Researches on Reduction Roasting of Low-Grade Manganese Oxide Ores Using Biomass Charcoal as Reductant. In Proceedings of the 4th International Symposium on High-Temperature Metallurgical Processing, San Antonio, USA, 3-7 March 2013; Jiang, T., Ed.; Wiley: Hoboken, NJ, USA, 2013; pp. 317-323. 
162. Song, J.; Zhu, G.; Zhao, Y.; Zhang, P. Reduction treatment of low-grade manganese ore by biomass roasting. Acta Metall. Sin. Engl. 2010, 23, 223-229. [CrossRef]

163. Cheng, Z.; Zhu, G.; Zhao, Y. Study in reduction-roast leaching manganese from low-grade manganese dioxide ores using cornstalk as reductant. Hydrometallurgy 2009, 96, 176-179. [CrossRef]

164. Li, K.; Chen, G.; Li, X.; Peng, J.; Ruan, R.; Omran, M.; Chen, J. High-temperature dielectric properties and pyrolysis reduction characteristics of different biomass-pyrolusite mixtures in microwave field. Bioresour. Technol. 2019, 294, 122217. [CrossRef]

165. Li, K.; Chen, J.; Chen, G.; Peng, J.; Ruan, R.; Srinivasakannan, C. Microwave dielectric properties and thermochemical characteristics of the mixtures of walnut shell and manganese ore. Bioresour. Technol. 2019, 286, 121381. [CrossRef]

166. Long, Y.; Le Ruan; Lv, X.; Lv, Y.; Su, J.; Wen, Y. TG-FTIR analysis of pyrolusite reduction by major biomass components. Chin. J. Chem. Eng. 2015, 23, 1691-1697. [CrossRef]

167. Long, Y.-F. Overall Reduction Kinetics of Low-grade Pyrolusite Using a Mixture of Hemicellulose and Lignin as Reductant. Kem. Ind. 2015, 64, 593-602. [CrossRef]

168. Sustainability Report 2016; ERAMET Norway: Porsgrunn, Norway, 2016. Available online: https://issuu.com/erametnorway/ docs/eramet_b_rekraftrapp2016_eng-issuu (accessed on 29 July 2020).

169. Sustainability Report 2017; ERAMET Norway: Porsgrunn, Norway, 2017. Available online: https://issuu.com/erametnorway/ docs/eramet_norway_sustainability_report (accessed on 29 July 2020).

170. Sustainability Report 2018; ERAMET Norway: Porsgrunn, Norway, 2018. Available online: https:/ /2kaamo43d6qnc0etemarvpj6twpengine.netdna-ssl.com/wp-content/uploads/Eramet-Sustainability-Report-2018-ENG-low.pdf (accessed on 29 July 2020).

171. Sustainability Report 2019; ERAMET Norway: Porsgrunn, Norway, 2019. Available online: https://2kaamo43d6qnc0 etemarvpj6t-wpengine.netdna-ssl.com/wp-content/uploads/Eramet_b\%C3\%A6rekraft_2019_EN_oppslag_web.pdf (accessed on 29 July 2020).

172. Safarian, J.; Kolbeinsen, L.; Tangstad, M.; Tranell, G. Kinetics and Mechanism of the Simultaneous Carbothermic Reduction of FeO and MnO from High-Carbon Ferromanganese Slag. Metall. Mater. Trans. B 2009, 40, 929-939. [CrossRef]

173. Safarian, J.; Tangstad, M. Slag-Carbon Reactivity. In Proceedings of the Twelfth International Ferroalloys Congress, INFACON XII, Helsinki, Finland, 6-9 June 2010; pp. 327-338.

174. Tranell, G.; Gaal, S.; Lu, D.; Tangstad, M.; Safarian, J. Reduction Kinetics of Manganese Oxide from HC FeMn Slags. In Proceedings of the Eleventh International Ferroalloys Congress, INFACON XI, New Delhi, India, 18-21 February 2007; pp. 231-240.

175. Braga, R.S.; Takano, C.; Mourão, M.B. Prereduction of self-reducing pellets of manganese ore. Ironmak. Steelmak. 2007, 34, 279-284. [CrossRef]

176. Yeşiltepe, S.; Şeşen, M.K. Production of Composite Pellets from Waste Coffee Grounds, Mill Scale and Waste Primary Battery to Produce Ferromanganese; A Zero Waste Approach. Acta Metall. Slovaca. 2020, 26, 45-48. [CrossRef]

177. Pistorius, P.C. Ilmenite smelting: The basics. J. S. Afr. Inst. Min. Metall. 2008, 108, 35-43.

178. Jones, R.T. DC Arc Furnaces-Past, Present, and Future. In Celebrating the Megascale, Proceedings of the Extraction and Processing Division Symposium on Pyrometallurgy in Honor of David, G.C. Robertson; Mackey, P.J., Grimsey, E.J., Jones, R.T., Brooks, G.A., Eds.; Springer: Cham, Switzerland, 2016; pp. 129-139. ISBN 978-3-319-48234-7.

179. Reva, V.P.; Yagofarov, V.Y.; Filatenkov, A.É.; Gulevskii, D.A.; Kuryavyi, V.G.; Mansurov, Y.N. Carbide Synthesis Resulting from Mechanical Activation of Titanium and Various Carbon Components. Refract. Ind. Ceram. 2017, 58, 169-173. [CrossRef]

180. Setiawan, A.; Harjanto, S. Effect of sulfur and sodium sulfate on phase transformation and microstructure on carbothermic reduction of Indonesian ilmenite. IOP Conf. Ser. Mater. Sci. Eng. 2020, 833, 12092. [CrossRef]

181. Guo, S.; Li, W.; Peng, J.; Niu, H.; Huang, M.; Zhang, L.; Zhang, S.; Huang, M. Microwave-absorbing characteristics of mixtures of different carbonaceous reducing agents and oxidized ilmenite. Int. J. Miner. Process. 2009, 93, 289-293. [CrossRef] 